\title{
Staff Working Paper No. 720 The distributional impact of monetary policy easing in the UK between 2008 and 2014
}

Philip Bunn, Alice Pugh and Chris Yeates

March 2018 


\title{
Staff Working Paper No. 720 The distributional impact of monetary policy easing in the UK between 2008 and 2014 Philip Bunn, ${ }^{(1)}$ Alice Pugh ${ }^{(2)}$ and Chris Yeates ${ }^{(3)}$
}

\begin{abstract}
Monetary policy has the potential to affect income and wealth inequality in the short run. This has always been true, but given the unprecedented period of accommodative policy in a number of advanced economies including the UK over the past decade, it has become more important to understand the size and direction of these effects. We use panel data from the ONS Wealth and Assets Survey on households' characteristics and balance sheet positions to estimate the distributional impacts of UK monetary policy between 2008 and 2014. Our results suggest that the overall effect of monetary policy on standard relative measures of income and wealth inequality has been small. Given the pre-existing disparities in income and wealth, we estimate that the impact on each household varied substantially across the income and wealth distributions in cash terms, but in percentage terms the effects were broadly similar. We estimate that households around retirement age gained the most from the support to wealth, but that support to incomes disproportionately benefited the young. Overall, our results illustrate the importance of taking a broad-based approach to studying the distributional impacts of monetary policy and of considering channels jointly rather than in isolation.
\end{abstract}

Key words: Monetary policy, households, inequality, distributional effects.

JEL classification: D12, D31, E52, E58.

(1) Bank of England. Email: philip.bunn@bankofengland.co.uk (corresponding author)

(2) Bank of England. Email: alice.pugh@bankofengland.co.uk

(3) Bank of England. Email: chris.yeates@bankofengland.co.uk

The views expressed in this paper are those of the authors, and not necessarily those of the Bank of England or its committees. This paper uses data provided by the UK Data Archive and by the ONS Secure Research Service. This work contains statistical data from ONS which is Crown Copyright. The use of the ONS statistical data in this work does not imply the endorsement of the ONS in relation to the interpretation or analysis of the statistical data. This work uses research datasets which may not exactly reproduce National Statistics aggregates. This version was finalised on 14 March 2018.

The Bank's working paper series can be found at www.bankofengland.co.uk/working-paper/Working-papers

Publications and Design Team, Bank of England, Threadneedle Street, London, EC2R 8AH

Telephone +44 (0)2076014030 email publications@bankofengland.co.uk 


\section{Introduction}

This paper investigates the distributional implications for households of the extraordinary period of accommodative monetary policy in the United Kingdom, focussing on the years between 2008 and 2014. During this period, the Bank of England's Monetary Policy Committee (MPC) cut Bank Rate towards zero and launched a Quantitative Easing (QE) programme in which the Bank of England purchased $£ 375$ billion of financial assets. Distributional issues also increased in prominence, with income and wealth inequality in particular becoming headline news in the aftermath of the financial crisis. Against this backdrop, there has been growing interest in the distributional impact of the MPC's monetary policy actions. ${ }^{1}$ A similar story has unfolded in a number of other advanced economies, including the US and Euro Area.

Standard relative measures of income and wealth inequality were broadly stable in the UK between 2008 and 2014, and our results suggest that the marginal contribution of monetary policy was also small. In cash terms our estimates of the impact of monetary policy on each household vary substantially across the income and wealth distributions. But that is because households had very different levels of income and wealth at the start of this period, and our results suggest that the contribution of monetary policy has been broadly similar across these distributions in percentage terms.

Looking across age groups, we estimate that monetary policy disproportionately supported the incomes of the young. Monetary easing led to lower unemployment and higher wages than would have otherwise been the case, which particularly benefited younger age groups because they are more likely to work than older groups and because their job prospects tend to be more pro-cyclical. Younger households are also more likely to be borrowers than savers and so have seen their interest payments fall. In contrast, older households are more likely to have lost out on savings income. But older households also tend to be wealthier, and they are estimated to have benefited the most from the support provided to asset prices. Real asset prices fell over the period as a whole, but without monetary easing the falls would have been larger still.

When we combine our estimates for income and wealth, we find that most households benefited overall from monetary policy between 2008 and 2014, relative to what would have otherwise happened. This illustrates the importance of considering all of the main monetary transmission channels together when assessing the distributional impact of monetary policy. It also highlights a communication challenge for policymakers: survey evidence shows that many households underappreciate the less direct ways in which they have benefited from accommodative monetary policy.

\footnotetext{
${ }^{1}$ For example, see the Terms of Reference for the UK's Treasury Committee inquiry on the 'Effectiveness and impact of post-2008 UK monetary policy' (Treasury Committee (2016)). A number of the submissions to the inquiry were critical of the distributional impact of monetary policy over this period. See Broadbent (2017) for the Bank of England's submission to the inquiry.
} 
Our results will be of interest to anyone with a stake in the public debate about the distributional impact of monetary policy. This includes policymakers in government who collectively have responsibility for weighing distributional developments, whatever the underlying causes, and for taking action if those developments are judged undesirable. But our results are relevant to monetary policymakers too. By law the MPC has to target macroeconomic objectives, but it is nonetheless a key stakeholder in the public debate about the distributional consequences of monetary policy and hence needs to understand the distributional consequences of its policy decisions. Indeed, a number of MPC members have previously spoken on the issue. ${ }^{2}$ Our work goes further by providing a more detailed quantitative assessment of the distributional consequences of monetary policy, and we hope that our new empirical evidence will help to inform the ongoing debate on this important issue.

Our paper complements and extends the small but growing empirical literature on the distributional effects of monetary policy on households. ${ }^{3}$ The existing papers tend to focus on one distributional dimension: most focus on income inequality, while a handful focus instead on wealth inequality. But distributional implications can be broader than the effects on measures of inequality. Households differ in many respects - for example by age and other economic or demographic characteristics, and any action that affects these groups differently can be said to have distributional consequences. We consider the impact of monetary policy on income and wealth inequality, but also look at the effects by other characteristics such as age. To the best of our knowledge, ours is the first UK study to investigate the impact of monetary policy in such detail at the household level.

Our analysis assesses the short-run impact of the cut in Bank Rate to $0.5 \%$ and of the first $£ 375$ billion of QE on measured income and wealth between 2008 and 2014. These estimates provide important insights into the short-run impact on households' mortgage payments, savings income, net worth and near-term job prospects for example, but they should not be interpreted as telling the full intertemporal story of the impact of a change in monetary policy. In particular, monetary policy is generally thought of as a short-run tool with a waning influence on the real economy and hence the effects that we report may diminish beyond our sample period. As such, changes in the standard statistical measures of income and wealth between 2008 and 2014 will not capture the impact of monetary policy on households' financial positions over their full life-cycle. We discuss this further in Section 4 of the paper.

\footnotetext{
${ }^{2}$ See, for example, Carney (2016), Broadbent (2016), Haldane (2016) and Vlieghe (2016).

${ }^{3}$ Although our paper focuses on the distributional effects for households, monetary policy can also have distributional implications in other parts of the economy too, for example there may be effects for banks, companies and pension funds. For example, Bunn et al (2018) discuss the effects of low interest rates on pension funds and the implications for the spending of the companies sponsoring those schemes.
} 
To conduct our analysis we combine existing estimates of the macroeconomic impact of monetary policy used by Carney (2016) with simple asset pricing models and panel microdata from the ONS Wealth and Assets Survey (WAS) to estimate the impact on each individual household in the survey between 2008 and 2014. We focus on six main channels: (i) the effects of lower interest rates in reducing the interest payments of borrowers and the savings income of savers; (ii) the effects on labour incomes that result from higher employment and wages in the macroeconomy; the effects of lower interest rates and higher asset prices on (iii) financial wealth, (iv) housing wealth and (v) pension wealth; and (vi) the effects of inflation on the real value of debts and deposits that are fixed in nominal terms. The impact of each of these channels on different households will depend, for example, on their balance sheet positions, whether they own or rent their house or whether or not they are in work.

The key benefits of our approach are: (i) that we can drill down as far as we want into the disaggregated data to examine distributional effects in many different cuts of the data and to understand the reasons for any differences; and (ii) that we can compare the size of different income and wealth channels at the household level to see if they push in the same direction or ameliorate each other to some extent.

Our key qualitative results flow from standard features of the monetary policy transmission mechanism and from the pre-existing distributions of income and wealth. There are numerous detailed assumptions involved in the underlying macroeconomic scenario and in mapping its impact to individual households, but our sensitivity analysis shows that our key findings are robust to a variety of different assumptions on household balance sheets. ${ }^{4}$ We would, however, emphasise the direction and broad relative magnitudes of our results rather than any of the precise figures.

The structure of this paper is as follows. Section 2 provides a review of the related literature. Section 3 provides some context on what happened to the UK economy during the financial crisis and on trends in inequality. Section 4 discusses the transmission channels from monetary policy to income and wealth distributions. Section 5 outlines our approach, including describing the data used and how we estimate the impact of monetary policy on different households. Section 6 presents our main results. Section 7 reports the survey evidence on how households perceive that they have been affected by monetary policy. Finally, section 8 concludes.

\footnotetext{
${ }^{4}$ This sensitivity analysis is shown in Annex 2.
} 


\section{Related literature}

This paper adds to the small but growing literature on the distributional effects of monetary policy. We categorise and briefly summarise this literature below (see also Deutsche Bundesbank (2016) or Monnin (2017) for a recent overview), highlighting how our paper fits in and where it breaks new ground. Our scope is wider than most of the existing studies, since we consider the impact of multiple channels of monetary policy on multiple dimensions including income, wealth and age amongst others. Most of the studies cited below focus on just one channel, with the impact on income inequality the most commonly explored. In broad terms, the existing literature tends to find a small, but in some cases statistically significant, impact of monetary policy on inequality.

The existing empirical studies can be broadly divided into two approaches. One approach uses time series econometric tools (e.g. VARs) to estimate the impact of monetary policy shocks on flowbased measures of inequality such as Gini coefficients of income, wages and consumption. This is primarily a top-down approach using aggregate data or partially dis-aggregated data (such as averages within income quintiles). This approach is not well-suited to analysing wealth inequality, since data on asset and liability stock positions are typically only available at a low frequency. The second approach estimates the impact of changes in monetary policy on the distribution of income or wealth from the bottom up, using detailed balance sheet data. These microsimulation studies typically focus on the initial impact via one particular transmission channel. ${ }^{5}$

In the first category, the benchmark time-series econometric study is Coibion et al (2017). They find that contractionary shocks to the FOMC's policy rate increase income and spending inequality in the US, and play a "non-trivial" role in accounting for their dynamics. A $150 \mathrm{bps}$ positive shock to the policy rate increases the Gini coefficient of income by 0.015 . The share of the income inequality forecast error variance explained by these shocks is less than $15 \%$. The authors suggest that differences in income composition across households could be a key channel through which monetary policy affects income inequality. Comparing the relative responses of spending and income also points to the possibility of a significant wealth channel. Our study includes both channels.

Using similar methods, broadly similar results are found for the euro area (Guerello (2017)) and in a panel of both advanced and emerging market countries (Furceri et al (2016)). Similar results are also found in the UK, with Mumtaz and Theophilopoulou (2017) estimating that an unexpected

\footnotetext{
${ }^{5}$ There are also a few studies which report estimates of the impact of policy rates on inequality in the US from calibrated heterogeneous agent models. These largely support the findings from the econometric studies cited below, with both Gornermann et al (2016) and Luetticke (2017) finding an increase in the Gini coefficients of income and spending following a surprise increase in the policy rate. Both studies also find a small increase in wealth inequality.
} 
$100 \mathrm{bps}$ increase in the policy rate increases the income Gini coefficient by around $0.3 \%$ (or 0.01 in original units) at the 1-year horizon, and that such shocks explain about $10 \%$ of the forecast error variance.

Turning back to the US, Davtyan (2017) and Hafemann et al (2017) find effects of the opposite sign, with lower policy rates increasing income inequality. Inui et al (2017) also find that lower policy rates increased income inequality in Japan before the 2000 s, but they find no significant impact over their full sample period (1981-2008).

Furceri et al (2016) emphasise the importance of heterogeneity in the response of labour income to monetary policy as a key channel, noting evidence that those at the bottom of the income distribution are most affected by changes in economic activity. Mumtaz and Theophilopoulou (2017) also find that wage inequality increases after a contractionary monetary policy shock, but they also put weight on the income composition channel noting that their results are consistent with Coibion et al's (2017) findings. Our paper also includes a channel capturing labour income heterogeneity.

The impact of unconventional monetary policy on income inequality is also estimated in a number of econometric studies. Mumtaz and Theophilopoulou (2017) proxy £200bn of QE purchases by a fall of 100bps in 10-year gilt yields in 2009 and use a counterfactual experiment to estimate an increase in the income Gini coefficient. In contrast to the results for conventional monetary policy, they (tentatively) conclude that stimulating the economy through QE increases income inequality. They estimate that average incomes increased for households in all quintiles, but more so for those on higher than lower incomes. Guerello (2017) also find some evidence of an increase in income inequality in the euro area after an expansion of the ECB's balance sheet. Broadly similar results are also reported in other studies for the US (Montecino and Epstein (2017)) and Japan (Saiki and Frost (2014)).

Studies using the second microsimulation approach typically focus on the direct impact of monetary policy on net interest income via the so called 'cash-flow' channel, or on net wealth.

Using microdata on the distribution of income in a set of OECD countries, O'Farrell et al (2016) conclude that changes in the policy rate have little effect on income inequality through the "cashflow' channel. Domanski et al (2016) use microdata on balance sheet positions for a set of advanced countries to estimate the impact of changes in actual asset prices (which could be driven by monetary policy and/or other factors) on wealth inequality in the post-crisis period. They note the importance of equities and housing in explaining changes in overall wealth inequality, and the possibility that monetary policy could increase inequality if the boost to equity prices (which are 
disproportionately held by the rich) outweighs the boost to house prices (which tend to account for a higher share of wealth for poorer households).

We are aware of only one existing study that combines microsimulations and multiple transmission channels. Casiraghi et al (2016) use microdata to estimate the impact of ECB policy on Italian households. They consider the direct impacts on financial income and net wealth, but also a broader macroeconomic channel operating through labour markets. Unlike the studies referenced above, Casiraghi et al estimate the impact on individual households rather than on the averages for particular percentiles of the distribution. They conclude that the impact of the ECB's conventional and unconventional monetary policy on both income and wealth inequality measures is small and mostly not statistically significant. They do, however, find that expansionary monetary policy reduces labour income inequality in a statistically significant way, whether conducted by conventional or unconventional means. The latter result has the opposite sign to the effects found for overall income inequality in Guerello's (2017) top-down econometric-based study for the euroarea.

Our paper adopts a similar approach to Casiraghi et al (2016), but using UK data and cumulating the impact of all the policy rate changes and QE purchases throughout the post-crisis period. We go further in some important areas, including by examining distributional effects by different household characteristics, such as by age. In addition, we also consider the percentage of households supported or otherwise by monetary policy, allow for effects via pension wealth and complement our empirical estimates with survey evidence. To the best of our knowledge, we are the first to combine granular household level analysis and multiple channels to estimate what the distributional effects of monetary policy have been in the UK.

Finally, while our paper and most of the empirical studies cited above focus on the impact of monetary policy on inequality, there is a more established literature looking at the relationship from the other direction. The transmission of monetary policy, in part, depends on the existence of heterogeneity and the fact that assets and liabilities are not equally distributed, for example one of the ways that monetary policy works is by redistributing income between borrowers and savers who have different marginal propensities to consume. A number of recent studies argue that such channels may play a more important role in transmitting monetary policy than previously thought (see, for example, Auclert (2017) and Cloyne et al (2016)). 


\section{The context for our analysis of distributional effects}

Our focus is on estimating the marginal impact of monetary policy on the distribution of household income and wealth between 2008 and 2014. But it is important to place those marginal estimates into the wider context of developments in the UK economy and in headline measures of inequality. This section discusses that context. ${ }^{6}$

\section{The financial crisis}

The financial crisis in 2008 led to the UK economy suffering its deepest recession since the Second World War. The level of output fell by $6 \%$ and the unemployment rate increased from $5 \%$ to $8 \%$ (Charts 1 and 2). The recovery from the recession has also been slow, leading to a decade of stagnating real earnings growth. The scale of the shocks associated with the financial crisis prompted an unprecedented monetary policy response. The MPC cut Bank Rate from $5.5 \%$ at the end of 2007 to $0.5 \%$ by early 2009 and launched a programme of asset purchases, or quantitative easing (QE), worth $£ 375$ billion by $2012 .^{7}$

\section{Chart 1: Real GDP}

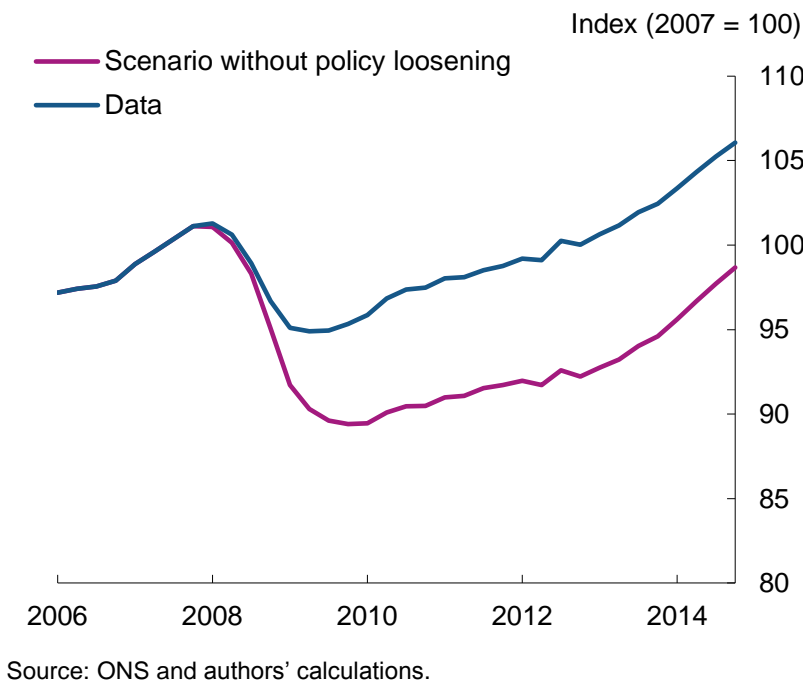

\section{Chart 2: Unemployment rate}

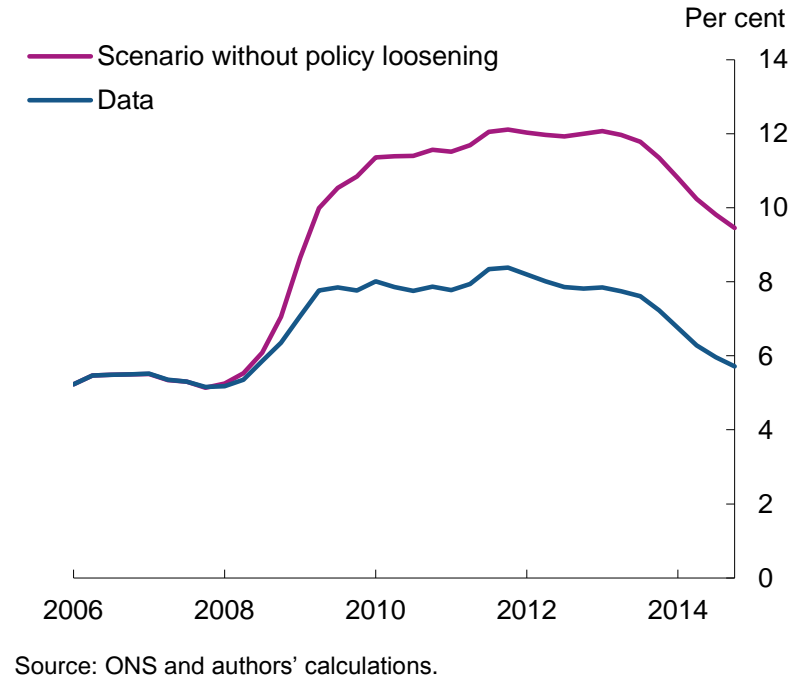

Despite the scale of the monetary policy response to the financial crisis, it was not enough to prevent a deep recession. But that does not mean that policy was not effective: without it, the economic outcomes may have been much worse. Carney (2016) and Haldane (2016) describe a simulation from the Bank's forecasting model which implies that GDP would have been up to 8\% lower than it actually was if there had been no change in monetary policy after 2007 Q4 (Chart 1)

\footnotetext{
${ }^{6}$ This section draws on material from Carney (2016). We only describe developments up to 2014 in this section given that we do not consider the distributional effects of monetary policy over more recent periods in our analysis.

${ }^{7}$ Bank Rate was reduced to $0.25 \%$ in August 2016 and there was a further expansion in QE. However, our analysis of distributional effects only goes up to 2014 and so these developments do not fall into our sample period.
} 
and the unemployment rate 4 percentage points higher (Chart 2). ${ }^{8}$ This simulation provides a useful counterfactual scenario to use in our analysis of the distributional impact of monetary policy on households, but it should be viewed as illustrative rather than definitive. In particular, if the MPC had attempted to maintain such a tight stance of monetary policy for such a long period of time this may have triggered a fundamental reassessment of the MPC's reaction function. This sets some limits on the power of monetary policy in the short run, and in practice means that policy rates tend to track equilibrium real interest rates over longer horizons.

Asset prices also fell in the UK after 2007, but those falls would likely have been larger and more persistent without monetary stimulus. In real terms, equity prices fell by a peak of $40 \%$, and were still $10 \%$ below their 2007 level in 2014, whilst house prices fell by $20 \%$ and were still $15 \%$ below their 2007 level in 2014 (Charts 3 and 4). Those falls in asset prices will have reduced the real value of wealth held by households. But those falls in wealth would have been even larger without a loosening in monetary policy. Our counterfactual scenario implies that real equity prices and real house prices in 2014 would have been $25 \%$ and $22 \%$ lower respectively than they actually were (Charts 3 and 4). So although monetary policy led to higher asset prices in a marginal sense, it only reduced the extent to which those prices fell relative to what would have otherwise been the case. Further details on the counterfactual scenario are provided in Annex 1.

Chart 3: Real equity prices ${ }^{(a)}$

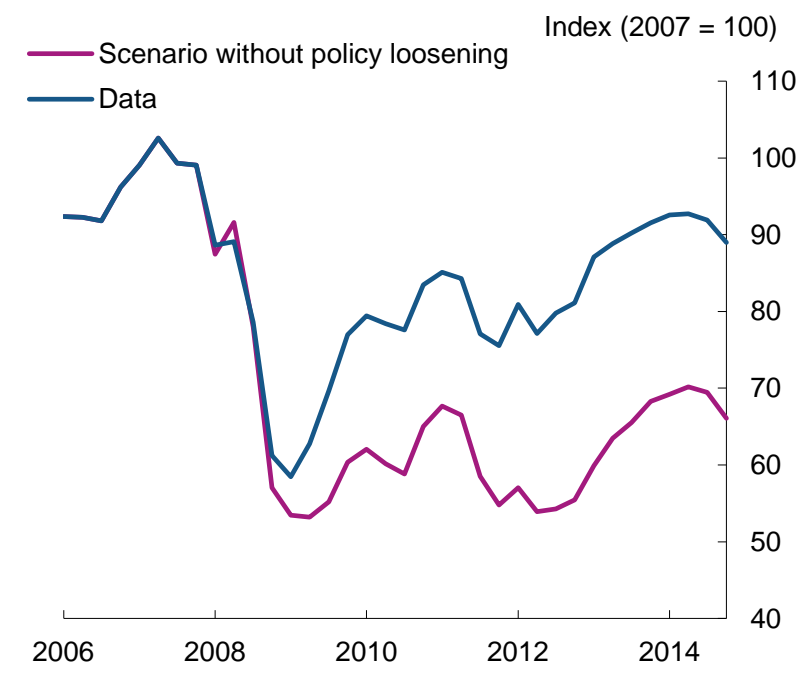

Source: ONS, Thomson Reuters Datastream and authors' calculations. (a) FTSE All-share index divided by the consumption deflator.
Chart 4: Real house prices ${ }^{(a)}$

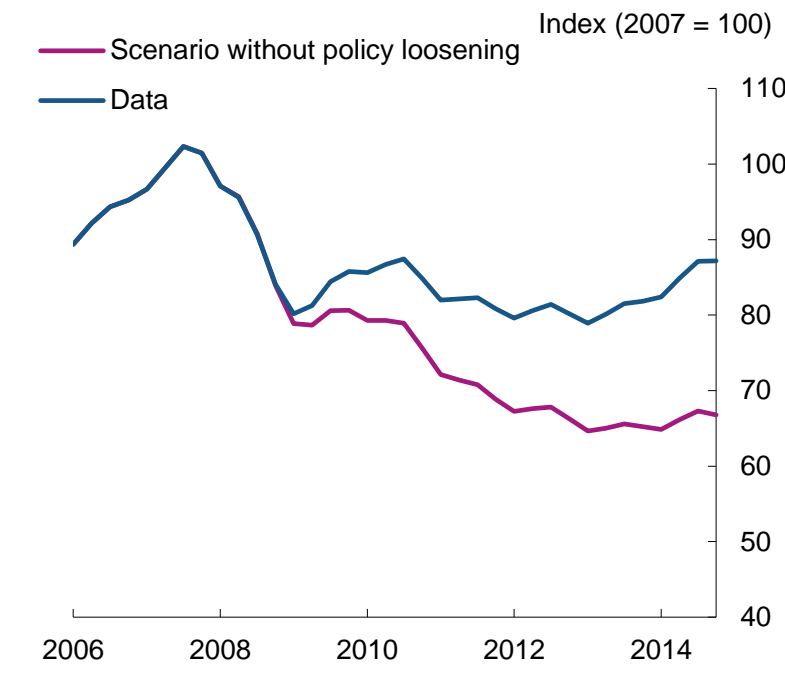

Source: ONS and authors' calculations.

(a) UK House Price Index divided by the consumption deflator.

\footnotetext{
${ }^{8}$ This scenario considers the implications of monetary policy remaining unchanged after the end 2007 . The interest rate required to maintain the balance between demand and supply in the economy, or the equilibrium interest rate, was falling prior to the financial crisis and is likely to have fallen further since 2007 (Rachel and Smith (2015)). Falling equilibrium interest rates would imply that unchanged policy rates would have represented an increasingly tight monetary policy stance.
} 


\section{Developments in inequality}

The existing distributions of income and wealth in the UK - and in many other countries - were already heavily skewed prior to the financial crisis. For example, in 2007 the richest $10 \%$ of households accounted for around a quarter of aggregate income. The skew in wealth holdings was even larger, with the top $10 \%$ of the distribution holding just over half of all net wealth. ${ }^{9}$ In other words, there were striking inequalities in the data before the 2008-14 period of accommodative monetary policy.

Whatever the marginal impact of the extraordinary period of accommodative monetary policy on inequality, it was not associated with an overall increase in summary measures of inequality.

Income inequality fell slightly after 2007, having risen sharply during the 1980s, using either the Gini coefficient or $90: 10$ ratio metrics (Chart 5). ${ }^{10}$ Consistent with that, households towards the bottom of the income distribution experienced the fastest growth in incomes after 2007, although real income growth was still low for all groups relative to pre-crisis trends (Chart 6).

\section{Chart 5: Measures of income inequality ${ }^{(a)}$}

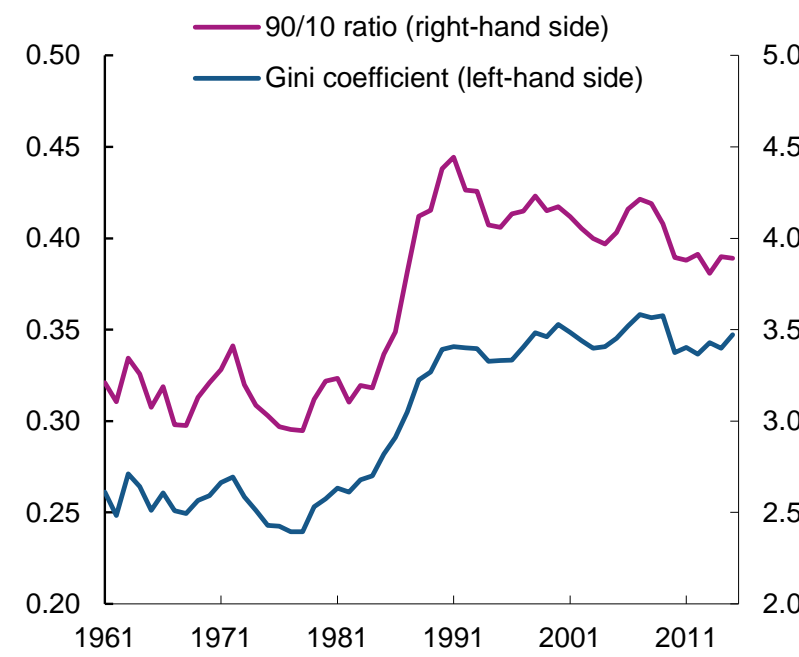

Source: Family Resources Survey (FRS) and IFS.

(a) Income before housing costs, net of direct taxes and inclusive of state benefits and tax credits. Data are for financial years.

\section{Chart 6: Change in real income from 2007 by income quintile}

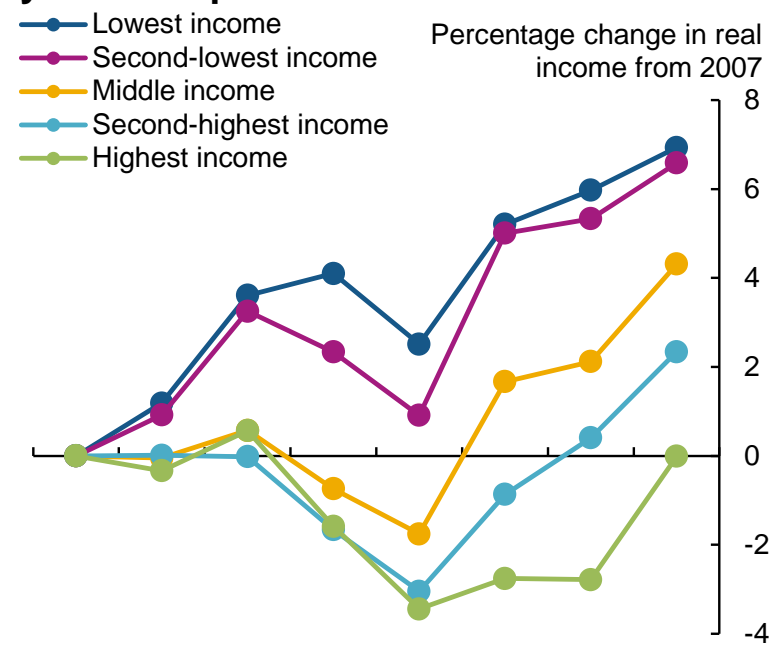

20072008200920102011201220132014

Source: FRS, ONS and authors' calculations.

(a) Mean income per household divided by the National Accounts

consumption deflator. Incomes are measured before housing costs, net of direct taxes and inclusive of state benefits and tax credits. Data are for financial years.

\footnotetext{
9 Income data are from the 2007/08 Family Resources Survey. Wealth figures are taken from wave 1 of the Wealth and Assets Survey, which covered mid-2006 to mid-2008.

${ }^{10}$ The Gini coefficient is the most commonly used measure of inequality. This summarises the extent to which the distribution of income or wealth between households deviates from perfect equality. A coefficient of 0 represents complete equality and a coefficient of 1 complete inequality. Alternative measures focus on particular parts of the distribution. For example the 90:10 ratio compares the households at the 90th and 10th percentiles. Other measures instead focus on the top or bottom tails such as measures of the income or wealth share of the top 1\%. Data from the World Wealth and Income Database suggest that the proportion of income accruing to the top $1 \%$ of UK households also fell slightly after 2006. Another approach is to measure income inequality after stripping out housing costs. The UK income Gini coefficient is higher on this after housing costs (AHC) basis, but has also fallen back slightly from its pre-crisis peak (Department for Work and Pensions (2018)). Looking over a longer horizon, The Resolution Foundation (2018) discuss how AHC income inequality has increased slightly over the past two decades.
} 
Wealth inequality has been broadly unchanged since 2007. Using data from the Wealth and Assets Survey (WAS), the wealth Gini coefficient is estimated to have been constant at 0.61 between 200608 and 2010-12, before increasing slightly to 0.63 in 2012-14 (Chart 7). ${ }^{11}$ Alternative measures of wealth inequality derived from this dataset, such as the 90:10 ratio and top 1\% share were also little changed. ${ }^{12}$ By wealth quintile, the poorest $20 \%$ of households saw their net wealth increase by more than the wealthiest group in proportionate terms (Chart 8$).{ }^{13}$ That partly reflects deleveraging within this group, although the fact that the net wealth of the bottom quintile is close to zero means that even small absolute changes in wealth can be large in percentage terms. There are fewer historical data available on wealth inequality than for income, but to the extent that data do exist they suggest that the wealth Gini coefficient fell over the decade or so prior to the financial crisis (these data paint a partial picture, however, as they include only net financial and housing wealth and exclude pension and physical wealth). ${ }^{14}$

\section{Chart 7: Wealth Gini coefficients}

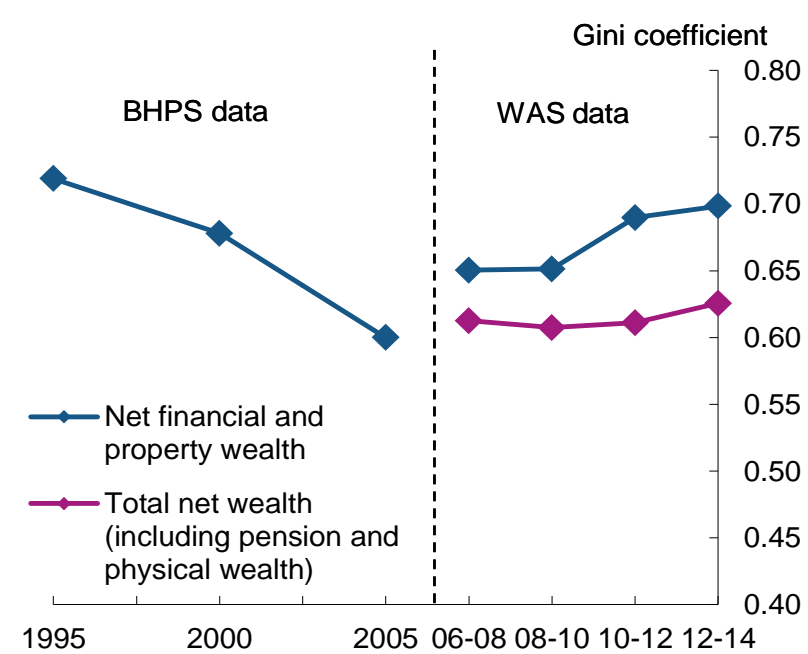

Source: British Household Panel Survey (BHPS), Wealth and Assets Survey (WAS) and authors' calculations. WAS data are for mid-2006 to mid-2008, mid-2008 to mid-2010, mid-2010 to mid-2012 and mid-2012 to mid-2014.

\section{Chart 8: Change in real net wealth from 2006-08 by wealth quintile ${ }^{(a)}$}

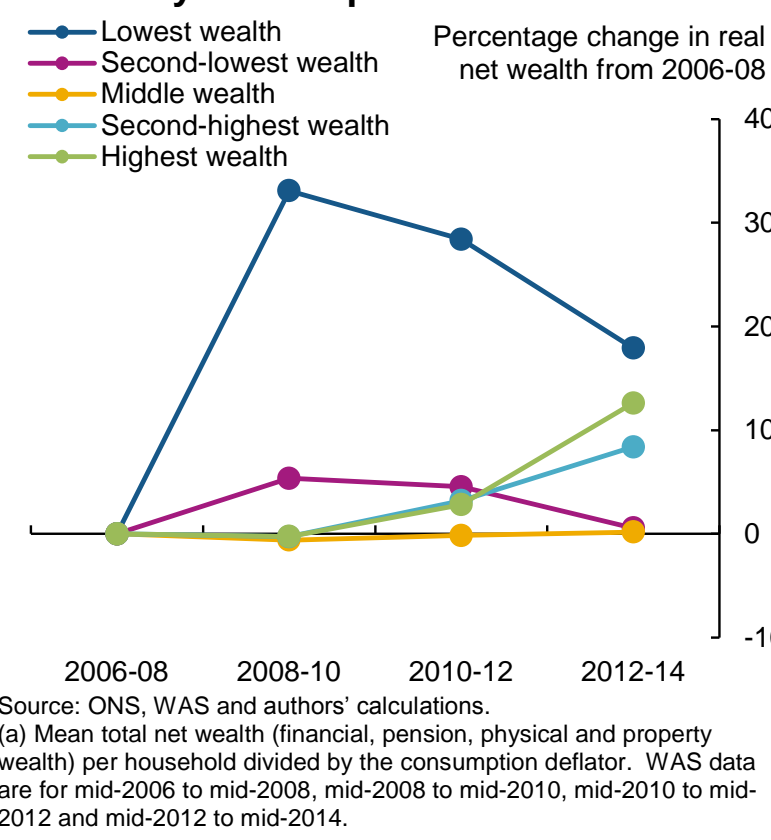

Examining the data by age, younger households were more adversely affected by the financial crisis than older households. That is partly because younger households tend to be more likely to lose their jobs in recessions. Wage growth was also very modest for those who remained in work,

\footnotetext{
${ }^{11}$ Although we only focus on the period up to 2014 in this section, the wealth Gini from the WAS was also little changed in 2014-16, at 0.62 .

${ }^{12}$ Using the Wealth and Assets Survey, the net wealth 90:10 ratio fell from 87 in 2006-08 to 83 in 2012-14, while the share of wealth accounted for by the top $1 \%$ of wealthiest households was constant at $13 \%$. Separate data from the World Wealth and Income Database show a higher share for the top $1 \%$ at around $20 \%$, but like the WAS data that share has been broadly stable over this period.

${ }^{13}$ This differs slightly from the wealth quintile chart in Carney (2016) as we report the change for total wealth, including physical wealth, and show it in real terms.

${ }^{14}$ Over a much longer period, data from the World Wealth and Income Database suggest that the share of wealth held by the wealthiest $1 \%$ of households fell for much of the 20 th century.
} 
and particularly so for the young. ${ }^{15}$ The only age group to see a material rise in real incomes since 2007 were those whose head was aged over 65 (Chart 9). Members of these households were less heavily affected by the financial crisis because they were typically already retired and not in work.

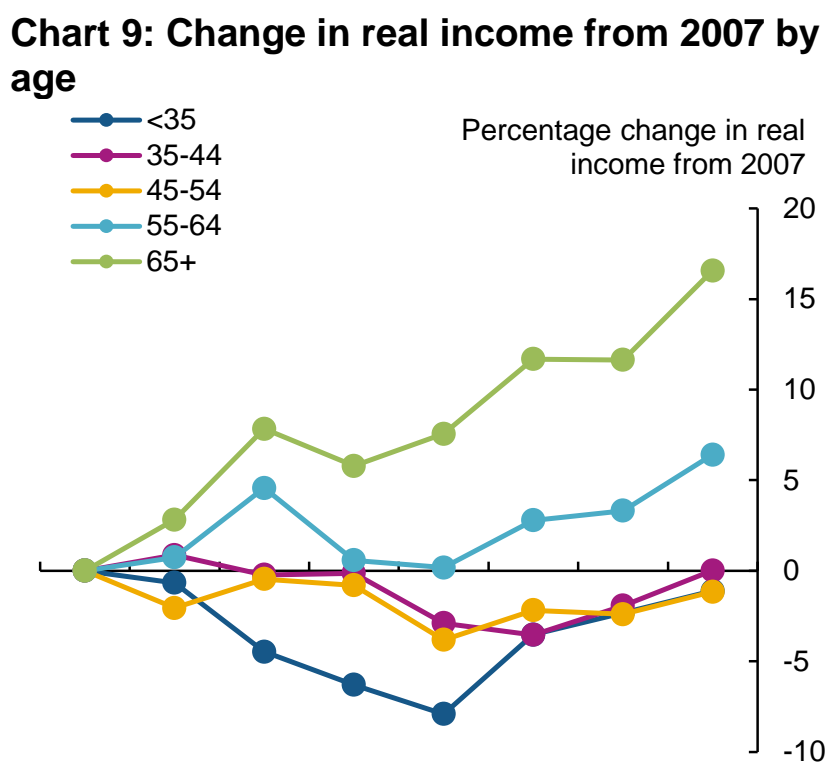

20072008200920102011201220132014

Source: FRS, ONS and authors' calculations.

(a) Mean income per household divided by the consumption deflator.

Incomes are measured before housing costs, net of direct taxes and

inclusive of state benefits and tax credits. Data are for financial years.

\section{Chart 10: Change in real net wealth from} 2006-08 by age

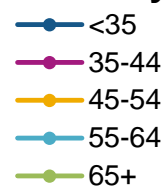

Percentage change in real net wealth from 2006-08

\section{0}

20

10

\section{0}

2006-08 2008-10 2010-12 2012-14

Source: WAS, ONS and authors' calculations.

(a) Mean total net wealth per household divided by the consumption deflator. WAS data are for mid-2006 to mid-2008, mid-2008 to mid-2010, mid-2010 to mid-2012 and mid-2012 to mid-2014.

Older households also saw a material rise in their net wealth after 2007 (Chart 10), having already disproportionately benefited from large increases in house prices over the decade prior to the financial crisis. Those increases in wealth since 2007 reflect a sizeable contribution from higher pension wealth, as lower interest rates pushed up the value of future pensions, but continued growth in real incomes will also have allowed these older households to accumulate more wealth to help offset the impact of lower asset prices. Younger age groups were less able to do that and their net wealth fell in real terms (Chart 10). ${ }^{16}$

In summary, the UK suffered a deep recession after 2007. The stimulus provided by monetary policy was unable to prevent that, but without it things would likely have been much worse.

Younger households were more affected by the crisis than older households, but the income and wealth distributions did not become more unequal in a relative sense. The remainder of this paper focuses on the marginal effects that monetary policy has had on inequality and on different types of households. We start by discussing the channels through which monetary policy might affect the income and wealth distributions and explaining how we attempt to quantify those channels.

\footnotetext{
${ }^{15}$ There is more detail on the effects of recessions on different age groups in Annex 3.

${ }^{16}$ Younger age groups also gained by less from higher pension wealth, given that pension wealth is relatively less important for them than for older households.
} 


\section{Transmission channels from monetary policy to income and wealth distributions}

Monetary policy works by influencing the incentives to spend and save, by redistributing income between borrowers and savers and by affecting asset prices, including the exchange rate.

Households and firms respond to these developments, leading to changes in aggregate output and inflation. All of these channels operate in the forecasting model underlying the macroeconomic impact in our counterfactual scenario.

In our analysis of distributional effects we consider the short-run impact of monetary policy between 2008 and 2014. Our analysis does not cover any longer-run considerations. ${ }^{17}$ We focus on six main channels that are likely to have different effects on different types of households: the "cashflow" channel of changes in interest payments and receipts; second round effects on labour incomes; effects of higher asset prices through financial wealth; effects via housing wealth and pension wealth; and the effects of inflation on the real values of debts and deposits that are fixed in nominal terms. ${ }^{18}$ These channels are summarised in Figure 1. Theory cannot pin down the overall direction or magnitude of the impact of monetary policy on income and wealth inequality across all of these channels. Empirical estimates are needed instead. Section 5 sets out more details on how we estimate the size of each of these channels.

\footnotetext{
${ }^{17}$ Under the conventional view of the long-run neutrality of money, monetary policy would have a waning influence on real variables over time (see for example Broadbent (2017)). Some authors do, however, argue that monetary shocks can have real effects beyond the business cycle. For example, Juselius et al (2016) argue that monetary policy through the financial cycle has a long-lasting impact on output and, by implication, on real interest rates.

${ }^{18}$ Coibion et al (2017) set out five channels for the impact of monetary policy on income inequality: income composition, financial segmentation, portfolio, savings redistribution and earnings heterogeneity channels. We capture the same channels although label them differently. Our cash-flow and labour market channels capture the same effects as their income composition, savings redistribution and earnings heterogeneity channels. We capture portfolio effects in our asset price channels, and the currency holding effect is the same as our real value of nominal debt and deposits channels. Our asset price channels may also be thought of as capturing financial segmentation to the extent that you view the current distribution of financial wealth as reflective of households' differing 'connections' to financial markets.
} 


\section{Figure 1: Transmission channels of monetary policy to income and wealth distributions}

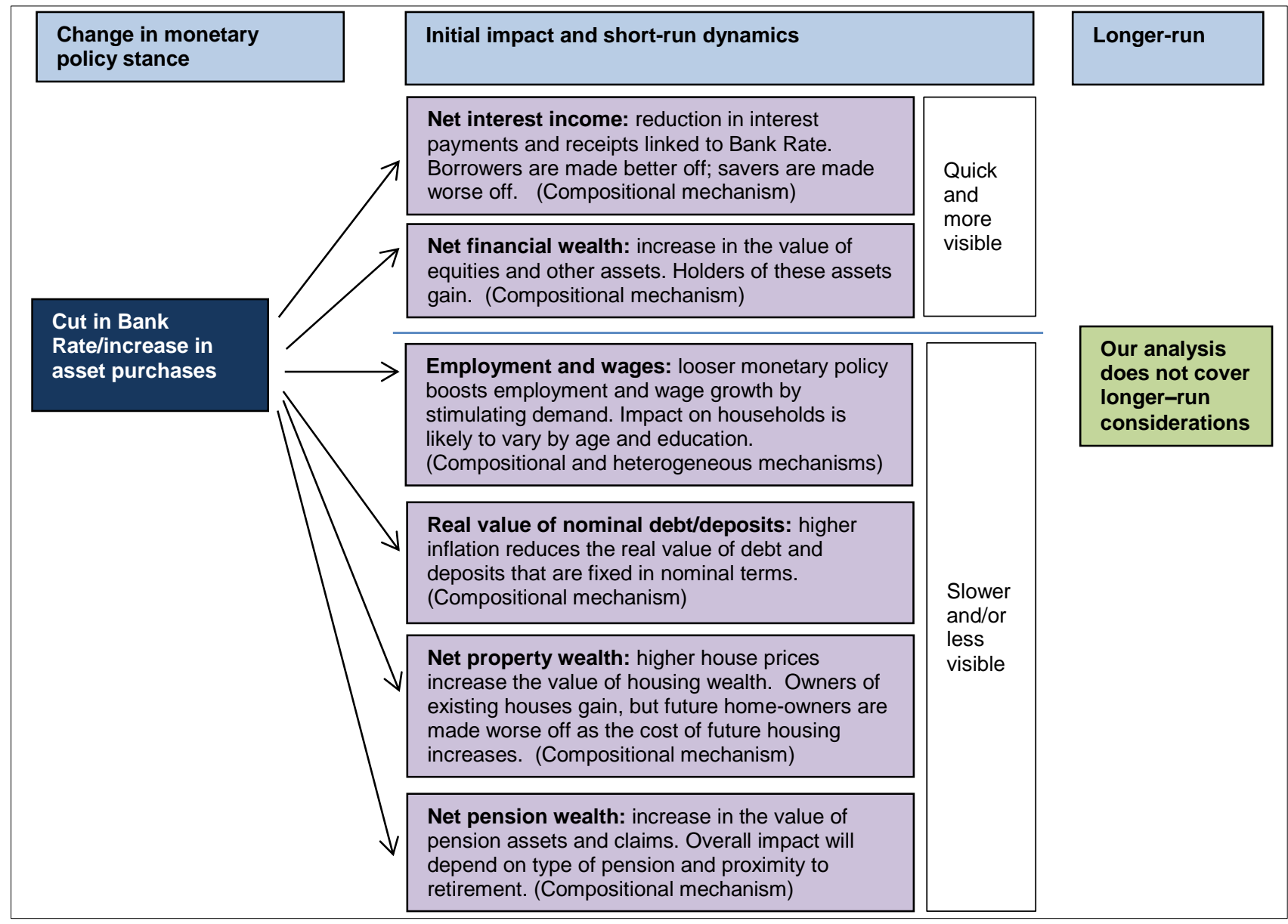

Underlying the channels in Figure 1 are two broad mechanisms through which monetary policy can affect income or wealth distributions: a compositional mechanism where monetary policy has a uniform effect on individual components of income and wealth which are held unevenly across households; and a heterogeneous mechanism where the impact of monetary policy on an individual component is itself uneven across households. Effects on net interest income and on wealth are likely to be primarily compositional, for example the effects for a household will depend on whether they are a borrower or saver or hold large amounts of financial assets or not. Effects on labour income could incorporate both compositional and heterogeneous mechanisms: the former because the share of labour income tends to increase with total income (Chart 11), and the latter because the effects may be different for different groups if, for example, the job prospects of younger and less educated people are more sensitive to the state of the economy than is the case for older and more educated people.

Charts 11 and 12 show how the relative importance of different components of income and wealth varies across the distribution. ${ }^{19}$ For example, the share of total wealth held in financial assets (light

\footnotetext{
${ }^{19}$ Annex 4 contains some additional charts on the distribution of income and wealth.
} 
blue bars) tends to increase with total wealth. Consequently a $10 \%$ (say) increase in the financial wealth of all households would likely lead to an increase in standard measures of wealth inequality (compositional mechanism). But a 10\% increase in house prices would be likely to lead to lower inequality because gross housing wealth accounts for a lower share of total net wealth at the top of the distribution than it does in the middle. Chart 12 shows that gross property and pensions tend to be the largest components of wealth $(45 \%$ and $40 \%$ of the net wealth of all households respectively). Gross financial wealth is smaller in comparison at only around $15 \%$ of net wealth. Within that, bank deposits are the largest component of financial wealth, directly held equities are smaller and account for only $6 \%$ of total net wealth.

\section{Chart 11: Composition of household income by income decile, 2012-14 ${ }^{\text {(a) }}$}

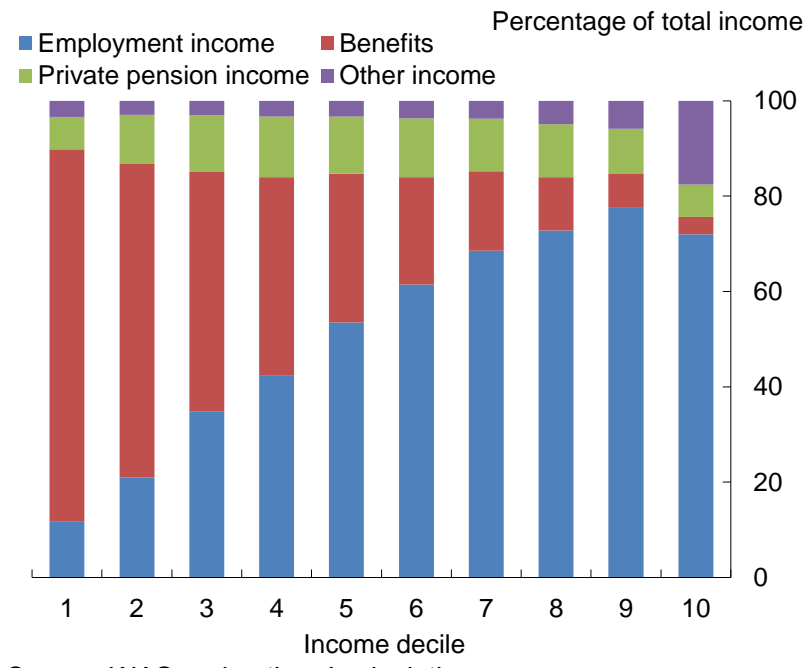

Source: WAS and authors' calculations.

(a) Post-tax income. 'Other' includes income from savings.

\section{Chart 12: Composition of household wealth by wealth decile, 2012-14 ${ }^{(a)}$}

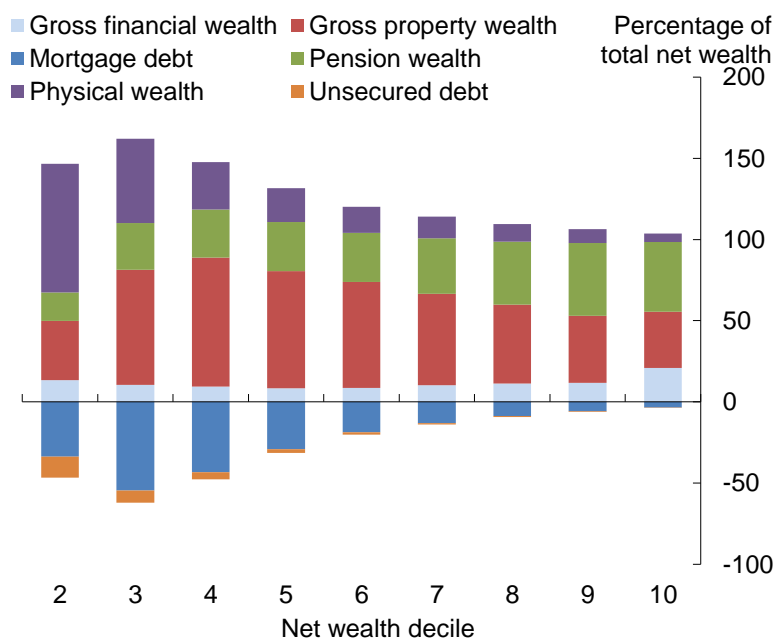

Source: WAS and authors' calculations.

(a) The bottom decile is excluded from this chart because net wealth is close to zero, implying that the components of gross wealth sum to around $600 \%$ of net wealth, offset by debts worth $-500 \%$.

Note that a uniform percentage change in total income or total wealth for all households in the UK would have no impact on the standard - relative - inequality measures such as Gini coefficients or 90:10 ratios. Individual households would of course see quite different impacts in cash terms though, given the skew in income and wealth distributions described in Section 3. For example, a $10 \%$ increase in net wealth for all households would be worth only $£ 200$ to the $10 \%$ of least wealthy households, but $£ 195,000$ to the top $10 \%$ of the distribution. In our results section we present disaggregated results in both proportional and cash terms. We think both aid understanding, but stress that the cash figures are heavily dependent on the pre-existing disparities in income and wealth. 


\section{Financial well-being over the life-cycle}

Charts 11 and 12 incorporate all of the components of income and wealth included in the WAS. It is important to note, however, that changes in these components are an imperfect gauge of changes in financial well-being over the full life-cycle. For example, human capital is not captured and measures of wealth can change without any effect on households' future spending power.

If discount rates fall, for example, then the measured wealth of households holding assets will increase. These households only gain though in the sense that they now hold a more expensivelypriced claim on the same future cash-flows. Households may prefer to sell some of these higherpriced assets and consume more today, but that will be at the expense of lower future consumption. While households are free to make this choice for a directly held financial asset, that is not the case for all forms of wealth. For example, higher pension wealth cannot easily be extracted to finance higher current consumption. It is also worth noting that the pension claims of households are of course liabilities of the pension providers, and in particular that changes in the deficits of defined benefit pension funds can be associated with increases in the measured pension wealth of households but an increase in the funding costs for those sponsoring the pension schemes.

Housing wealth is another important special case, given that homeowners who might cash-in on higher house prices by selling their house today still need somewhere to live tomorrow. Although homeowners gain from increased house prices today, higher house prices also increase the cost of consuming housing services in future. ${ }^{20}$ Those future cost effects will be more pronounced for households who currently rent but want to get onto the housing ladder in the future and for those who want to 'trade-up'. Changes in the value of the current stock of housing - as captured in the WAS and used in our main analysis - do not include any of these future costs, although we do touch on them in an extension to our main results.

In summary, assessing the impact of monetary policy on financial well-being over the life-cycle is beyond the scope of this paper. We instead focus on the important but narrower goal of better understanding the impact of monetary policy on the standard statistical measures of income and wealth between 2008 and 2014. Our results will capture the most tangible impacts for households over this period, but they will not tell the whole intertemporal story of the impact of monetary policy.

\footnotetext{
${ }^{20}$ The relationship between house prices and consumption is discussed in more detail by Benito et al (2006).
} 


\section{Method}

The key ingredients and steps in our method to analyse the distributional effects of monetary policy on UK households are as follows:

(i) Select a set of aggregate variables which capture the main transmission channels of monetary policy for the household sector;

(ii) Conduct a simulation exercise using the Bank's main forecasting model to provide estimates of the impact of monetary policy on these aggregate variables between 2008 and 2014;

(iii) Use survey data on households' characteristics and balance sheets to map the changes in these aggregate variables into changes in income and wealth for a representative sample of individual households;

(iv) Calculate what these changes in income and wealth imply for headline inequality measures such as Gini coefficients;

(v) Drill down into the microdata to analyse distributional effects along other dimensions such as age;

The aggregate variables that we select in step (i) to capture the transmission of monetary policy into the distribution of income and wealth are interest rates, employment, wages, equity prices, house prices and a measure of consumer prices (the consumption deflator). The simulation exercise described in step (ii) is the same as that described by Carney (2016) and Haldane (2016) and which was discussed in the earlier context section of this paper. It implies that real GDP would have been up to $8 \%$ lower than it actually was if there had been no change in monetary policy after 2007 Q4 (Chart 1) and the unemployment rate 4 percentage points higher (Chart 2). Further details on this scenario are provided in Annex 1. Given that these aggregate estimates are drawn from existing work, the contribution of our paper is to assess how they have affected different parts of the distribution rather than provide any new insights into the aggregate impact of monetary policy.

\section{Microdata and mapping the transmission channels to individual households}

To map the estimates of the aggregate impact of monetary policy into the distribution we use microdata from the Wealth and Assets Survey (WAS). The WAS is a household survey with a large panel element that is run by the UK statistical agency, the Office for National Statistics (ONS). It is the primary source of disaggregated data on households' balance sheet positions in the UK with households interviewed once every 2 years, and it contains the detailed information that is required 
for us to be able to map our counterfactual scenario into the distribution. ${ }^{21}$ We use data from the first four waves of the survey: mid-2006 to mid-2008, mid-2008 to mid-2010, mid-2010 to mid-2012 and mid-2012 to mid-2014. ${ }^{22}$

We exploit the panel structure of the WAS to follow the same households through time. In our analysis we restrict the sample to only those households who are in all of the first four waves of the survey - just under 10,000 households - and we used weights that allow that sample to be representative. ${ }^{23}$ We use households' actual balance sheet positions to estimate the impact on each household in each wave if monetary policy had remained unchanged after 2007 . We then deflate the estimates so that they are in real terms, and where relevant, cumulate the effects across the waves.

One challenge in modelling the distributional effects of monetary policy is how to account for households' behavioural responses to changes in monetary policy. In order to produce a precise estimate of the reduction in household savings income due to low interest rates, for example, we would ideally want to know what each household's stock of bank deposits would have been if policy had been unchanged. But in practice we only observe what deposits actually were, which will include any response by households to the change in monetary policy. For example, lower interest rates tend to reduce the incentive to save, all else equal.

In our counterfactual scenario, we use households' actual balance sheet positions in each wave, which will include the endogenous responses to the actual loosening in monetary policy. An alternative approach, which will not contain any endogenous responses, is to assume balance sheet positions were fixed as of 2007. But this approach will exclude changes that are part of the normal life cycle, as well as responses to other aspects of the financial crisis, which should be accounted for. Neither approach shows exactly what would have happened had monetary policy remained unchanged after 2007.

\footnotetext{
${ }^{21}$ The WAS is the only household survey that contains comprehensive data on the wealth of British households. It incorporates an oversampling technique to adjust for the lower response rate of wealthy households and ensure that the survey is as representative as possible. The WAS is collected from private households, and therefore does not include people living in publicly provided housing. Using the household unit also means inequalities within households are hidden. For example young adults living with their parents while saving to purchase their own home will not be separately identified in the results. The survey excludes Northern Ireland and therefore only covers Great Britain. But given that households in Northern Ireland only account for around $2.5 \%$ of all UK households, the results based on GB data are still likely to provide a close approximation to the results for the UK as a whole.

${ }^{22}$ These were the only waves available when the analysis presented in this paper was carried out. The fifth wave of the survey, covering mid-2014 to mid-2016 was released as the paper was being finalised. We take the first wave, 2006-08, as an approximation of balance sheet positions in 2007 and use data from later waves to analyse the impact of the monetary policy changes that took place after the end of 2007. The interview window for the 2006-08 survey ran from July 2006 to June 2008 . This provides the best available baseline from the WAS data for gauging the distributional impact of Bank Rate cuts (which began in December 2007 but accelerated from late 2008) and of QE (the MPC announced the first $£ 75$ billion of purchases in March 2009).

${ }^{23}$ We construct our own weights, which take the WAS cross sectional weights and add an inverse probability adjustment to allow for the fact that certain types of households may be more likely to have remained in the survey for all 4 waves (and to have data on all of the variables that we require for our analysis). That inverse probability adjustment takes account of position in the income and wealth distributions and characteristics such as age, education, gender, economic activity and housing tenure.
} 
In practice, the results from the two approaches of using actual or pre-crisis balance sheet data are relatively similar, and the choice does not affect the main conclusions that we draw. We choose to report results using actual balance sheet positions because we think that changes in balance sheets that are part of normal life cycle and responses to other aspects of the financial crisis are likely to be larger than endogenous responses to monetary policy changes. But this does not make a large difference to the results given that flows, for example of saving or debt repayment, tend to be relatively small in relation to stocks in any one period. A comparison of results using actual and precrisis balance sheets is reported Annex 2 . The difficulty in stripping out these endogenous responses reinforces the point that our results should be considered as providing a stylised indication of the overall trends and not as precise estimates.

Most of our analysis focusses on real changes in income and wealth, since only real changes make households better or worse off. However, when assessing the implications of monetary easing after 2007 for Gini coefficients we use estimates in nominal space so that we evaluate what the reported Gini's would have actually been. For income, we assume that the boost to prices from monetary policy fed through to higher nominal income for all components except savings income. ${ }^{24}$ For wealth, we assume that the higher price level was passed through to higher nominal valuations for all components except debt and deposits which we assume are fixed in nominal terms. These assumptions about the effects of higher prices feeding through to some but not to all components of income and wealth also have some impact on the respective Gini coefficients. These effects are reported in the results section.

Having described our broad approach, the remainder of this section provides some more detail on how we quantify the real effects of monetary policy on the main components of income and wealth.

\section{(a) Effects on net interest income via interest receipts and payments:}

We use each household's stock of debt and deposits to estimate how different their interest payments and receipts would have been had interest rates been held constant. ${ }^{25}$ To do this, we use changes in the average effective interest rates on debt and deposits from aggregate data since the end of 2007. These data are shown in Chart A1 in Annex 1. This does not differentiate between households whose debt or deposits were held in fixed and variable rate products because that information was not available in the WAS. All household are assumed to face the same change in the interest rates, although this will only affect the results if fixed/variable rates were more or less prevalent in certain parts of the population.

\footnotetext{
${ }^{24}$ We do not capture any distributional impacts which might stem from differences in consumption baskets between households that might lead to some types of households having different inflation rates to others.

25 Debt includes mortgages (on main home and other properties) and unsecured loans.
} 


\section{(b) Macroeconomic effects on labour incomes}

Looser monetary policy led to lower unemployment and higher real wage growth than otherwise would have been the case. To map this into the distribution of households, we randomly draw some individuals who were actually in employment in each wave of the WAS as people who would have otherwise been unemployed. The probability of being drawn in this way is allowed to depend on age and education level: during the recent recession, younger and less educated people were more likely to have lost their jobs, although this was also the case in earlier recessions too. More details on exactly how this was done are described in Annex 3.

For people who remained in work, labour income is adjusted downwards, in line with the lower overall profile for wages in the macroeconomic scenario. The adjustments are again allowed to be larger for younger and less educated people and smaller for those who are older and more educated, in line with recession experience. The effects on labour incomes are calculated at the person level and then aggregated within households in order to give the household-level estimates that are used in the analysis.

\section{(c) Financial asset prices:}

We use the value of equities and gilts that are held directly, and estimates of the boost to prices (in both nominal and real terms) from lower interest rates and $Q E$, in order to calculate the increase in financial wealth attributable to monetary policy. This only considers assets held directly. Our treatment of assets held in pension funds is discussed below.

\section{(d) Effects of inflation on the real value of debt and deposits:}

Looser monetary policy leads to higher inflation than would have otherwise been the case. That reduces the real value of any components of income or wealth that are fixed in nominal terms because a given amount of cash can be used to buy a smaller quantity of goods and services. We revalue the stocks of debt and deposits that each household has in line with the differences in the aggregate price level in our counterfactual scenario to calculate the change in their real value.

\section{(e) House prices:}

Lower interest rates and QE will, all else equal, have boosted UK house prices and raised the housing wealth of existing home-owners. Our baseline results only consider the impact of increases in the value of existing homes. Our approach to estimating the change in measured housing wealth attributable to monetary policy is similar to that used for financial asset prices. 
We extend this analysis later in the paper, however, to also consider the implications of higher future housing costs. This extended analysis is based on a user cost type framework, whereby higher house prices raise the future discounted cost of housing consumption, and it assumes that households follow a similar pattern to previous generations in how they consume housing over their life cycle. The calculations are described in more detail in Annex 3. The calculations of future housing costs are sensitive to the parameters chosen. For simplicity they assume that house prices are persistently higher, although this may not be the case in practice if monetary policy does not have real effects over the long term. And they assume that there are no bequests or intergenerational transfers, which again may overstate the true effects. They may therefore be likely to represent more of an upper bound rather than a central estimate.

\section{(f) Pension wealth:}

Pensions are a complex area and there a number of different types of pension schemes that household may be part of. But they are also an important source of wealth. We group pensions into three main categories: defined benefit (DB) schemes (where a given future income scheme is guaranteed by the scheme sponsor), defined contribution (DC) schemes (where contributions are invested and used to buy a stream of pension income at retirement ${ }^{26}$ and pensions that are already in payment (irrespective of the type of scheme). ${ }^{27}$ We only consider the value of occupational and personal pensions and not state pensions, following the definition used in the WAS, although claims on future state pensions are a considerable source of wealth for households too.

Changes in the value of DC pensions on account of monetary policy are valued in a similar way to directly held financial assets as changes in asset prices translate directly into the value of those pensions. We assume a 50-50 split in the assets held in these funds between equities and gilts. DB pensions and pensions in payment are valued by discounting a fixed future income stream, and it is through the discount rate that monetary policy will affect the value of these pensions. Annuity rates (which are age and gender specific) are used as the discount rates in the WAS. Estimating the impact of monetary policy on these annuity rates is difficult and therefore for simplicity we assume that all of the changes in annuity rates after the first wave of the WAS (2006-08) reflect monetary policy. Clearly this is an over simplification given that factors like longevity will be relevant too, but it does provide us with a practical way to estimate how the value of these pensions have changed: we revalue the real pension wealth of households in the fourth wave of the WAS (201214) using the annuity rate assumptions from the first wave and we attribute the difference to monetary policy, or to be more precise, to lower interest rates.

\footnotetext{
${ }^{26}$ We include occupational DC schemes and personal pensions in this category.

${ }^{27}$ Approximately, around $50 \%$ of pension wealth in wave 4 of the WAS (2012-14) was accounted for by pensions in payment, $40 \%$ DB pensions not yet drawn and 10\% DC. These occupational pensions included unfunded government schemes.
} 
As discussed earlier, this exercise is an attempt to estimate the impact of monetary policy on measured pension wealth. It does not imply any change in real future cash-flows - at least in the case of DB pensions and pensions in payment - which would more obviously make households better off, it simply implies that the cost of providing those future cash-flows has gone up and therefore that the value of the claim on those cash-flows has increased. ${ }^{28}$

\footnotetext{
${ }^{28}$ For people in DC schemes the net effect of higher asset prices and lower interest rates on future income streams is ambiguous. On one hand, higher asset prices increase the size of the pension pot, but on the other it becomes more expensive to buy a given future income stream. The exact effects on individual households will depend on how their pension scheme is invested and annuity rates at the point of retirement. We do not attempt to model this, although we note that only $4 \%$ of households contained somebody who started to draw down a DC pension during our sample period and may have seen the value of their DC pension income stream affected by monetary policy. The effects that we estimate on pension wealth also take no account of the fact that some DB pension schemes may have made benefits less generous, particularly with respect to future accruals, in response to low interest rates increasing the costs of providing future pensions.
} 


\section{Results}

In this section we report the results of our analysis. We start by analysing how changes in monetary policy since 2007 have affected measures of inequality and different parts of the income and wealth distributions. We then analyse the distributional effects of monetary policy for households with different characteristics, with a particular focus on breaking the results down by age. The main part of our analysis reports the average effects for different groups, but we also go on to show the results according to a different metric of how many households are estimated to have seen their real measured income and wealth rise/fall. Finally, we compare the distributional impacts of Bank Rate and QE: the two effects are combined in most of the analysis.

\section{$\underline{6.1 \text { Effects on measures of inequality }}$}

We assess the impact of changes in UK monetary policy since the end of 2007 on inequality by considering their impact on Gini coefficients for income and net wealth. In order to do this we construct an estimate of what those Gini coefficients might have been had interest rates been held constant and no asset purchases been undertaken. The difference between that counterfactual Gini coefficient and the actual coefficient is then an estimate of the contribution of monetary policy to inequality.

The initial focus of this analysis is on how measured inequality would have been affected. We therefore use the definitions of nominal income and wealth that are typically used in the calculation of Gini coefficients, even though that might not fully capture some of the ways in which households may have been made better or worse off by changes in monetary policy. For example, the measure of income used includes savings income but is not net of interest payments, and housing wealth only measures the value of currently owned properties and takes no account of future housing costs. We do, however, consider these additional channels later in our analysis.

As discussed earlier, Gini coefficients are relative measures that are unaffected if all parts of the income or wealth distribution see their income/wealth increase by the same proportion. But such a change would still imply sizeable differences in cash terms given the skew of the existing income and wealth distributions. We therefore also report our results in cash terms too when we come to assessing the impact of monetary easing on different parts of the income and wealth distributions.

Changes in monetary policy since 2007 are only estimated to have had a small effect on both income and wealth inequality as measured using Gini coefficients. ${ }^{29}$ Given the pre-existing disparities in income and wealth, we estimate that the impact on each household varies

\footnotetext{
${ }^{29}$ This conclusion is robust to using other relative measures of inequality such as $90: 10$ ratios.
} 
substantially across the income and wealth distributions in cash terms, but in percentage terms the effects are broadly similar. These results are discussed in more detail below.

\section{$\underline{6.1 \text { (a) Income inequality }}$}

Changes in monetary policy since 2007 are likely to have affected measured real incomes in two main ways: through lower interest rates reducing interest income earning on savings and through higher labour incomes that follow from lower unemployment and higher wages. ${ }^{30}$ Both of these channels are estimated to have had a very small impact on the income Gini coefficient in 2012-2014 (Table 1).$^{31}$ Lower inflation also has very little impact on the income Gini in the counterfactual scenario given that all components of income except savings income are assumed to be linked to prices.

Table 1: Effects of monetary policy changes since 2007 on income Gini coefficient

\begin{tabular}{|c|c|c|c|c|}
\hline & \multirow[b]{2}{*}{ Income Gini } & \multicolumn{3}{|c|}{ Impact via: } \\
\hline & & $\begin{array}{l}\text { Real savings } \\
\text { income only }\end{array}$ & $\begin{array}{l}\text { Real labour } \\
\text { income only }\end{array}$ & Inflation only \\
\hline 2012-14 data & 0.360 & 0.360 & 0.360 & 0.360 \\
\hline $\begin{array}{l}\text { Counterfactual: no } \\
\text { change in policy }\end{array}$ & 0.362 & 0.361 & 0.361 & 0.361 \\
\hline Monetary policy impact & -0.001 & -0.001 & 0.000 & -0.001 \\
\hline
\end{tabular}

Looking at labour incomes, the effects of monetary policy are estimated to have been larger in cash terms towards the top of the income distribution (Chart 13). ${ }^{32}$ But that largely just reflects the fact that the level of income was already higher for these households. In percentage terms, differences are estimated to have been relatively small (Chart 14), consistent with our estimate that monetary policy has only had a small impact on the income Gini coefficient. The marginal gains in real labour income are estimated to have been worth no more than $5 \%$ of annual income in each year for any decile of the income distribution. To the extent that there are some differences, the gains are estimated to have been smallest at the bottom of the distribution, reflecting the fact that employment

\footnotetext{
${ }^{30}$ In these calculations, and throughout the paper, the unemployment benefit that would have been received by people who would have lost their jobs in the counterfactual scenario is included as labour rather than benefit income.

${ }^{31}$ The results are very similar for all other WAS waves in our sample period to those reported in Table 1 for wave 4 . The baseline income Gini coefficient of 0.36 reported in the first row of Table 1 is calculated over our sub-sample of the WAS for consistency with the counterfactual estimate. It is very similar to the FRS based figure of 0.35 reported in Section 3 . In Tables 1 and 2 , the contributions from changes in individual components need not exactly add up the total effect of when changes in all components of income/wealth are included together in the total column.

${ }^{32}$ Charts 13 and 14 show the effects on annual income in 2012-14. Cumulative effects on income are shown in Annex 4.
} 
rates are lower among these households (at least in part because they are more likely to be retired). The labour income effects are bigger in the top half of the distribution than in the bottom half, but the largest effect is for the $7^{\text {th }}$ income decile. The effects for the top decile are close to the average of the full sample.

Looking at savings income, households across the distribution are estimated to have seen their real income fall by a similar proportion as a consequence of lower interest receipts on savings (Chart 14). That explains why changes in savings income are estimated to have had very little impact on the income Gini coefficient. For most deciles of the income distribution, this lower savings income is only equivalent to around $2 \%$ of total income. The impact on the lowest income decile is slightly larger at around $4 \%$. Including the effects of lower interest payments too (which are not part of the standard statistical measures of income, but make a positive contribution to disposable income), this largely offsets the effects of lower savings income for all deciles as borrowers and savers are spread throughout the income distribution (Chart 13).

\section{Chart 13: Effects of monetary policy changes since 2007 on income by income decile in cash terms}

Average impact of policy changes since 2007 on annual income in 2012-14 (£)

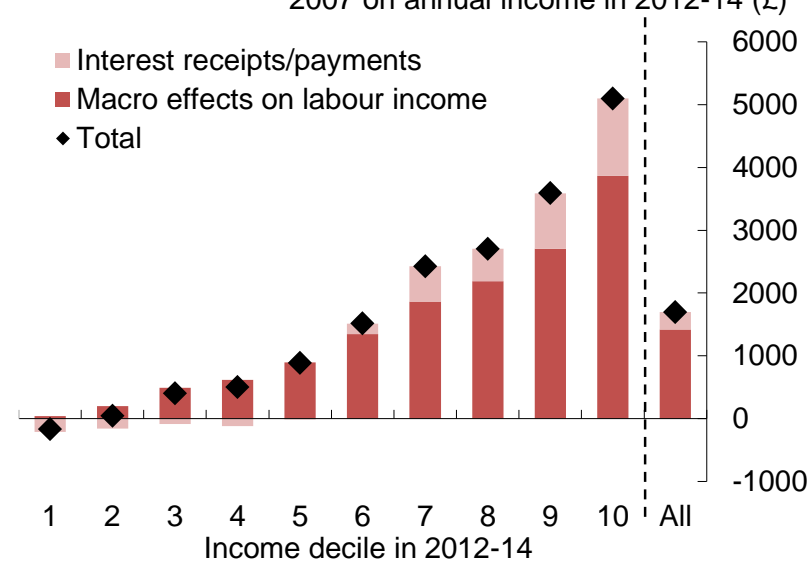

\section{Chart 14: Effects of monetary policy changes since 2007 on income by income decile in percentage terms}

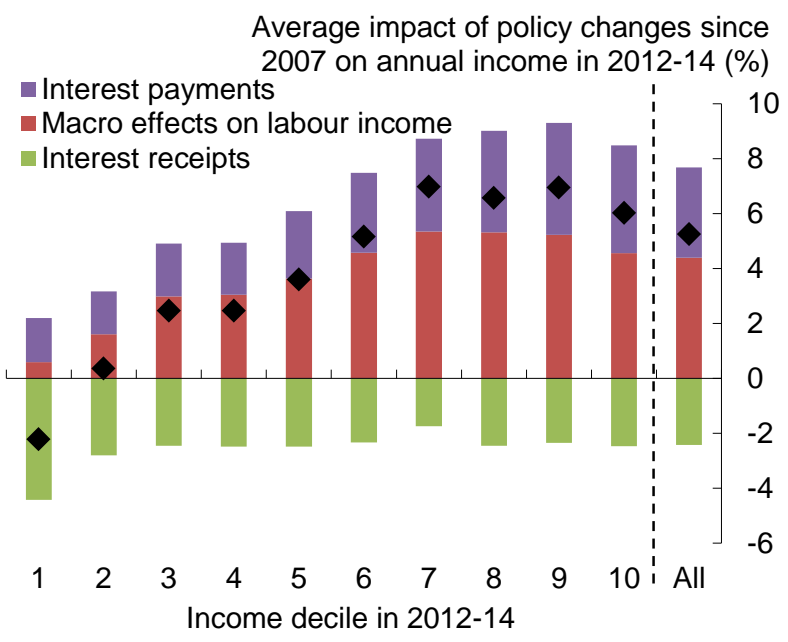

\section{1 (b) Wealth inequality}

Our estimates imply that monetary policy loosening after 2007 lowered the net wealth Gini coefficient in $2012-14$ by 0.017 , relative to what would otherwise have been the case (Table 2 ). ${ }^{33}$ Increases in the value of financial wealth and pension wealth on account of monetary policy/low interest rates are estimated to have put upward pressure on the wealth Gini, given that these components account for a higher share of wealth further up the wealth distribution (as shown on

\footnotetext{
${ }^{33}$ As was the case with the income estimates in Table 1, the Gini coefficients reported in Table 2 are based on the WAS sample that we use for our analysis (households that are in all four waves of the survey with weights adjusted accordingly) and they differ slightly from those for the full sample (using the full sample, the net wealth Gini coefficient in 2012-14 was 0.63, compared to 0.61 for our estimation sample).
} 
Chart 12). ${ }^{34}$ But those effects are more than offset by housing wealth and the effects of inflation acting in the opposite direction and helping to reduce the Gini coefficient.

Table 2: Effects of monetary policy changes since 2007 on net wealth Gini coefficient

\begin{tabular}{l|c|cccc} 
& $\begin{array}{c}\text { Net wealth } \\
\text { Gini }\end{array}$ & $\begin{array}{c}\text { Real gross } \\
\text { financial } \\
\text { wealth only }\end{array}$ & $\begin{array}{c}\text { Real gross } \\
\text { housing } \\
\text { wealth only }\end{array}$ & $\begin{array}{c}\text { Real } \\
\text { pension } \\
\text { wealth only }\end{array}$ & Inflation only \\
\hline $2012-14$ data & 0.612 & 0.612 & 0.612 & 0.612 & 0.612 \\
$\begin{array}{l}\text { Counterfactual: no } \\
\text { change in policy }\end{array}$ & 0.630 & 0.611 & 0.625 & 0.606 & 0.621 \\
Monetary policy impact & -0.017 & 0.001 & -0.013 & 0.007 & -0.008
\end{tabular}

Increases in real house prices are estimated to have pushed down on the wealth Gini coefficient because housing wealth is a more important source of wealth in the middle of the distribution than it is at the top (Chart 12). The negative contribution of real gross housing wealth to changes in the Gini coefficient more than offsets the positive effects from real financial and pension wealth because gross housing wealth is the largest component of net wealth across much of the distribution (again, as shown on Chart 12). As is usually the case in the calculation of wealth Gini coefficients, these calculations only take account of changes in the value of the properties that households currently own and not of any changes in the future cost of housing. We consider this future cost channel in an extension below in the context of our analysis of distributional effects by age.

Given that the distribution of wealth was already heavily skewed towards the wealthiest households before 2007, the marginal gains from subsequent changes in monetary policy for wealthier groups are estimated to have been much larger in cash terms than for less wealthy households, with the main contributions coming from higher housing wealth and pension wealth. The $10 \%$ of least wealthy households are only estimated to have seen a marginal increase in their measured real wealth of around $£ 3000$ between 2006-08 and 2012-14, compared to $£ 350,000$ for the wealthiest $10 \%$ (Chart 15). As with all our estimates, we quote these numbers to illustrate the broad relative

\footnotetext{
${ }^{34}$ Table 2 shows the contribution that different components of wealth are estimated to have made to changes in the Gini coefficient for overall net wealth. By focussing on the effects on total wealth we account for the fact that different components of wealth may have offsetting effects on inequality, and developments in inequality of total wealth should be of most interest to policymakers rather than inequality in any particular component of wealth. However, it is also possible to apply this approach to individual components of wealth and that does lead to some larger effects. The financial wealth Gini coefficient in wave 4 of the WAS (2012-14) was 0.92 , but our estimates suggest that it would have been around 0.89 without monetary policy changes since 2007 , implying that policy added to inequality of financial wealth. But policy is estimated to have lowered inequality in housing wealth, the net property wealth Gini was 0.65 in the data in wave 4 , but we estimate that it would have been 0.75 in the counterfactual scenario.
} 
magnitudes and encourage them not to be taken too literally as point estimates. And as explained in Section 4, increases in measured wealth, particularly housing and pension wealth, do not necessarily make households better off in the sense of allowing them to have a higher level of consumption than they had previously expected. It is also important to remember that these figures are the marginal contributions of monetary policy. As discussed in the context section, house prices and equity prices fell in real terms over the period we focus on, which will have disproportionately reduced the real wealth of richer households in cash terms. So these marginal gains would have mitigated the extent to which asset holders lost out rather than necessarily making them better off overall.

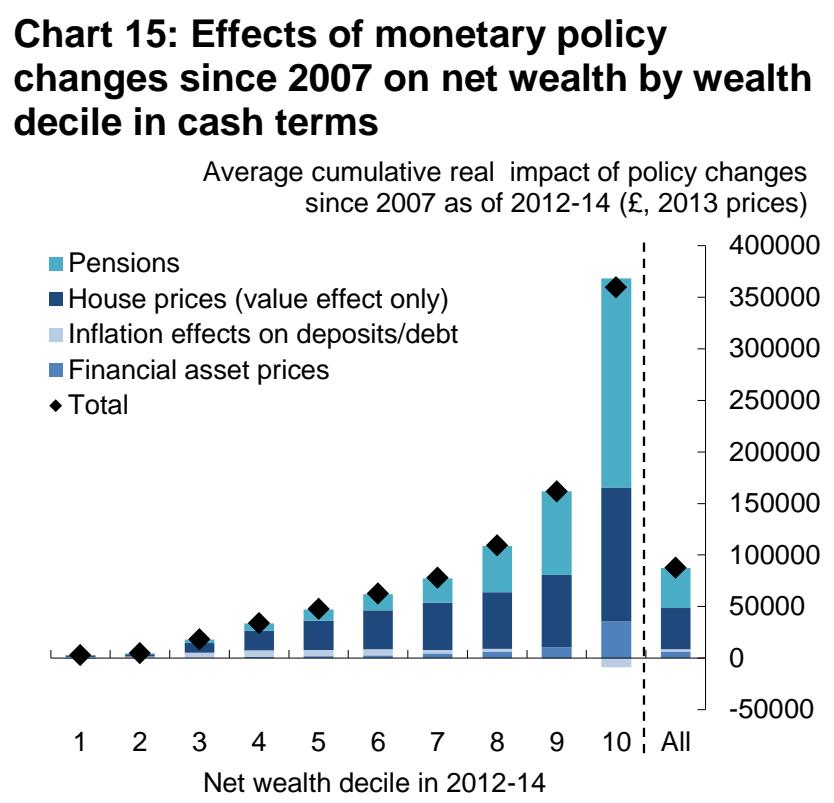

\section{Chart 16: Effects of monetary policy changes since 2007 on net wealth by wealth decile in percentage terms}

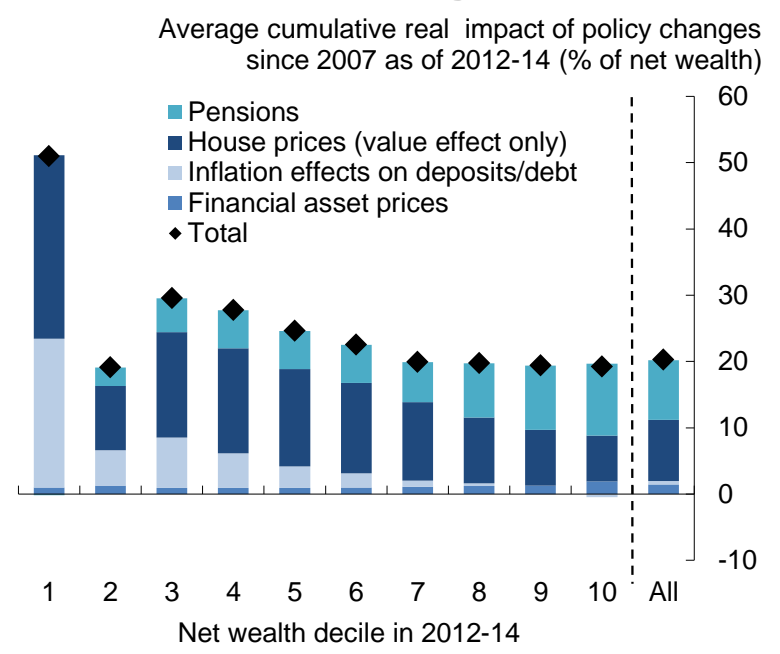

Despite the fact that there are large differences in cash terms, households in the bottom half of the wealth distribution are estimated to have actually experienced a larger percentage increase in real net wealth than those at the top (Chart 16). That is consistent with monetary policy being estimated to have slightly reduced the net wealth Gini coefficient, relative to what otherwise would have been the case. The effects are largest in percentage terms for the bottom decile because the net wealth of this group is close to zero and therefore even very small absolute changes in wealth can be large in percentage terms. So overall, monetary policy changes since 2007 have not made the distribution of measured wealth more unequal in a relative sense, and if anything they are estimated to have reduced wealth inequality slightly. ${ }^{35}$

The source of the increase in wealth varies across the distribution, which helps to illustrate why when we assessed the implications for Gini coefficients, increases in housing wealth and the effects of inflation were estimated to have reduced inequality while pension and financial wealth increased

\footnotetext{
${ }^{35}$ Additional results showing combined effects on income and wealth by income and wealth deciles are reported in Annex 4 .
} 
it. The effects of inflation in eroding the real value of debts are also estimated to have been important at the bottom of the distribution where households more often tend to be net borrowers, often with relatively few assets. For those at the bottom and in the middle of the wealth distribution, housing wealth is estimated to have accounted for most of the marginal increase in their total wealth, whereas pension, and to a lesser extent, financial wealth made relatively larger contributions at the top of the distribution.

\subsection{Distributional effects along other dimensions}

The previous section described how changes in monetary policy since 2007 might have affected the income and wealth distributions. But monetary policy can have important distributional effects along other dimensions too. This section considers how the impact of monetary policy may have varied by age and other characteristics.

\section{$\underline{6.2(a) \text { Distributional effects by age }}$}

Younger households are estimated to have typically benefited from both higher net interest income and stronger real labour income, relative to what would have otherwise been the case without an easing in monetary policy after 2007 (Chart 17). Younger households are more likely to be borrowers than savers and so, on average, they have been made better off by lower interest rates because the interest payments on their debts have fallen by more than the interest income on their savings. But the opposite is true for older households who are much more likely to be savers and who lost out on savings income. Younger people are also more likely to be in work, whereas most older households are retired and not working. That helps to explain why younger households are estimated to have benefited the most from the effects of lower unemployment and higher wages that result from a stronger economy: there is no direct benefit to those who are not in work from this channel. Moreover, our calculations allow for the fact that the employment prospects of younger people tend to be more adversely affected by recessions, which skews the labour income effects further towards younger households. ${ }^{36}$

\footnotetext{
${ }^{36}$ These estimates may also underestimate the true positive effects for younger households because they take no account of any longterm scarring effects or depreciation of skills that there might have been if unemployment had been higher. Cribb et al (2017) show how joining the labour market when the economy is weak can affected an individual's longer term employment and pay prospects.
} 


\section{Chart 17: Effects of monetary policy changes since 2007 on income by age}

Average cumulative real impact of policy changes since 2007 as of 2012-14 (\% of annual income)

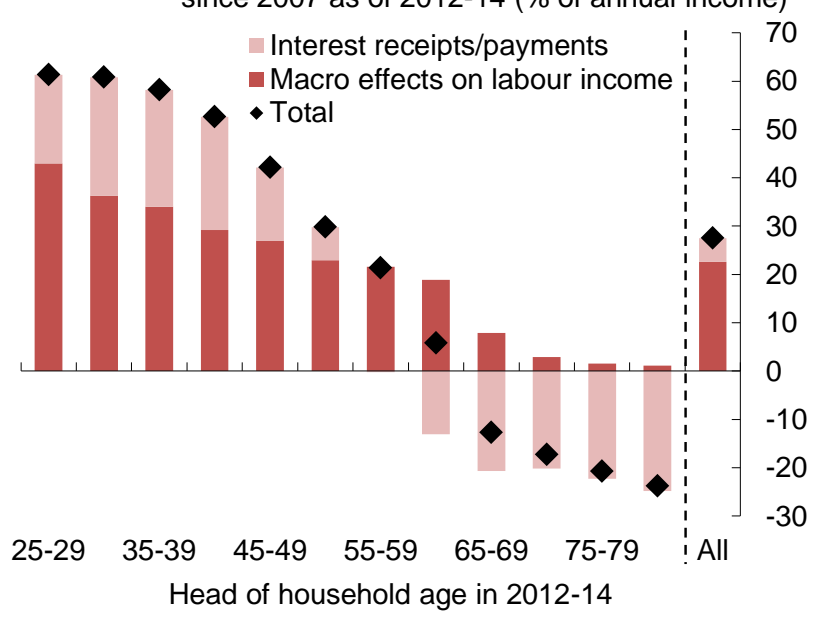

\section{Chart 18: Changes in real income since 2007 by age of head of household ${ }^{(a)}$}

Percentage change in real income from wave 1 (2006-08)

Solid lines are actual data, dotted lines are the counterfactual scenario:

- Age under 40

Age 65 or over

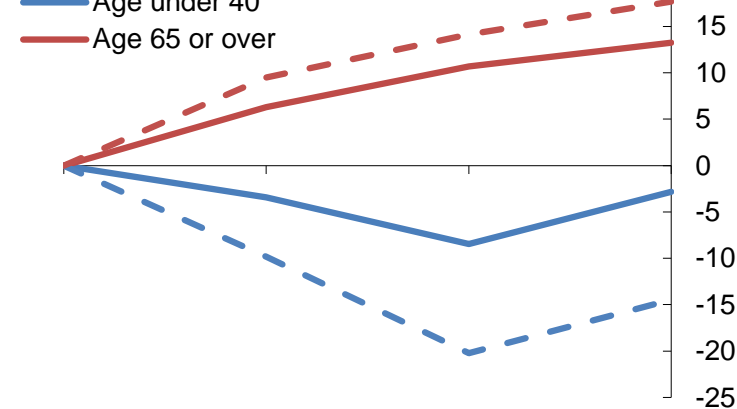

$1(2006-08) \quad 2(2008-10) \quad 3(2010-12) \quad 4(2012-14)$

WAS wave

(a) Income data are taken from the Family Resources Survey and include savings income but do not net off interest payments. The counterfactual scenario does allow for effects from both interest payments and receipts. WAS data are for mid-2006 to mid-2008, mid-2008 to mid-2010, mid-

2010 to mid-2012 and mid-2012 to mid-2014.

The estimated distributional effects on income by age group are material when cumulated over the six year period that we focus on (Chart 17). ${ }^{37}$ For households where the head is aged under 40, monetary policy is estimated to have boosted annual income by an average of around $10 \%$ each year, or $60 \%$ of a single year of annual income in total. But households where the head is over the age of 65 are estimated to have seen their incomes reduced by an average of around $3 \%$ a year, or $20 \%$ of a year of income over a 6 year period. ${ }^{38}$

Despite these marginal effects from changes in monetary policy since 2007, younger households still did much worse than older households during the financial crisis period overall, as was discussed in the context section. Our analysis implies that monetary policy reduced the extent to which younger people were made worse off by the financial crisis and helped to narrow the gap in income experience between younger and older households in an absolute sense (Chart 18).

Without monetary easing after 2007 the real incomes of younger households would have fallen by much more than they actually did. The real incomes of older households still rose over this period, just by less than they otherwise would have done.

Although older households are estimated to have lost out on income as a result of changes in monetary policy since 2007, they are estimated to have seen the real value of the financial assets that they hold (directly) increase as a result of higher asset prices. At least up until the age of 70 , holdings of these financial assets tend to increase with age. The effects of higher inflation eroding the real value of deposits are estimated to have offset some of the gains from higher asset prices,

\footnotetext{
${ }^{37}$ Although not all category labels are shown, Chart 17 and all other charts by age show five year age buckets with the top group being $80+$ unless otherwise stated.

${ }^{38}$ Additional charts showing estimates of the effects on income in annual space and in cash terms are shown in Annex 4.
} 
although not all of them (Chart 19). ${ }^{39}$ This illustrates the importance of considering all the different channels together. However, these are only average effects and within each age group there will also be some households who have done better than average and some who have done worse (this is discussed in more detail in Section 6.3 below).

\section{Chart 19: Effects of monetary policy changes since 2007 on income and financial wealth by age}

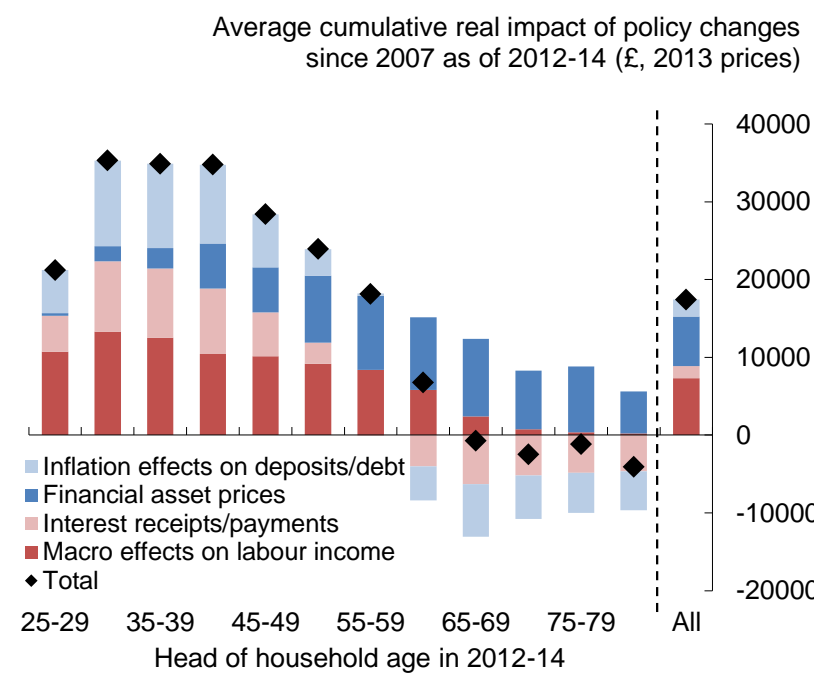

Chart 20: Effects of monetary policy changes since 2007 on income and wealth by age

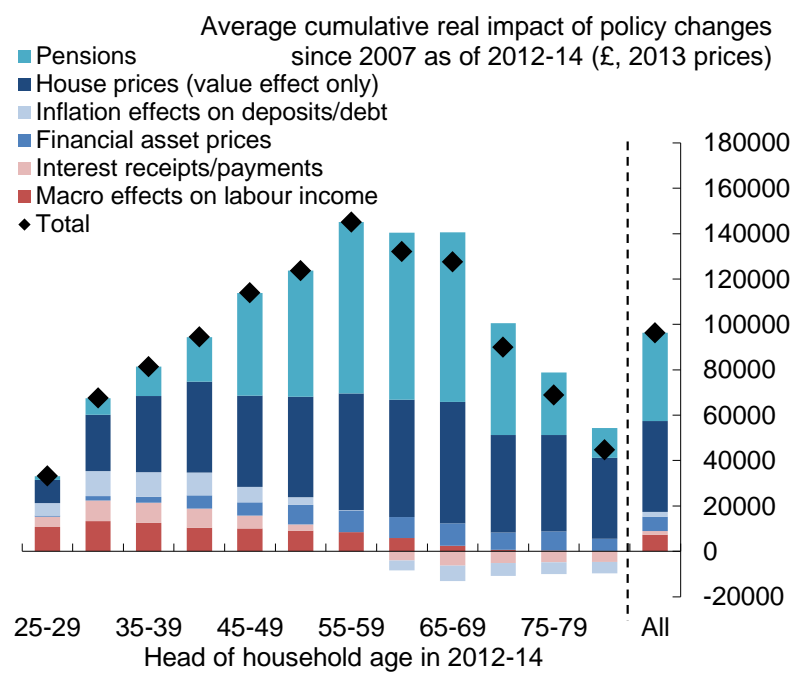

In quantitative terms, the real effects of changes in interest receipts/payments, higher financial asset prices, higher inflation and better labour market outcomes are all estimated to have been of relatively similar size. However, these effects are dwarfed by the marginal increases in the value of measured housing and pension wealth. These effects are largest for households who are close to retirement age, who tend to live in valuable houses and who have built up large pension pots but are yet to draw heavily on them (Chart 20). ${ }^{40}$ But increases in the value of housing wealth and pension wealth do not make households better off in the same way that higher income or an increase in the value of equity holdings does and so the housing and pension wealth effects may not be directly comparable with the other channels. Housing wealth is illiquid and can only be easily used to finance consumption once a household downsizes to a smaller property and extracts some of that wealth (although it may also be used as collateral to borrow against to bring forward some of that spending). And increases in the measured value of pension wealth on account of low interest rates do not typically imply a higher future income stream, only that the same future income stream has become more expensive to provide.

\footnotetext{
${ }^{39}$ These calculations of the effects on income and wealth are clearly sensitive to the point in time at which they are taken. They compare cumulated changes in the flow of income with changes in the stock of wealth. Wealth is likely to respond relatively quickly to changes in monetary policy, particularly financial wealth, whereas the cumulative effects on incomes build more gradually.

${ }^{40}$ The effects on wealth are actually larger in as a percentage of net wealth for younger households, but mostly only because these younger households tend to have relatively low net wealth. Charts showing the effects as a percentage of both wealth and income for different age groups are included in Annex 4.
} 


\section{$\underline{6.2 \text { (b) Distributional effects by other household characteristics }}$}

Our approach allows us to analyse the distributional effects of monetary policy by other household characteristics as well as age. In Annex 4 we also report our results by housing tenure, whether the household is a net borrower or saver, by economic activity and education of the head of household and by region.

The results by housing tenure and the borrower/saver split are similar to the age breakdowns discussed above. Mortgagors/borrowers are disproportionately younger households and have gained from lower interest payments and higher labour incomes, whereas outright owners, who are also mostly older and savers, lost out on savings income but benefited from the support to the value of their financial assets. Both groups have seen the value of their housing assets supported. Renters have clearly not experienced these marginal gains in housing wealth, and they have also seen relatively smaller effects through the other channels too. By economic activity, the effects for those in work are most similar to those for mortgagors whilst the effects for retired households are essentially the same as those for older households and savers.

In proportionate terms, monetary policy is estimated to have had very similar effects across all regions. ${ }^{41}$ That is because there is not much variation in the composition of income and wealth between regions. However, there are more substantial differences in cash terms, with the largest marginal gains being in London and the South East. As before, that simply reflects the fact that the existing levels of income and wealth were already higher in those regions. This is true across most components of income and wealth, but the differences in housing wealth are the largest, reflecting the higher level of house prices in London and the South East.

\section{$\underline{6.3 \text { Number of households with higher and lower measured income and wealth }}$}

The analysis above is based around the average effects for different groups. Those average effects provide a summary of the main distributional effects of monetary policy, but within different groups there can also be households who have had a different experience to average. Because we calculate estimates of the size of the different channels at the individual household level we can also construct estimates of the number of households who have been made better off and worse off as a consequence of changes in monetary policy since 2007. Being better or worse off here is defined as a marginal gain or loss of $£ 500$ or more in real terms.

\footnotetext{
${ }^{41}$ An important assumption underlying this regional analysis is that the impact of changes in monetary policy on the components of income and wealth has been the same in all regions in percentage terms. With this assumption, only differences in the composition of income and wealth could lead to different proportionate effects across regions. In practice, this may be an oversimplification, for example if some industries are more sensitive to the state of the economy than others and if they are concentrated in particular regions, there could be different effects in different regions. But assessing these is beyond the scope of our study.
} 
Around a third of all households are estimated to have been $£ 500$ or more worse off through lower net savings income as a consequence of monetary policy changes since 2007 (Chart 21). This proportion falls to $24 \%$ once all effects on financial wealth and labour incomes are allowed for and only $4 \%$ after including increases in current property values and pension wealth. However, higher housing and pension wealth may not necessarily make households feel better off in the way that higher income or having more money in the bank would. An increase in the present value of pension wealth, for example, cannot easily be used to finance higher current spending. And homeowners may not feel that they are better off if they have no intention of moving and extracting some of their additional housing wealth.

As when considering average effects, older households have been most adversely affected by lower interest receipts, with around $70 \%$ of households where the head is aged over 65 losing out by $£ 500$ or more through this channel (Chart 22). That proportion falls to around $60 \%$ once effects via financial wealth and labour incomes are accounted for, and 10\% allowing for housing value effects and pensions. The type of household most likely to have been made worse off by monetary policy changes since 2007 would be one with nobody in work (most commonly retired), living in rented accommodation, with sizeable savings in bank deposits but little in the way of other financial assets.

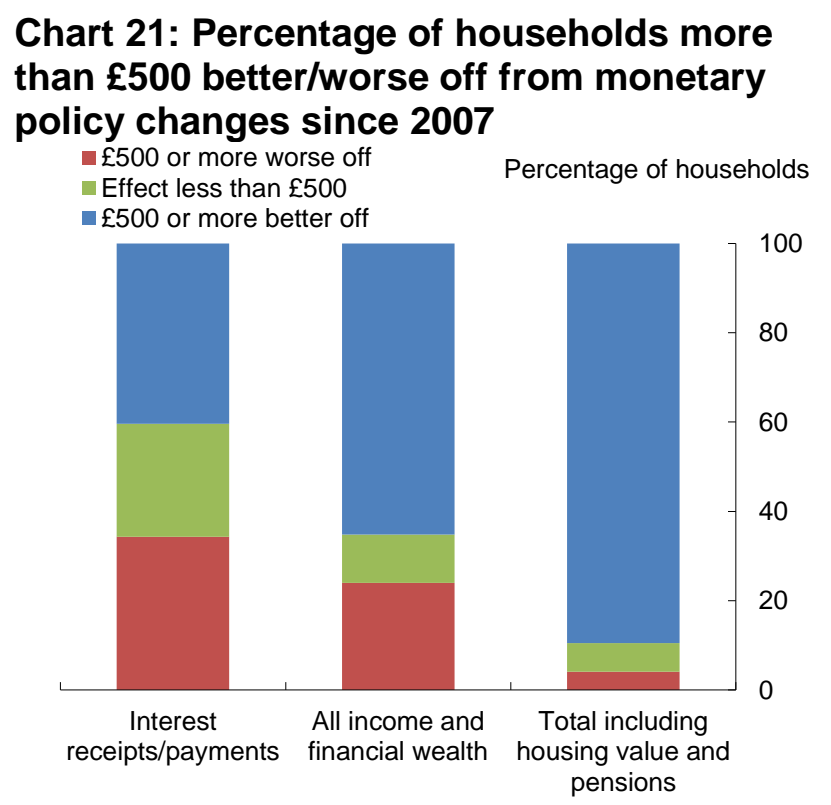

\section{Chart 22: Percentage of households more than $£ 500$ worse off from monetary policy changes since 2007 by age}

Percentages of households

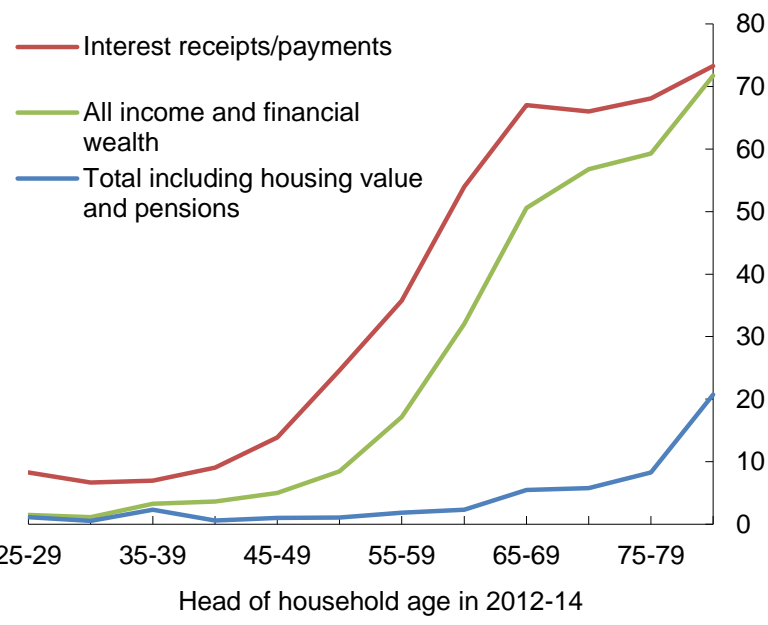




\subsection{Distributional effects of Bank Rate versus QE}

Although the majority of our analysis considers the effects of Bank Rate and QE together, we also examine how the two policies have had different distributional effects. Consistent with our main analysis, both Bank Rate and QE are estimated to have had only a small effect on Gini coefficients.

Overall, the distributional effects of lower Bank Rate are estimated to have been larger than those associated with asset purchases, simply because Bank Rate is estimated to have accounted for the majority of the cumulative boost to GDP by the end of our period. Those absolute effects are reported in Annex 4. In this section we focus on the relative distributional effects of the two policies to give a clearer sense of how they work differently. To do this we scale the results to show the distributional effects of an equivalent policy loosing that would have boosted the level of GDP by an average of $1 \%$ a year during our sample period using either policy. We exclude pension wealth from this part of the analysis as our approach to estimating the effects of lower interest rates on pension wealth does not provide a clear distinction between the effects of conventional policy and QE.

There are differences in the estimated distributional effects of Bank Rate and QE, although some of those differences offset once all of the channels are taken together. Again, these are most clearly evident when analysing the results by age group (Charts 23 and 24). ${ }^{42}$ The net interest income channel of lower interest payments and receipts is specific to Bank Rate, which does more to boost the incomes of younger households at the expense of older households. ${ }^{43}$ Older households benefit from lower Bank Rate primarily through higher house prices whereas with QE, financial wealth effects become more important for these older households given QE's larger effects on financial asset prices. This follows from changes in Bank Rate having a larger effect on house prices than QE in our simulations, whereas QE has bigger effects on financial asset prices. Amongst individual households, lower Bank Rate will therefore disproportionately have benefited homeowners, whereas households who own large amounts of equities will have gained the most from QE. The effects on labour incomes and the effects on inflation on the real value of debt and deposits from the two policies are estimated to have been similar.

\footnotetext{
${ }^{42}$ In Annex 4, we also compare the effects of Bank Rate and QE across the income and wealth distributions.

${ }^{43}$ We are referring here to the channels operating in our simulations. We do not take account, for example, of the possibility that QE might have lowered short rates and hence affected net interest income. In practice, this and other channels may have operated to some extent, though we think they would be less material than the channels included in our simulations.
} 
Chart 23: Distributional effects of Bank Rate change to boost GDP by $1 \%$ a year (mid2008 to mid-2014) by age

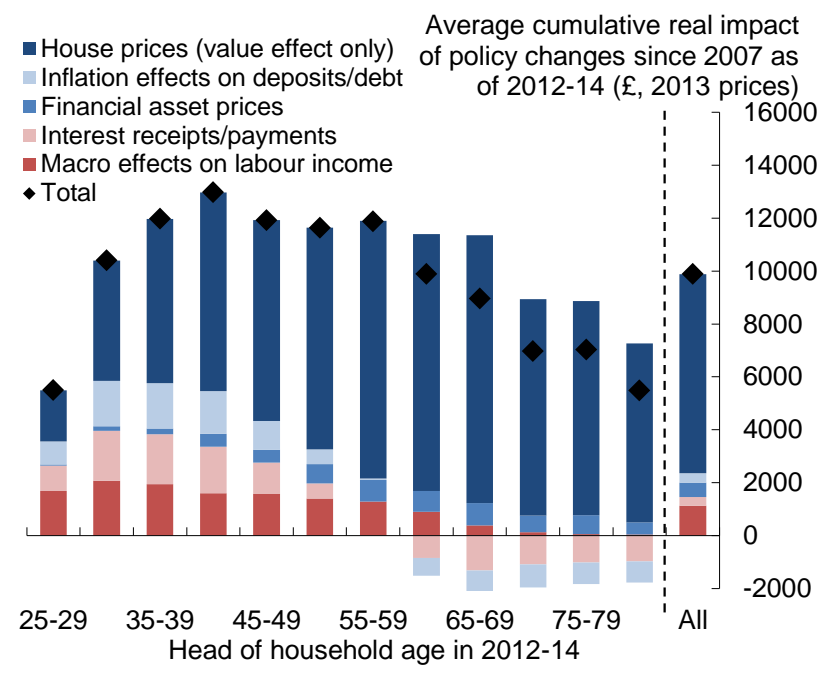

Chart 24: Distributional effects of QE change to boost GDP by $1 \%$ a year (mid2008 to mid-2014) by age

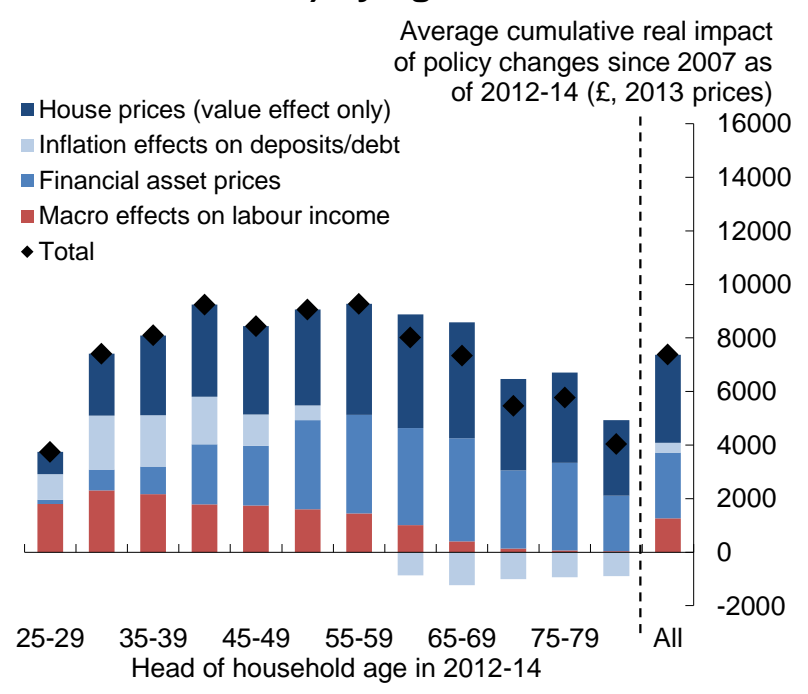

\subsection{Extending the analysis to include future housing costs}

The results that we have reported so far capture the impact via house prices on the value of properties that household currently own, which is the standard statistical measure of housing wealth. However focussing on the implications for the measured value of the properties that households currently own also misses the fact that higher house prices may also have important distributional effects by increasing future housing costs. Everybody needs to live somewhere, and higher house prices make it more expensive for people to buy their first home or trade up in the future. In addition, rents tend to increase with house prices which in turn raise the cost of housing for renters. Quantifying these future costs is challenging, but to give some sense of how important this channel might be we extend our analysis by attempting to estimate what such changes imply for the discounted future costs of housing in a user-cost framework. These future cost estimates are based on a number of assumptions and are likely to represent more of an upper bound than a central estimate, for example because they assume that house prices are permanently higher and that there are no intergenerational transfers. The methodology used to estimate future housing costs is discussed in more detail in Annex 3.

In aggregate, increases in future housing costs are estimated to offset much of the increase in the value of current homes (Chart 25). But there are some large differences for different age groups. Younger households, who typically would expect to move into larger houses in the future and who have much more of their lives to live with higher housing costs are likely to be made significantly worse off by higher future housing costs. For older people, the increase in future costs is estimated to be small and heavily outweighed by the marginal gains in the value of their current homes.

Overall, considering these future housing costs is likely to offset some of the estimated gains from 
monetary policy easing since 2007 for younger households, although the effects on future housing costs are hard to quantify with any precision (Chart 26). ${ }^{44}$

\section{Chart 25: Effects of monetary policy changes since 2007 on housing wealth by age}

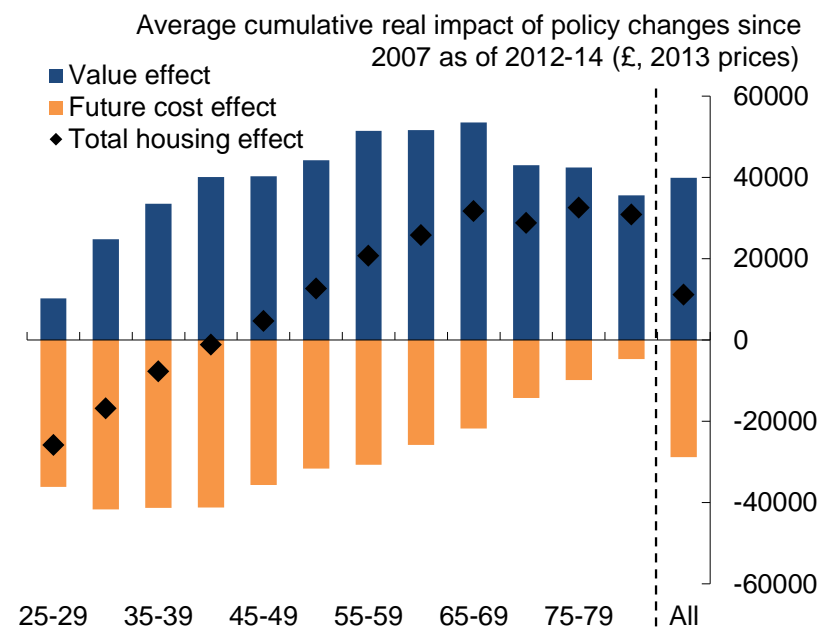

Head of household age in 2012-14

\section{Chart 26: Effects of monetary policy changes since 2007 on income and wealth by age, including future housing costs}

Average cumulative real impact of policy changes since 2007 as of 2012-14 ( $£, 2013$ prices)

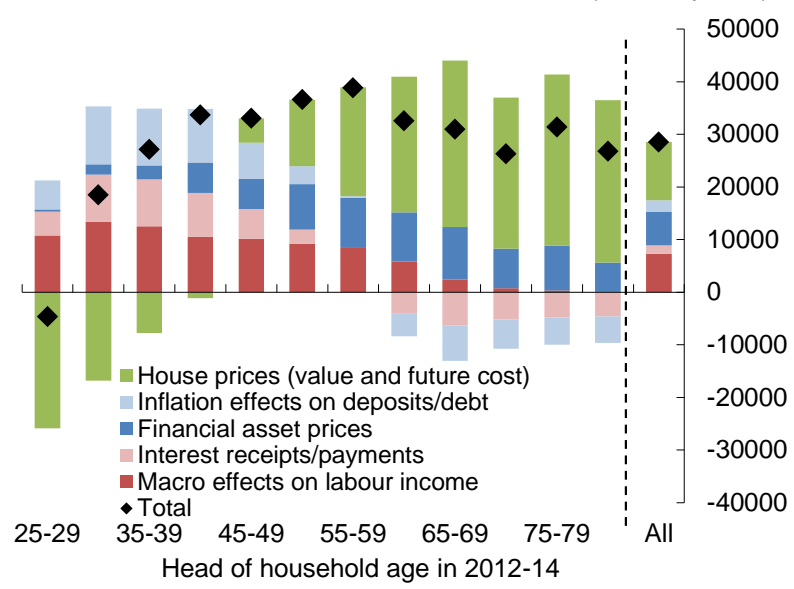

\section{Households' perceptions}

The calculations described above provide estimates of how different groups have been affected by changes in monetary policy since 2007. But given that an important motivation for us in doing this analysis is to help inform public debate on the distributional consequences of monetary policy changes, it is also important to know whether households agree with our assessment and to understand which channels they think of. To help better understand public perceptions of the distributional impact of monetary policy, a set of questions were included in a household survey commissioned by the Bank of England. ${ }^{45}$ The survey covered 6000 households and was conducted online during April 2017 by NMG Consulting on behalf of the Bank.

In the survey, households were asked 'Taking into account all of the ways in which you think you have been affected, do you think that lower interest rates (Bank Rate) have made you better or worse off than would have been the case if interest rates had remained at $4.5 \%$ in every year since 2008?'. They were then asked a follow up question about the channels through which they had been affected.

Around a third of households reported that they thought that lower interest rates had made them worse off, with only $13 \%$ saying that they were better off. The rest either did not know or thought

\footnotetext{
${ }^{44}$ In a similar vein, to the extent that interest rates remain low for a long period of time that could also make younger households worse off by making it more expensive to save to provide pensions for retirement in the future, as discussed by Johnson (2016).

${ }^{45}$ See Anderson et al (2016) for more background details on this survey and its methodology.
} 
that lower rates had made no difference. There were striking differences in these results by age group. Older households were much more likely to think that they had been worse off while the proportion who thought they were better off and worse off was similar for younger age groups (Chart 27).

\section{Chart 27: Households' views on how they have been affected by low interest rates}

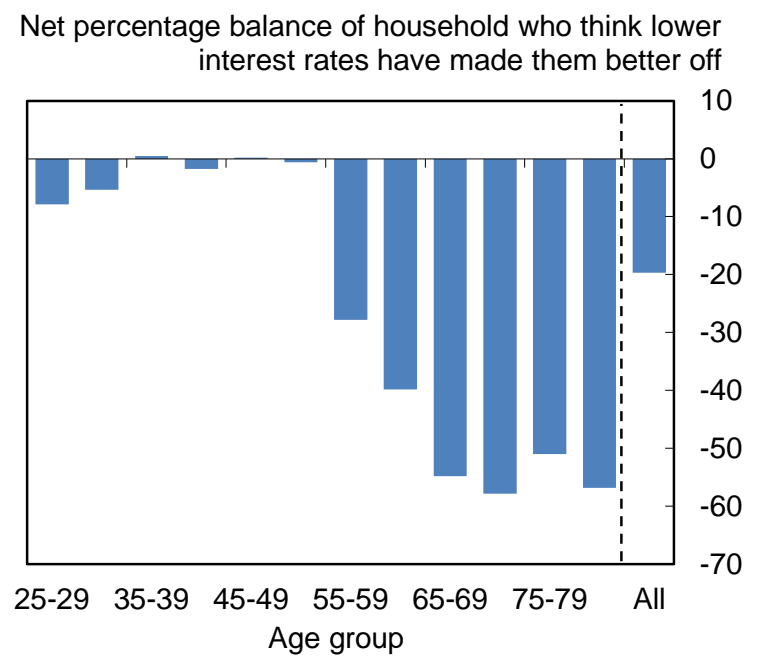

\section{Chart 28: Channels through which households think they have been affected by low interest rates}

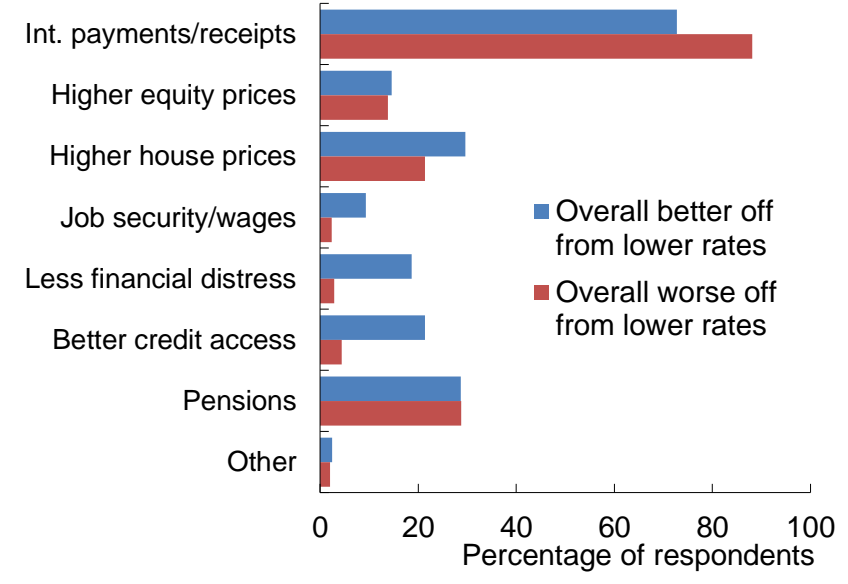

By far the most common way that households thought they have been affected by lower interest rates is through lower interest payments and receipts, which was cited by around $80 \%$ of people who thought they had been affected by lower rates (Chart 28). Around a quarter thought they had been affected through higher house prices and 15\% through equity prices, and no more than $10 \%$ thought lower rates had affected them through an impact on job security and wages, despite these channels being as quantitatively important in the earlier analysis as interest payments and receipts.

The finding that older people view themselves as being worse off overall because of lower interest rates (Chart 27) is consistent with lower interest payments and receipts being the main channel that people think of (Chart 28). The analysis in the previous section (for example Chart 17) showed that older people were adversely affected through this channel. The survey findings also suggest that people under-appreciate the less direct ways in which they are affected, and have benefited, from monetary policy changes over this period. When unemployment has actually risen, explaining that monetary policy made people better off by stopping things from being even worse may be a difficult message for policymakers to get across. This poses a communication challenge to central banks to find ways of helping households to better understand how monetary policy is affecting them. 


\section{Concluding remarks}

Distributional issues have increased in prominence since the financial crisis, with income and wealth inequality becoming headline news. Against this backdrop, there has been growing interest in the distributional impact of the extraordinary period of accommodative monetary policy in the UK and elsewhere. This paper has used household microdata to try and improve our understanding of the distributional consequences of monetary policy since the end of 2007 in the United Kingdom. It provides a broader and more quantitative assessment than previous work on this topic and offers some valuable new insights.

Changes in interest payments and receipts, higher financial asset prices, higher house prices and better labour market outcomes from a stronger economy have all been important channels through which monetary policy has affected the distribution of income and wealth between 2008 and 2014 . Standard relative measures of inequality such as Gini coefficients were, however, broadly stable in the UK during this period, and our results suggest that the marginal contribution of monetary policy was also small. Reflecting the pre-existing disparities in income and wealth, we find that the impact on each household varied substantially in cash terms across the income and wealth distributions, but in percentage terms, the effects are estimated to have been broadly similar.

Looking at income, our results show that monetary policy had very different effects on different age groups. Younger households gained in a marginal sense, whereas older households who are more reliant on savings income tended to lose out. But despite this support from monetary policy, younger households still saw their real incomes fall overall during the financial crisis, whereas they continued to increase for older households. Monetary policy therefore acted to reduce the extent to which younger households were made worse off. Looking at wealth, older households gained from the support provided by monetary policy to financial asset and house prices. But real equity prices and real house prices were still lower in 2014 than in 2007, so these marginal gains were again more about mitigating the extent to which asset holders lost out rather than making them better off overall.

We have showed how it is important to consider all of the ways in which households are affected by monetary policy together, since the effects on income and wealth can often work in opposing direction. Overall, our results suggest that the majority of households have gained from the accommodative stance of monetary policy over this period, relative to what would have otherwise been the case. But when asked directly, households mostly only recognise the interest payments/receipts channel. That highlights a communication challenge for policymakers to explain to the public how monetary policy works and to help them understand all of the less direct ways in which they have benefited. 
Our results also only provide one window in time on the impact of monetary policy. When policy is tightened, you might expect broadly offsetting effects in the opposite direction. And as the existing population ages and their circumstances change (e.g. by becoming a homeowner), the effects of future monetary policy cycles on particular households will likely be different to those experienced by the same households in previous cycles. Assessing the impact of monetary policy on households through their life-cycle, and indeed the overall welfare impact of using monetary policy to stabilise the macroeconomy in both upswings and downswings, is far beyond the scope of this paper. 


\section{References}

Anderson, G, Bunn, P, Pugh, A, Uluc, A, (2016), 'The Bank of England/NMG Survey of household finances', Fiscal Studies, 37 (1), 131-152.

Auterson, T (2014), 'Forecasting house prices', Office for Budget Responsibility Working Paper No. 6.

Auclert, A (2017), 'Monetary Policy and the Redistribution Channel', NBER Working Paper no. 23451.

Benito, A, Thompson, J, Waldron, M and Wood, R (2006), House prices and consumer spending', Bank of England Quarterly Bulletin 2006 Q2, pages 142-154.

Broadbent, B (2016), 'The distributional implications of low structural interest rates and some remarks about monetary policy trade-offs', speech given at the Society of Business Economists Annual Conference,

https://www.bankofengland.co.uk/speech/2016/the-distributional-implications-of-low-structural-interest-ratesand-some-remarks-about-monetary.

Broadbent, B (2017), 'Submission to Treasury Select Committee Inquiry: The effectiveness and impact of post-2008 UK monetary policy', letter available at

http://data.parliament.uk/writtenevidence/committeeevidence.svc/evidencedocument/treasurycommittee/effectiveness-and-impact-of-post2008-uk-monetary-policy/written/69227.html

Bunn, P, Mizen, P and Smietanka, P (2018), 'Growing pension deficits and the expenditure decisions of UK companies', Bank of England Staff Working Paper No. 714.

Burgess, S, Fernandez-Corugedo, E, Groth, C, Harrison, R, Monti, F, Theodoridis, $K$ and Waldron, M (2013), 'The Bank of England's forecasting platform: COMPASS, MAPS, EASE and the suite of models', Bank of England Staff Working Paper No. 471

Carney, M (2016), "The Spectre of Monetarism", speech given at Liverpool John Moores University http://www.bankofengland.co.uk/publications/Documents/speeches/2016/speech946.pdf

Casiraghi, M, Gaiotti, E, Rodano, R, and Secchi, A (2016), 'A 'reverse Robin Hood'? The distributional implications of non-standard monetary policy for Italian households', Banca d'Italia Working Paper, No. 1077.

Cloyne, J, Ferreira, C and Surico, P (2016), 'Monetary policy when households have debt: new evidence on the transmission mechanism', Bank of England Staff Working Paper No. 589

Coibion, O, Gorodnichenko, Y, Kueng, L, and Silvia, J (2016), 'Innocent Bystanders? Monetary policy and inequality', Journal of Monetary Economics Vol. 88(C), pages 70-89.

Cribb, J, Hood, A, Joyce, R, and Norris Keiler, A (2017), 'Living standards, poverty and inequality in the UK: 2017', IFS available at https://www.ifs.org.uk/uploads/publications/comms/R129\%20-

\%20HBAl\%20report\%202017.pdf.

Cribb, J, Hood, A, Joyce, R (2017), 'Entering the labour market in a weak economy: scarring and insurance', IFS Working Paper (W17/27).

Davtyan, K (2017), 'The Distributive Effect of Monetary Policy: The Top One Percent Makes the Difference' Economic Modelling, 65, pp. 106-118

Department for Work and Pensions (2018), 'Households below average income: an analysis of the income distribution 1994/95 to 2016/17', March 2018.

Deutsche Bundesbank (2016), 'Distributional effects of monetary policy', Monthly Report September.

Domanski, D, Scatigna, M, and Zabai, A (2016), 'Wealth inequality and monetary policy' BIS Quarterly Review March 2016.

Furceri, D, Loungani, P, and Zdzienicka, A (2016), 'The Effects of Monetary Policy Shocks on Inequality', IMF Working Paper, WP/16/245. 
Gornemann, N, Kuester, K, and Nakajima, M (2016), 'Doves for the Rich, Hawks for the Poor? Distributional Consequences of Monetary Policy', International Finance Discussion Papers 1167, Board of Governors of the Federal Reserve System (U.S.).

Guerello, C (2017), 'Conventional and Unconventional Monetary Policy vs. Household Income Distribution: An Empirical Analysis for the Euro Area', Journal of International Money and Finance.

Hafemann, L, Rudel, P, and Schmidt, J (2017), 'Moving Closer or Drifting Apart: Distributional Effects of Monetary Policy', MAGKS Papers on Economics No. 21-2017

Haldane, A , Roberts-Sklar, M, Wieladek, T and Young, C (2016), "QE: the story so far", Bank of England Staff Working Paper No. 624

Haldane, A (2016) "One Car, Two Car, Red Car, Blue Car", speech given at Materials Processing Institute, Redcar, https://www.bankofengland.co.uk/speech/2016/one-car-two-car-red-car-blue-car.

Inui, M, Sudo, N, and Yamada, T (2017), 'Effects of Monetary Policy Shocks on Inequality in Japan', Bank of Japan Working Paper Series No.17-E-3.

Johnson, P (2016), 'Ultra-low interest rates come with a high price for future generations', https://www.ifs.org.uk/publications/8412.

Joyce, M, Lasaosa, A, Stevens, I and Tong, M (2011a), 'The financial market impact of quantitative easing in the United Kingdom', International Journal of Central Banking, Vol. 7, No. 3, pages 113-61

Joyce, M, Tong, M and Woods, R (2011b), 'The United Kingdom's quantitative easing policy: design, operation and impact', Bank of England Quarterly Bulletin, 51, issue 3, p. 200-212

Juselius, M, Borio, C, Disyatat, P, and Drehmann, M (2016), 'Monetary policy, the financial cycle and ultralow interest rates', Publication BIS Working Papers No 569.

Luetticke, R (2017), 'Transmission of Monetary Policy with Heterogeneity in Household Porfolios', manuscript available at https://www.dropbox.com/s/22m9w42hzr6ykyw/Luetticke\%202017.pdf?dl=0

Meen, G (2009), 'A simple Model of Housing and the Credit Crunch', University of Reading, Department of Economics mimeo.

Monnin, P (2017), "Monetary policy, macroprudential regulation and inequality", Council on Economic Policies Working Paper, 2017/2.

Montecino, J, and Epstein, G (2017), 'Did Quantitative Easing Increase Income Inequality?', manuscript available at http://www.juanmontecino.com/wp-content/uploads/QE inequality 2017.pdf .

Mumtaz, H, and Theophilopoulou, A (2017), 'The Impact of Monetary Policy on Inequality in the UK. An Empirical Analysis', European Economic Review 98 (2017) 410-423.

O'Farrell, R, Rawdanowicz, L, and Inaba KI (2016), 'Monetary Policy and Inequality', OECD Working Paper, No. 1281.

Office for National Statistics (2017), 'The effects of taxes and benefits on household income: financial year ending 2016', April 2017.

Office for National Statistics (2015), 'Chapter 2: Total Wealth, Wealth in Great Britain, 2012 to 2014', Wealth and Assets Survey July 2012 to June 2014.

Rachel, L, and Smith, T (2015), 'Secular drivers of the global real interest rate', Bank of England Staff Working Paper No. 571.

Resolution Foundation (2018), 'The Living Standards Outlook 2018', February 2018.

Saiki, A. and Frost, J (2014), 'Does unconventional monetary policy affect inequality? Evidence from Japan', Applied Economics, 46(36), 4445-4454 
Treasury Committee (2016), 'Effectiveness and impact of post-2008 UK monetary policy', Terms of Reference available at http://www.parliament.uk/business/committees/committees-a-z/commonsselect/treasury-committee/inquiries1/parliament-2015/post-2008-uk-monetary-policy-16-17/

Vlieghe, G (2016), 'Umbrella's don't cause rain', speech given at Sheffield University, https://www.bankofengland.co.uk/speech/2016/umbrellas-dont-cause-rain. 


\section{Annex 1 - The counterfactual macro scenario}

We use an existing counterfactual experiment as our starting point. The experiment uses the Bank's main forecasting model to estimate the impact on the UK economy if the MPC had made no adjustment to monetary policy after the end of 2007. In this counterfactual, Bank Rate is held at its end 2007 level of $5.5 \%$ rather than being cut to $0.5 \%$ and the effective interest rates on loans and deposits are also assumed to be fixed at 2007 Q4 levels (Chart A1). This scenario also assumes that the MPC undertook no Quantitative Easing (QE), whereas in practice they had purchased £375 billion of government bonds by the middle of 2012 (Chart A2).

\section{Chart A1: Interest rates}

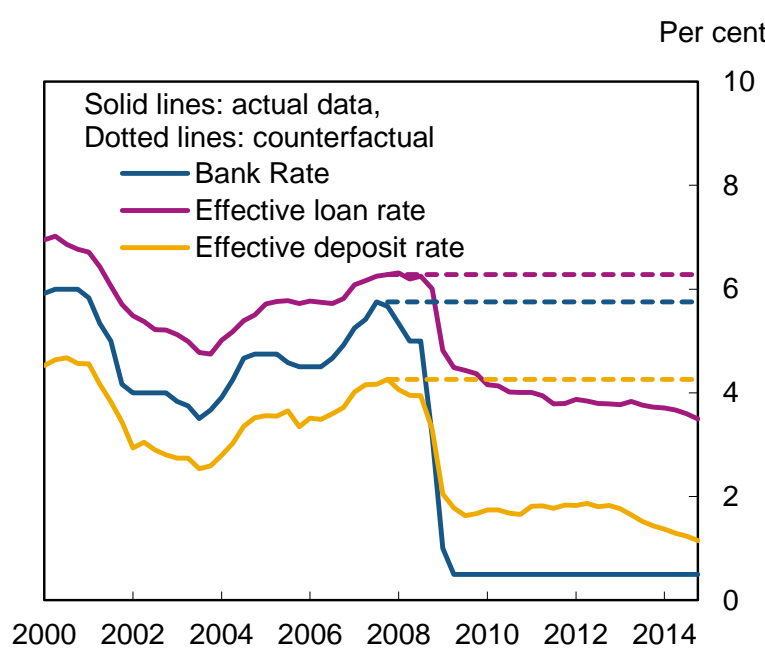

\section{Chart A2: Stock of asset purchases}

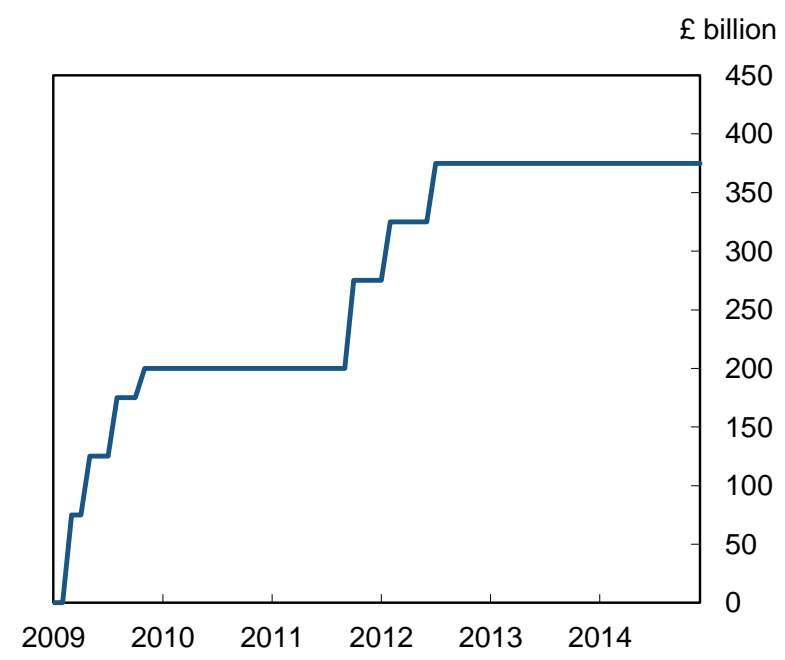

The counterfactual experiment that we use is that same as the one used by Carney (2016) and Haldane (2016). It is run using the Bank's main forecasting model. Further detail on the underlying modelling framework can be found in Burgess et al (2013). The scenario is implemented in the model by applying a sequence of unanticipated monetary policy shocks. Each quarter agents expect monetary policy to be eased in line with the weak macroeconomic conditions, but they are repeatedly surprised to find that no adjustment is made. This sequence of policy shocks makes macroeconomic conditions worse than they otherwise would have been. Charts A3 and A4 summarise the deviations from base for our key variables of interest: real GDP, real wages per head, employment and the price level. Chart A5 shows the impact on CPI inflation. 
Chart A3: Effects of monetary policy changes since 2007 on GDP, employment and wages

Percentage difference if monetary policy not loosened from 2007 Q4

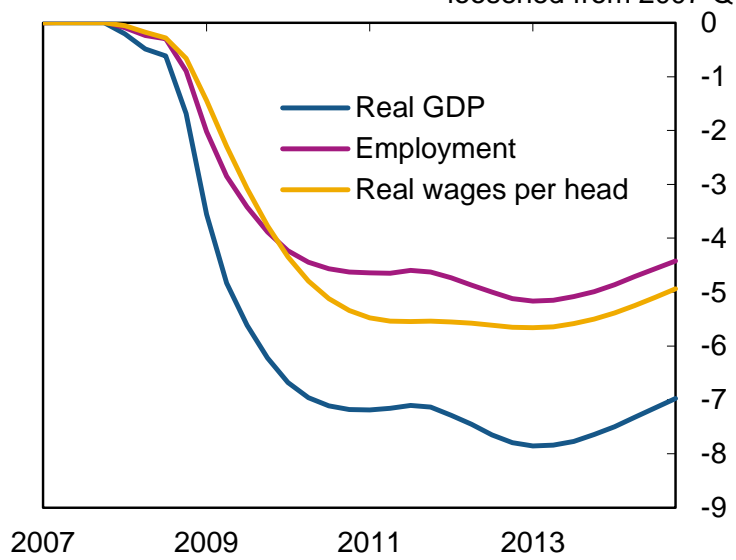

Chart A4: Effects of monetary policy changes since 2007 on the consumer price level

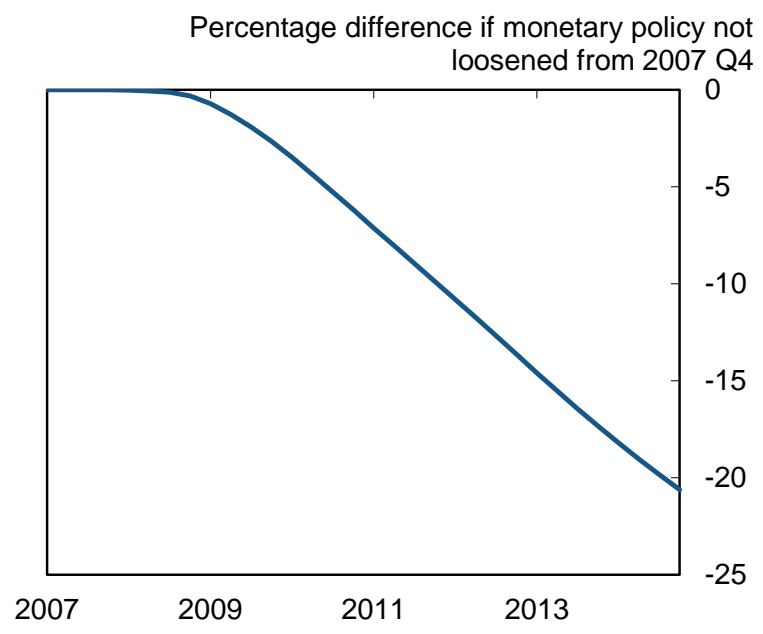

The details of the macro modelling are not the focus of this paper, but a few points should be noted. First we make no adjustment for any falls in equilibrium interest rates. So, to the extent they that have fallen over the period, holding Bank Rate fixed at 5.5\% would have represented an increasingly tight stance of monetary policy. Second the model assumes no change to how agents form their inflation expectations. But if the MPC really had made no adjustment to monetary policy as the financial crisis unfolded, their credibility may have been undermined and you might have expected agents to react very differently. In this sense, the macro counterfactual might be too benign.

For our purposes we also need counterfactual paths for equity prices, gilt prices and for house prices. These are not endogenously determined within the main forecasting model and therefore we use other research/satellite models to inform these estimates.

For the equity/gilt price counterfactual our starting point for the impact of QE are published estimates from Joyce et al (2011b). This work estimates that the first $£ 200$ billion of QE lowered gilt yields by around 100 basis points. A portfolio balance model is then used to estimate the implications for equity prices, which suggests an initial impact of around $20 \%$ from $£ 200$ billion of asset purchases. Details of the portfolio balance model used, and other potential approaches, are described in Joyce et al (2011a). We assume the same proportional impact for the further $£ 175$ billion of asset purchases undertaken during 2011/12, but also that the impact of asset purchases on real asset prices decays over time during an 'adjustment phase' (as discussed by Joyce et al 2011b). Consequently the impact of QE on equity prices in our counterfactual increases as new rounds of purchases are undertaken, but decreases as the effects of each round start to decay. There is considerable uncertainty about the size and persistence of the effect of QE on equity prices, particularly as equity prices did not react uniformly to QE announcements (Haldane et al (2016)). 
For the impact of Bank Rate, we use a relatively simple discount model to estimate the impact on equity prices in each quarter and assume that the nominal gilt yield curve remains at its end-2007 level in the no-policy counterfactual (we assume that the equity risk premium and expected cashflows are constant throughout). Combining the effects of $Q E$ and Bank Rate, real equity prices in the counterfactual scenario would have averaged around 25\% less than their actual values in 2014 (Chart A6).

This combined estimate of the impact of monetary policy on equity prices may include some doublecounting. We are apportioning all of the difference between the counterfactual and actual yield curves over this period to the different path for Bank Rate. But some of the differences in longerdated gilt yields might reflect the asset purchase programme and have already been captured in the QE estimates. We are, however, comfortable erring on the side of including a larger estimate for the asset price effect as this provides a stricter test of whether the support from monetary policy for asset prices had a material distributional effect.

\section{Chart A5: Effects of monetary policy changes since 2007 on CPI inflation}

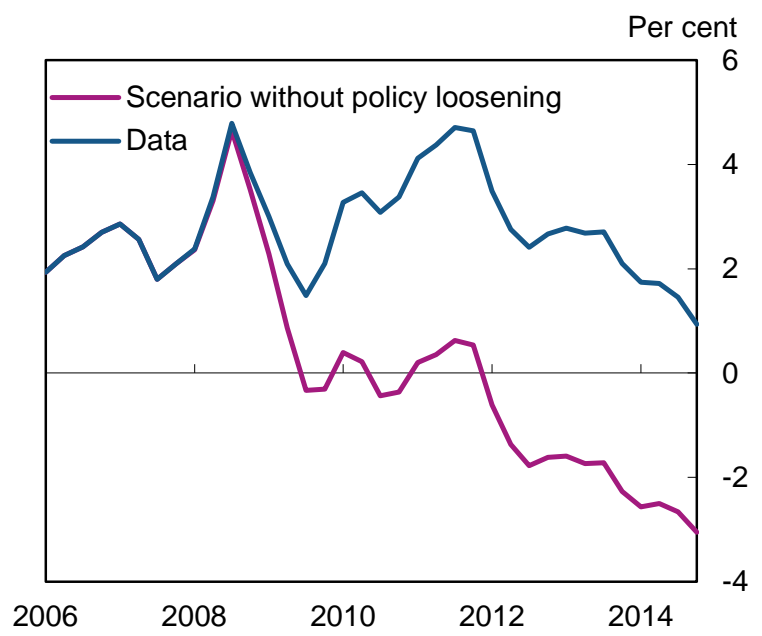

Chart A6: Effects of monetary policy changes since 2007 on real equity and house prices

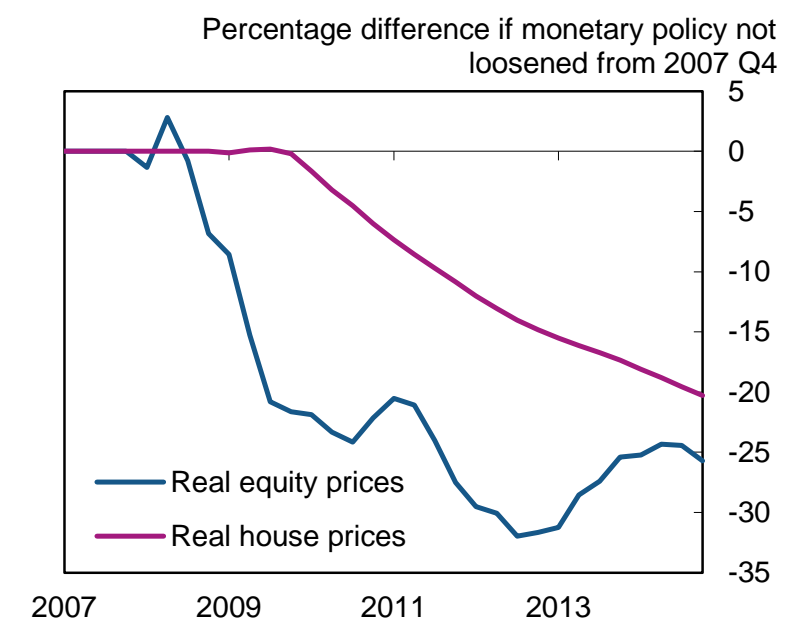

For house prices we use a reduced-form user cost model (similar to Meen (2009) and Auterson (2014)) to estimate that real house prices would have been an average of around $20 \%$ lower than they actually were in 2014 (Chart A6). In that model, house prices depend on real income per household, real wealth, the labour share of income, a measure of housing supply and a household discount rate. The impact of monetary policy is estimated as the difference between a conditional forecast from the model with all explanatory variables set to their actual values and one where the variables that are affected by our macro scenario are set to their counterfactual values described above. The impact of $\mathrm{QE}$ is captured by building a shadow path for the discount rate which reflects the stimulus from asset purchases. 


\section{Annex 2 - Sensitivity of results to different assumptions about balance sheets}

In our results we use actual balance sheets in each wave to estimate the effects of monetary policy on net interest income and on wealth. As discussed in the main paper this will include some degree of endogenous response to monetary policy and does not capture exactly how balance sheets would have looked if policy had not changed after 2007, for example households' stocks of bank deposits will include some response to the fact that lower interest rates reduced the incentive to save.

An alternative approach, which will not contain any endogenous responses, is to assume that balance sheet positions were fixed as of 2007 (based on data from wave 1 of the WAS which was collected between mid-2006 and mid-2008). But this approach will exclude changes that are part of the normal life cycle, as well as responses to other aspects of the financial crisis, which should be accounted for. Neither approach shows exactly what would have happened had monetary policy remained unchanged after 2007. In practice it does not make a large difference which assumption is used, as shown by Charts B1 to B8. These charts also show that simplifying the analysis and only using balance sheet data from wave 4 of the WAS (2012-14) would also make little difference.

\section{Chart B1: Effects of monetary policy changes since 2007 on net interest income by age}

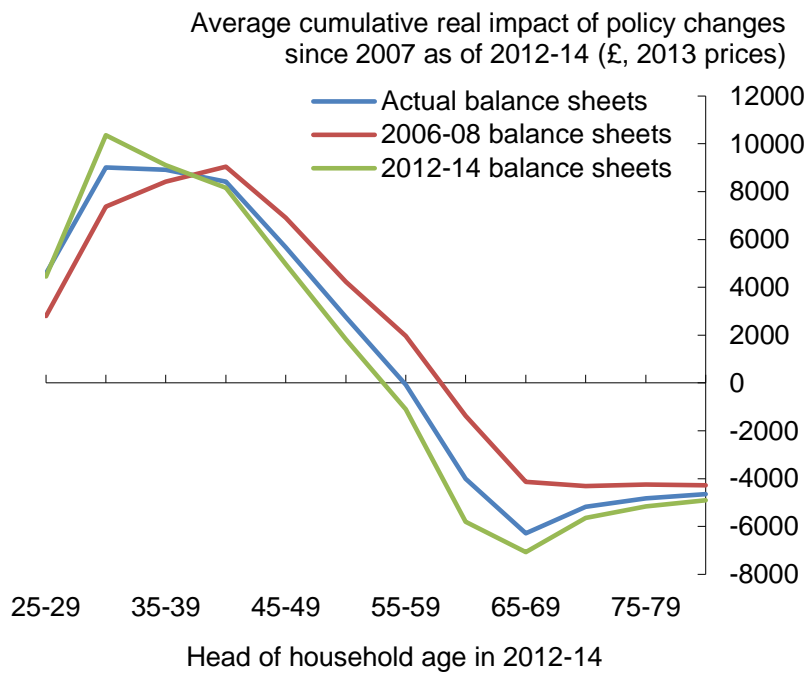

Chart B2: Effects of monetary policy changes since 2007 from higher financial asset prices by age

Average cumulative real impact of policy changes since 2007 as of 2012-14 ( $£, 2013$ prices)

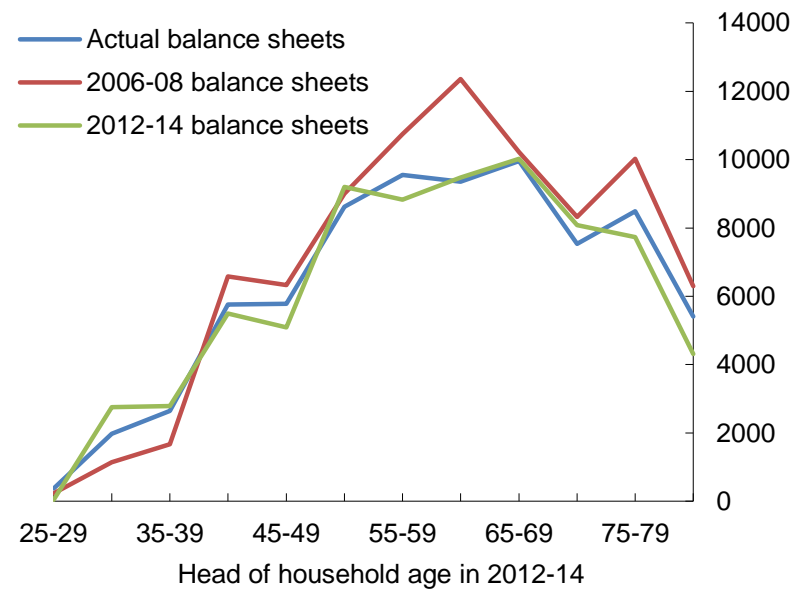


Chart B3: Effects of monetary policy changes since 2007 on current housing values by age

Average cumulative real impact of policy changes since 2007 as of 2012-14 ( $£, 2013$ prices)

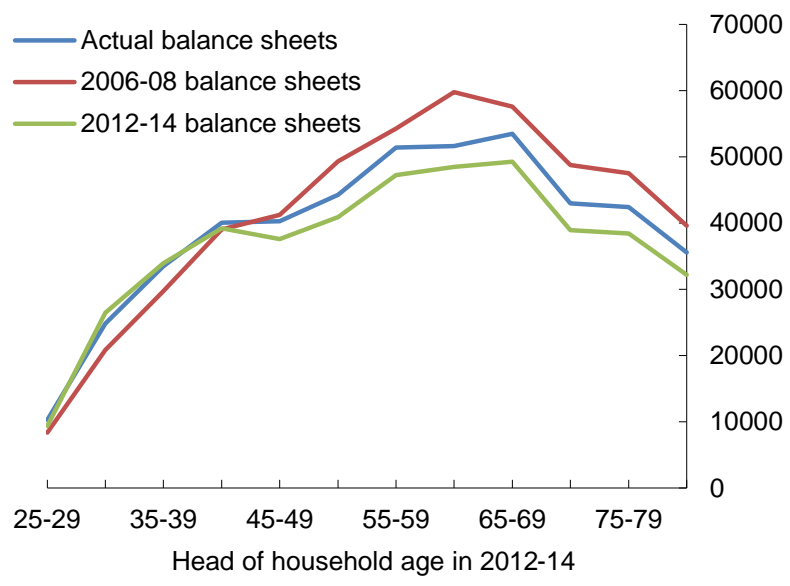

Chart B5: Effects of monetary policy changes since 2007 on net interest income by income decile

Average cumulative real impact of policy changes since 2007 as of $2012-14$ ( $£, 2013$ prices)

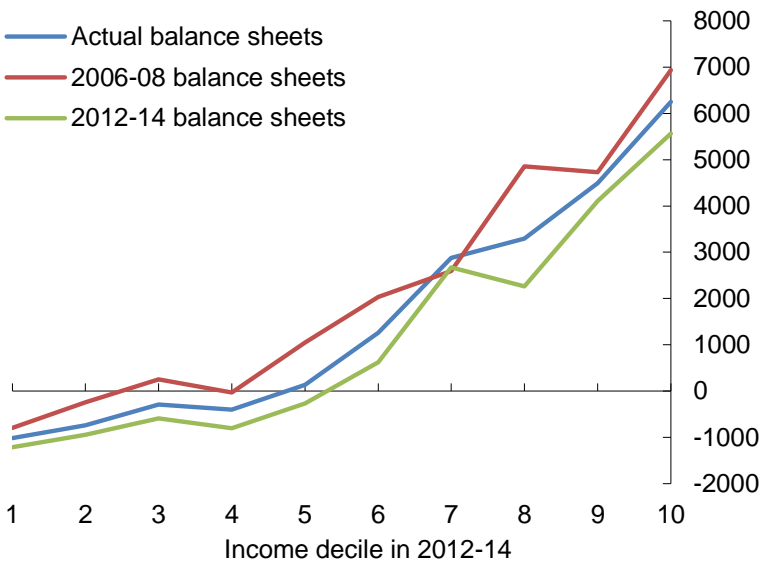

Chart B7: Effects of monetary policy changes since 2007 on net wealth by wealth decile

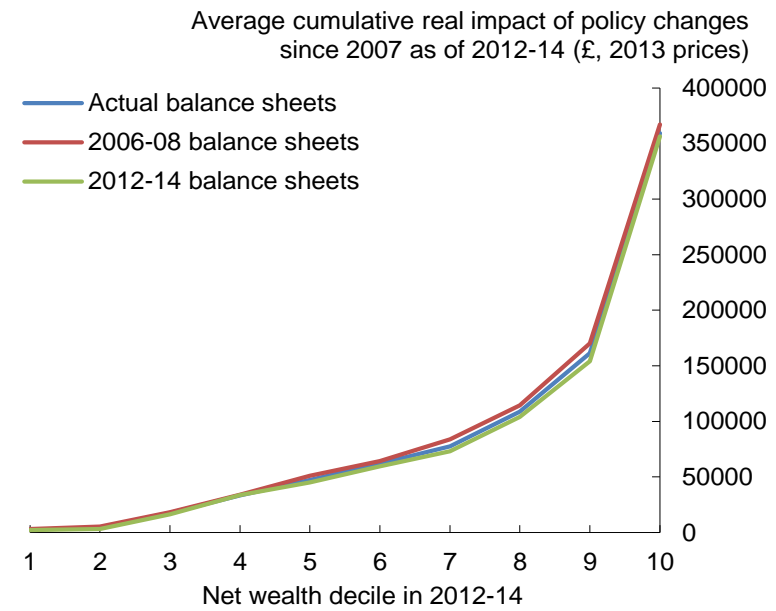

Chart B4: Effects of monetary policy changes since 2007 on total of income and wealth by age

Average cumulative real impact of policy changes since 2007 as of 2012-14 ( $£, 2013$ prices)

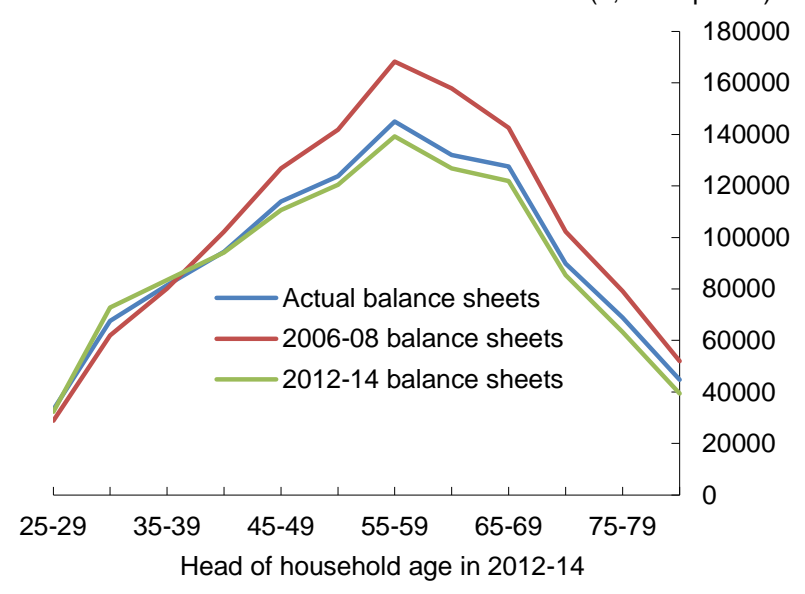

Chart B6: Effects of monetary policy changes since 2007 on total income by income decile

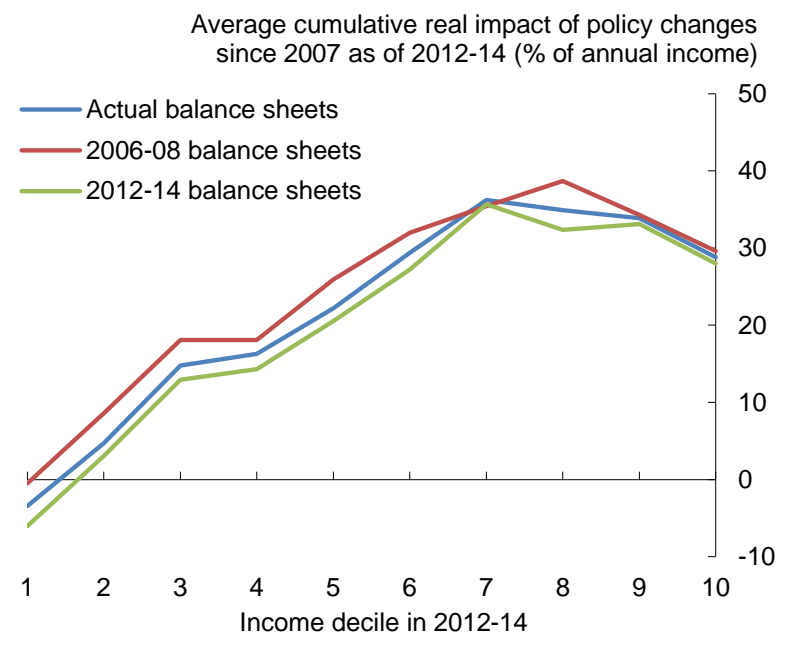

Chart B8: Effects of monetary policy changes since 2007 on net wealth by wealth decile

Average cumulative real impact of policy changes since 2007 as of $2012-14$ (\% of net wealth)

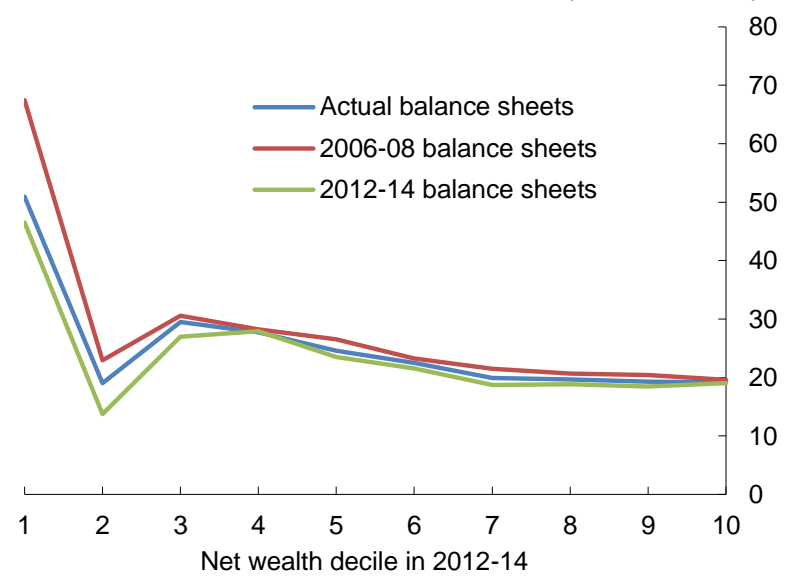




\section{Annex 3 - Further details on the labour income and future housing cost calculations}

\section{Effects on labour incomes}

Looser monetary policy led to lower unemployment and higher real wage growth than otherwise would have been the case. To map this into the distribution of households, we randomly draw some individuals who were actually in employment in each wave of the WAS as people who would have otherwise been unemployed. The probability of being drawn in this way is allowed to depend on age and education level: during the recent recession, younger and less educated people were more likely to have lost their jobs (Charts C1 and C2). Chart C3 summarises the scaling factors used for mid-2012 to mid-2014 (wave 4 of the WAS), although the estimates for earlier waves are similar. These show the chance of unemployment for an individual in a given age/education group relative to the average probabilities for the population as a whole. The way to interpret these is that the probability of being drawn as unemployed for a 16 to 24 year old with no qualifications, for example, is around 4 times that of the average person, but somebody aged over 55 with a degree is only half as likely to be drawn.

For people who are employed but drawn as would have otherwise been unemployed if policy had not changed, we set their labour income equal to unemployment benefit. For people who remained in work, labour income is adjusted downwards in line with the lower overall profile for wages in the macroeconomic scenario. Charts C4 and C5 show that younger and less educated groups saw larger falls in wage relative to earlier trends during the financial crisis than people who were older and more educated. The size of the adjustments made to the wages of different groups reflects this. Chart C6 summarises the size of those adjustments for different groups in 2012-14, relative to the adjustment for the average person.

The effects on labour incomes are calculated at the person level and then aggregated within households in order to generate the household level estimates that are used in the analysis. 
Chart C1: Change in unemployment since 2007 by age

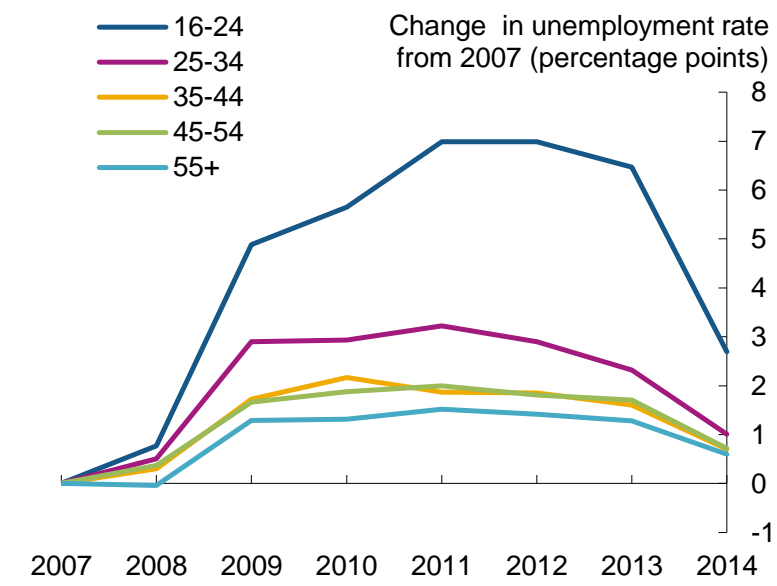

Source: Labour Force Survey (LFS) and authors' calculations.

\section{Chart C3: Chance of being made unemployed relative to average for all in employment ${ }^{(a)}$}

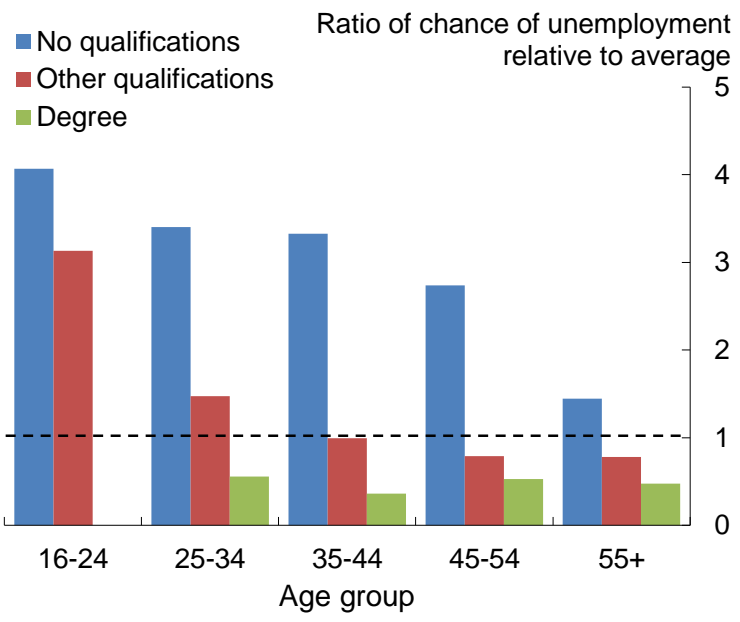

Source: LFS and authors' calculations.

(a) 16-24 year-olds with a degree are combined with those with other qualficiations due to the samll sample size. Scalars for 2012-14.

\section{Chart C5: Changes in level of wages since 2007 by education}

Percentage change in wages from path implied by 1999-07 average growth

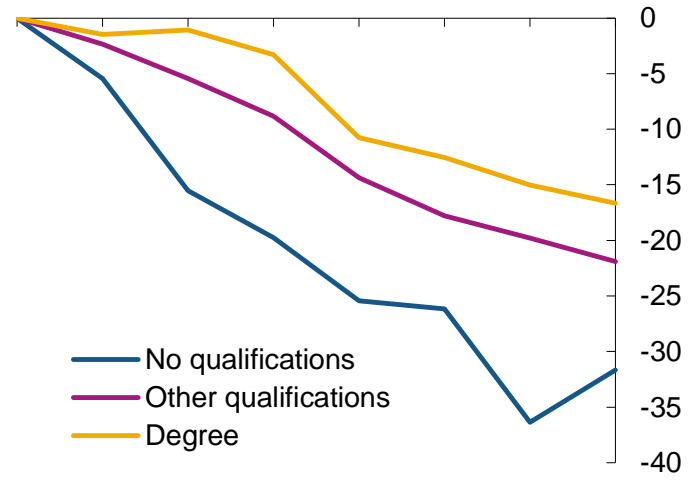

20072008200920102011201220132014

Source: FRS and authors' calculations.
Chart C2: Change in unemployment since 2007 by education

Change in unemployment rate from 2007 (percentage points)

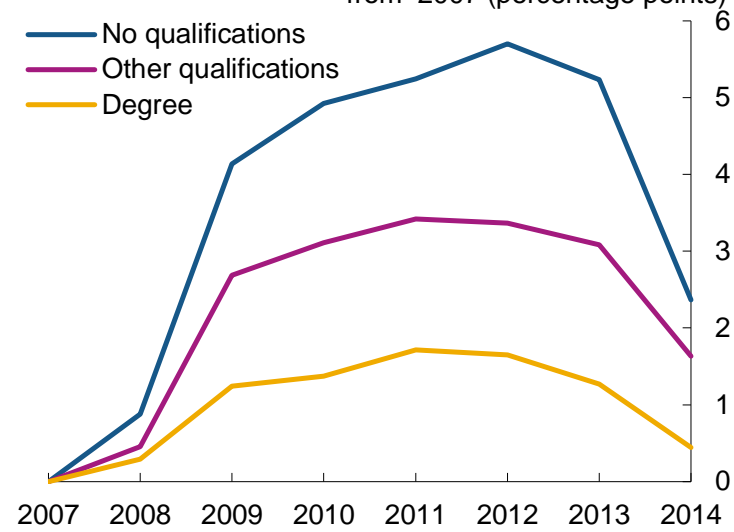

Source: LFS and authors' calculations.

\section{Chart C4: Changes in level of wages since 2007 by age}

Percentage change in wages from path implied by 1999-07 average growth

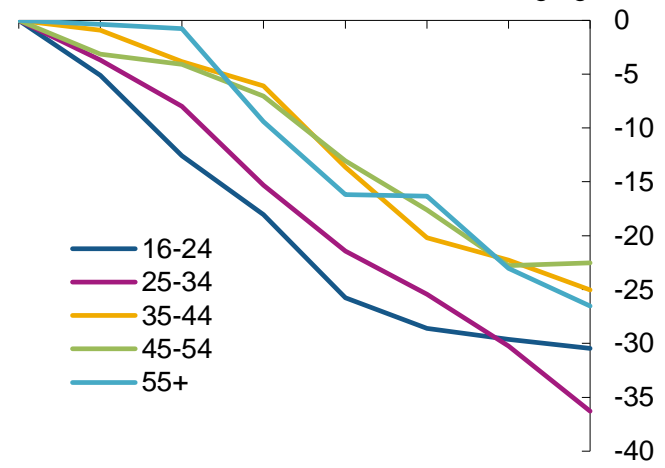

20072008200920102011201220132014

Source: FRS and authors' calculations.

Chart C6: Effect on wages relative to average for all in employment ${ }^{(a)}$

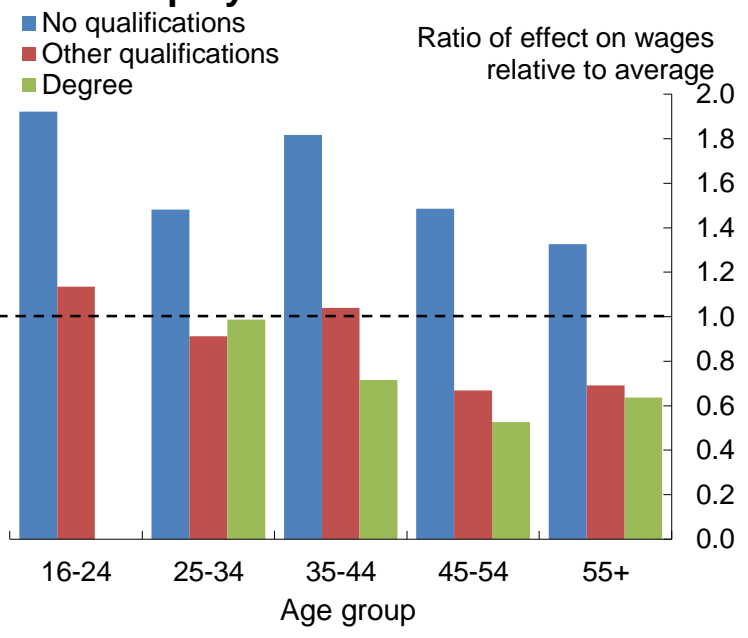

Source: FRS and authors' calculations.

(a) 16-24 year-olds with a degree are combined with those with other qualficiations due to the samll sample size. Scalars for 2012-14. 
Charts C7 and C8 show the difference made to the estimated impact of monetary policy on labour income from allowing the chance of unemployment and effect on wages to vary by age and education, relative to an alternative where the effects are assumed to be the same for everybody in employment. The boost to labour income from monetary policy changes after 2007 is larger for households where the head is under the age of 40 and smaller otherwise when recession experience is allowed for. Likewise the effects are smaller for those with a degree and larger for those with other or no qualifications once recession experience is accounted for. But overall the biggest factor that drives relative differences in the effects on labour incomes by age is still the fact that employment rates decline substantially as households approach retirement age. These charts also only show household level effects according to the age/education of the head of household whereas not all members of the household will have the same characteristics as the head of the household.

\section{Chart C7: Estimated impact of monetary policy changes since 2007 on labour income by age}

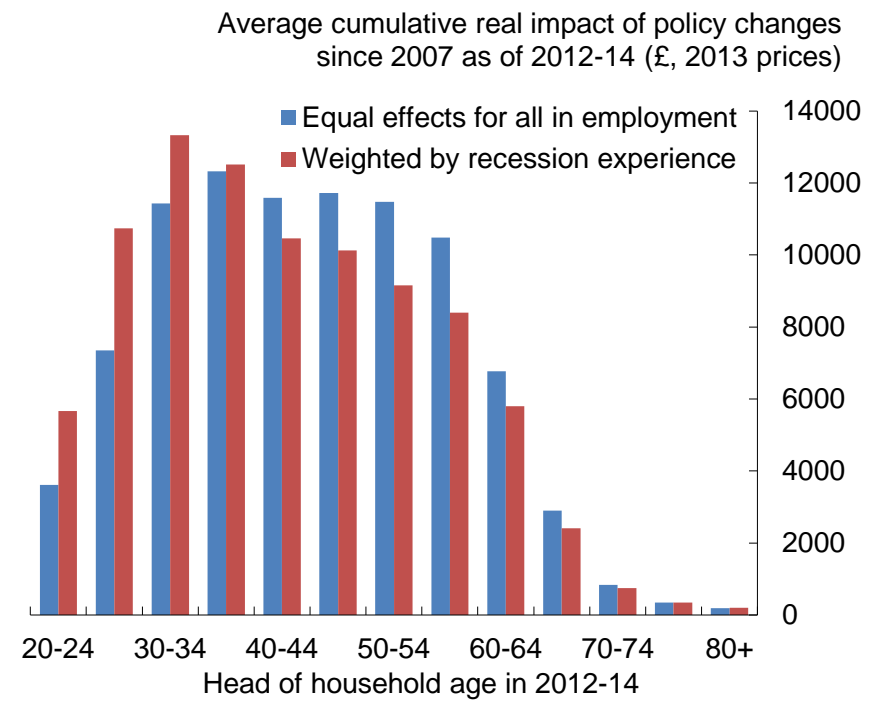

Chart C8: Estimated impact of monetary policy changes since 2007 on labour income by education

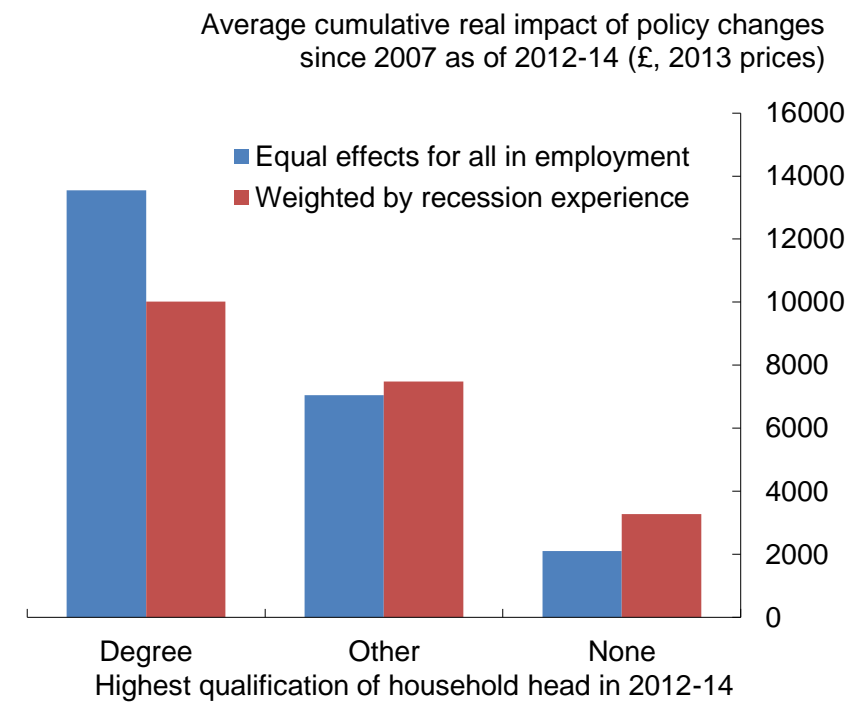

\section{Effects on future housing costs}

By raising house prices, looser monetary policy will have raised the value of housing wealth for existing home-owners. Set against that, higher house prices increase the costs of future housing consumption, potentially making households who are currently renting, or want to trade up, worse off. To estimate the size of these future housing costs we use a simple user cost framework to estimate the amount by which higher house prices are likely to have altered the cost of future housing consumption, using the following steps: 
- The probabilities of future home ownership over the life cycle are assumed to evolve in line with the averages of the past, as estimated from the British Household Panel Survey (BHPS) between 1991 and 2008. In other words, each household's home ownership status is assumed to evolve as it has previously for a household of a given age group and current home-ownership status.

- Relative changes in the costs of housing at different points in the life cycle are also assumed to move in line with the average of the past, again based on BHPS data. For example, if at age 40 people tend to own houses that are worth $20 \%$ more than those owned by 30 year olds, that differential is assumed to be maintained through time as aggregate house prices rise. Average costs are calculated separately for owners and renters.

- The future cost of housing is discounted using the average mortgage rate between 2006 and 2014 , adjusted for housing taxation costs and a depreciation rate of $1 \%$ per year.

- Finally, in order to calculate the impact of monetary policy on the cost of future housing consumption, we take the difference between the estimates produced using the methodology above, and the equivalent estimates produced by multiplying the cost of housing in each future period by the estimated impact of monetary policy on house prices (where looser policy is assumed to have raised prices by around $20 \%$ in 2014 relative to a situation where policy did not change).

- Since house prices and rents tend to move together, monetary policy is also assumed to affect the cost of renting in the future. Looser monetary policy is assumed to increase rents in line with household incomes.

Although this methodology is relatively simple, it does require some strong assumptions. First, house prices are assumed to remain permanently higher as a result of looser monetary policy, whereas in reality we would expect policy not to have real long run effects. Second, we do not take account of the fact that households may leave some of their housing wealth as bequests to their children. Third, we assume that historical lifecycle patterns of housing consumption are maintained, and so are unaffected by changes in the macroeconomic environment and the fact that houses are now relatively more expensive than they were in the 1990s. 


\section{Annex 4: Additional results}

\section{Chart D1: Distribution of income in 2012-14}

Average income per household ( $£$, thousands)

\section{Employment income}

Benefits

Private pension income

-Other income

- Total
100

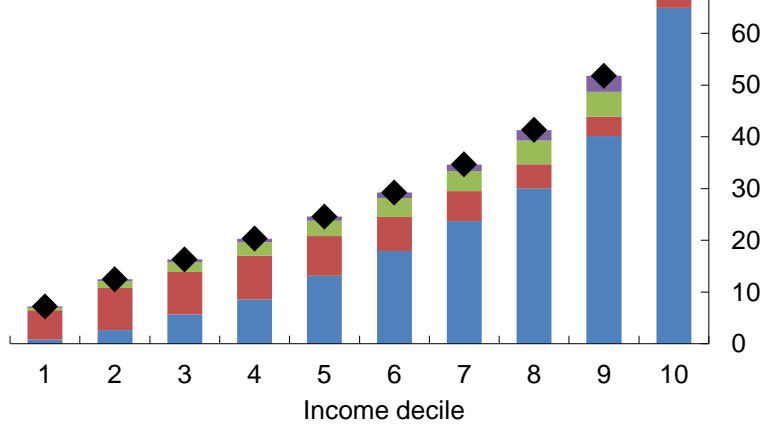

Chart D3: Average income by age in 2012-14

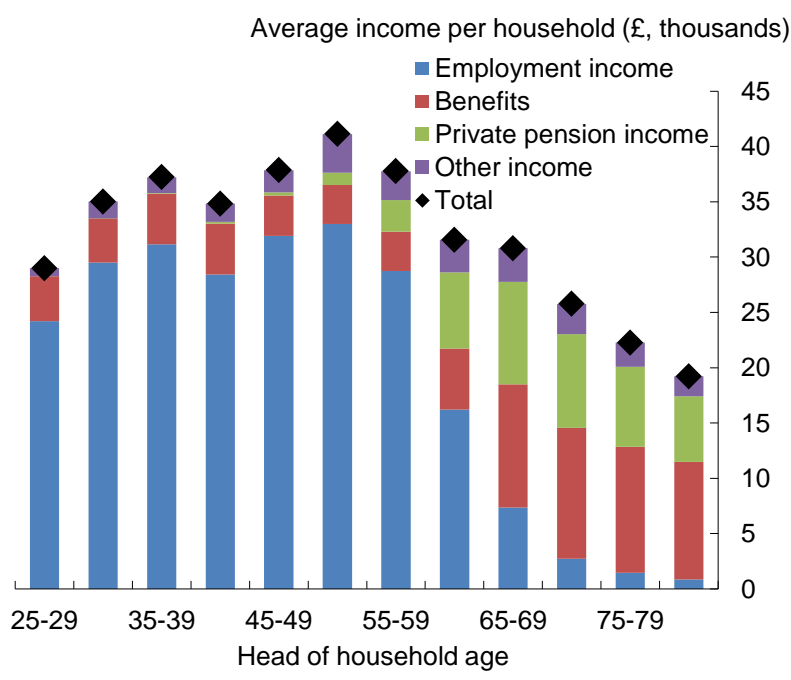

Chart D5: Average wealth by age in 2012-14

Average net wealth per household ( $£$, thousands)

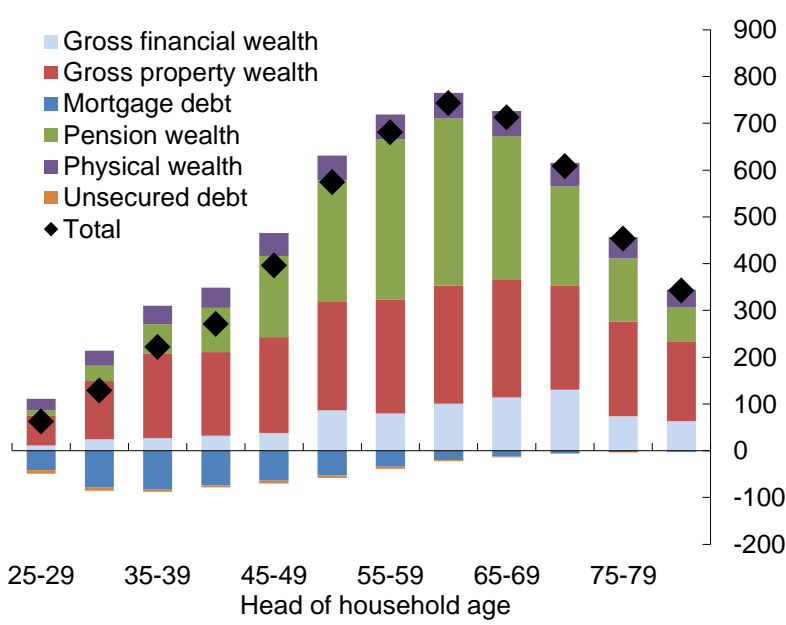

Chart D2: Distribution of wealth in 2012-14

Average net wealth per household ( $£$, thousands)

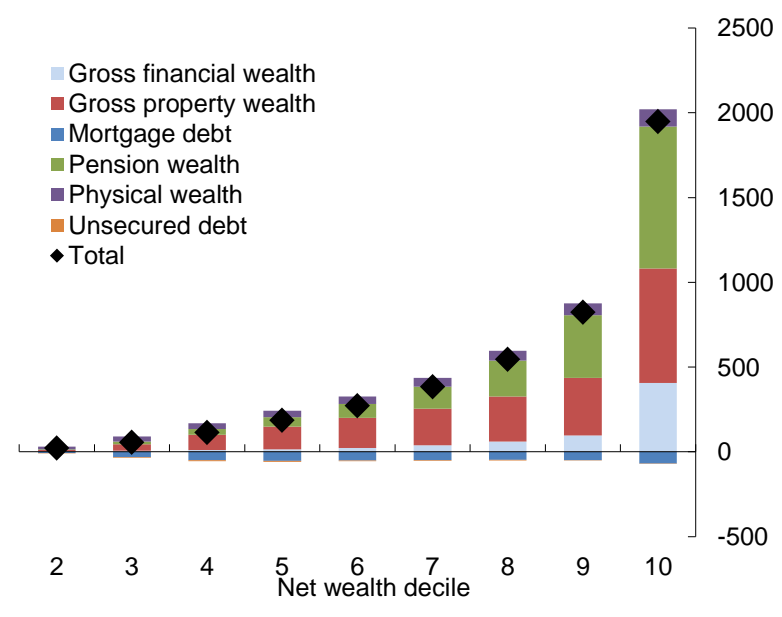

Chart D4: Composition of income by age in 2012-14

Employment income

Benefits

Percentage of total income

Private pension income

-Other income

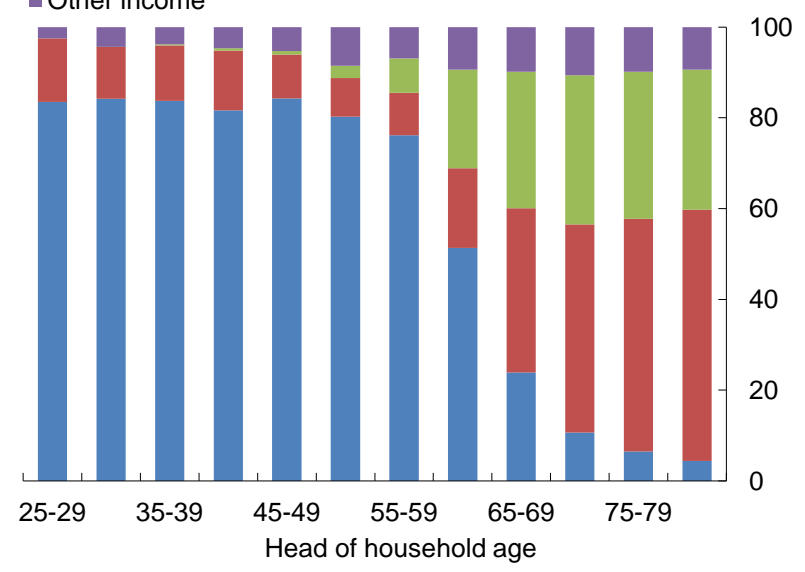

Chart D6: Composition of wealth by age in 2012-14

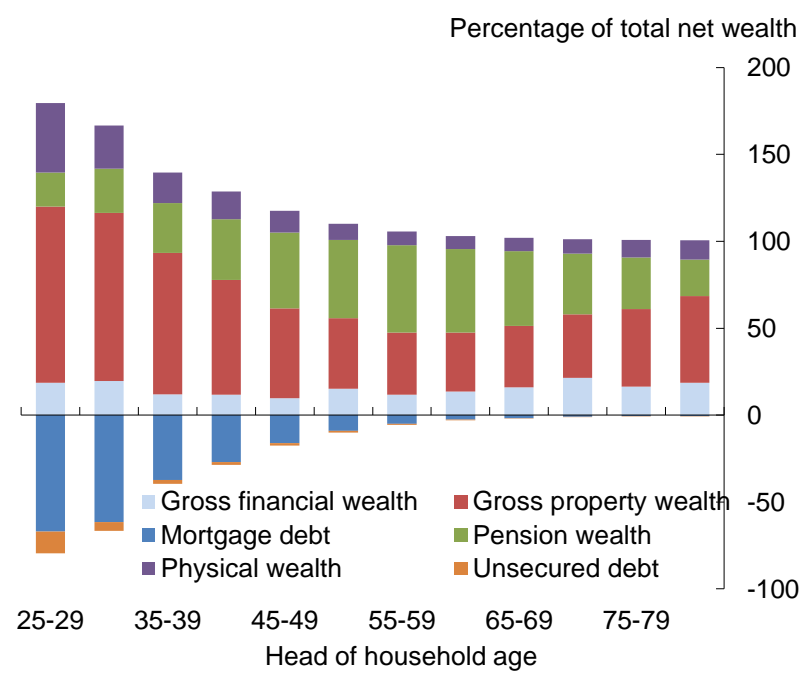


Distributional effects of monetary policy changes since 2007 by income and wealth decile: additional results

\section{Chart D7: Effects on income by income decile in cash terms}

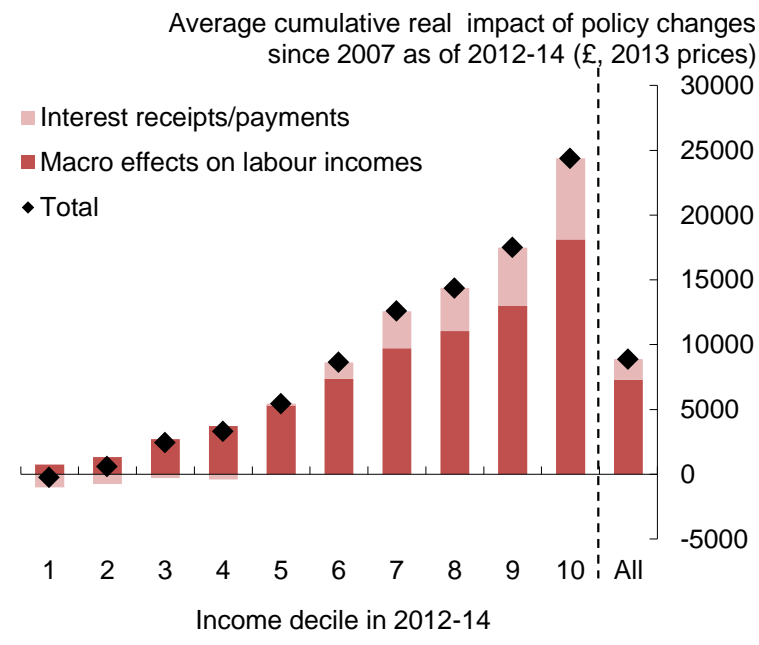

Chart D9: Effects on income and wealth by income decile as a percentage of income

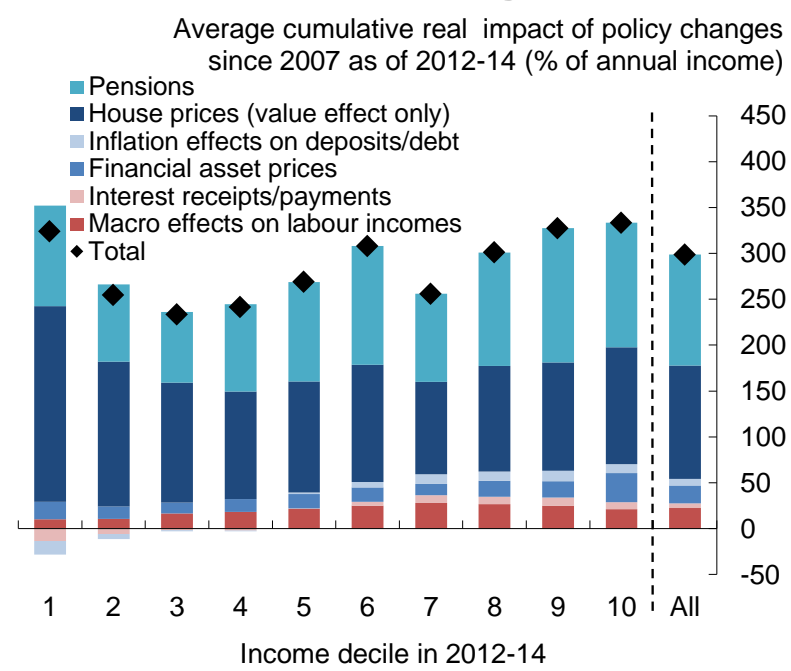

\section{Chart D8: Effects on income by income decile as a percentage of income}

Average cumulative real impact of policy changes since 2007 as of $2012-14$ (\% of annual income)

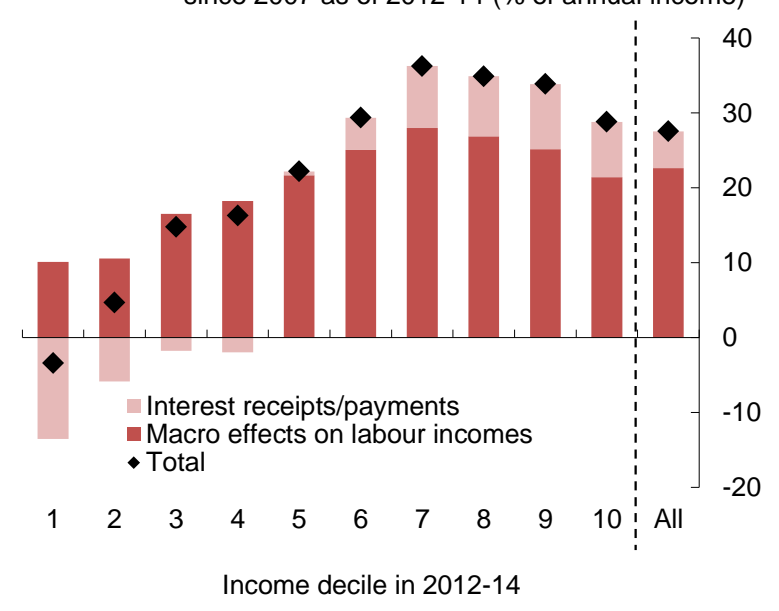

Chart D10: Effects on income and wealth by income decile as a percentage of wealth

Average cumulative real impact of policy changes

- Pensions since 2007 as of $2012-14$ (\% of net wealth)

- House prices (value effect only)

- Inflation effects on deposits/debt

- Financial asset prices

Interest receipts/payments

- Macro effects on labour incomes

- Total

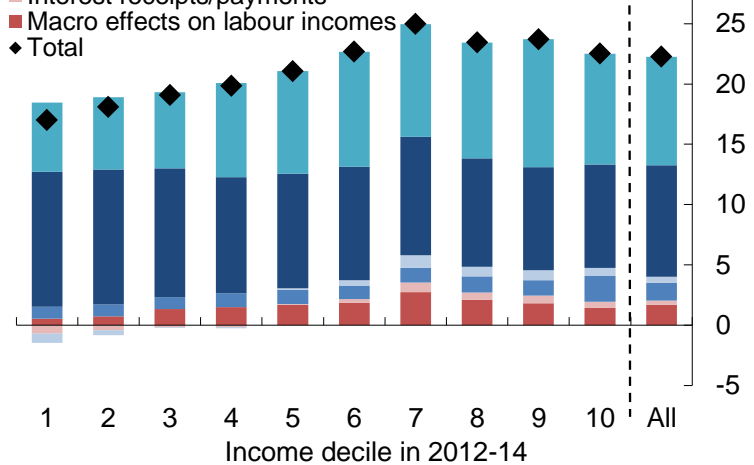




\section{Chart D11: Effects on income and wealth by income decile in cash terms}

Average cumulative real impact of policy changes since 2007 as of 2012-14 ( $(2013$ prices)

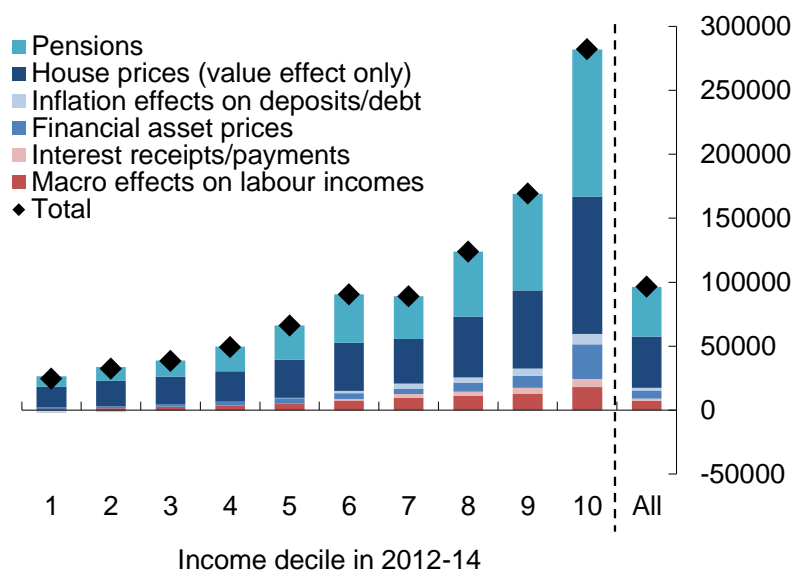

Chart D13: Effects on income and wealth by wealth decile as a percentage of wealth

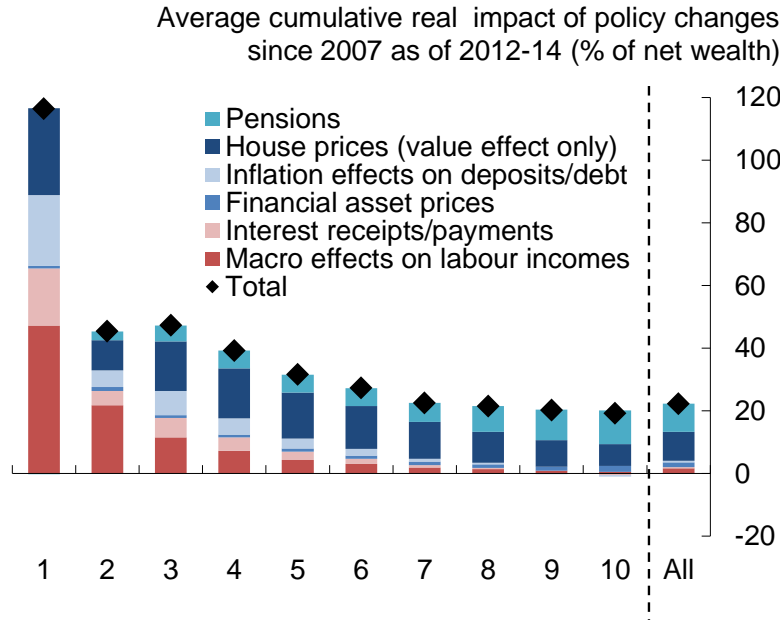

Net wealth decile in 2012-14
Chart D12: Effects on income and wealth by wealth decile as a percentage of income

Average cumulative real impact of policy changes since 2007 as of 2012-14 (\% of annual income)

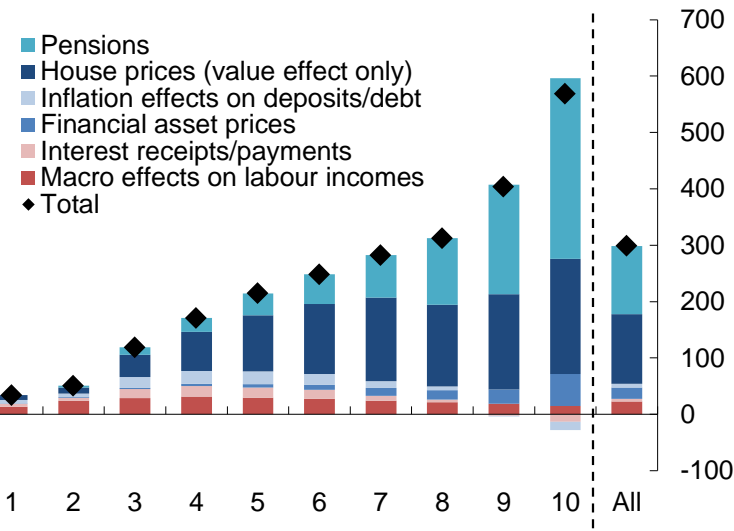

Net wealth decile in 2012-14

Chart D14: Effects on income and wealth by wealth decile in cash terms

Average cumulative real impact of policy changes since 2007 as of 2012-14 ( $£, 2013$ prices)

- Pensions

- House prices (value effect only)

Inflation effects on deposits/debt

- Financial asset prices

- Interest receipts/payments

- Macro effects on labour incomes

- Total

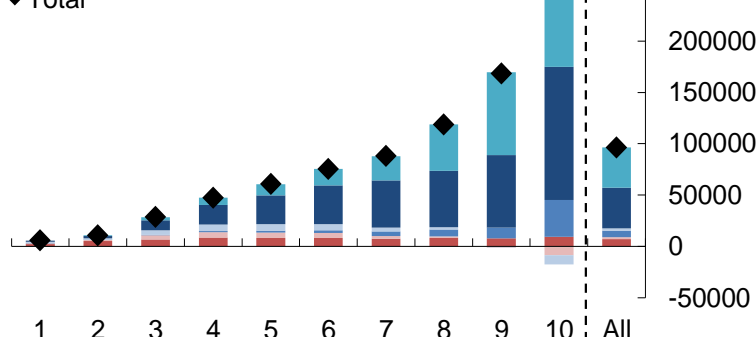

Net wealth decile in 2012-14
400000

350000

300000

250000

200000

150000

50000

$-50000$ 


\section{Chart D15: Effects on income in cash terms}

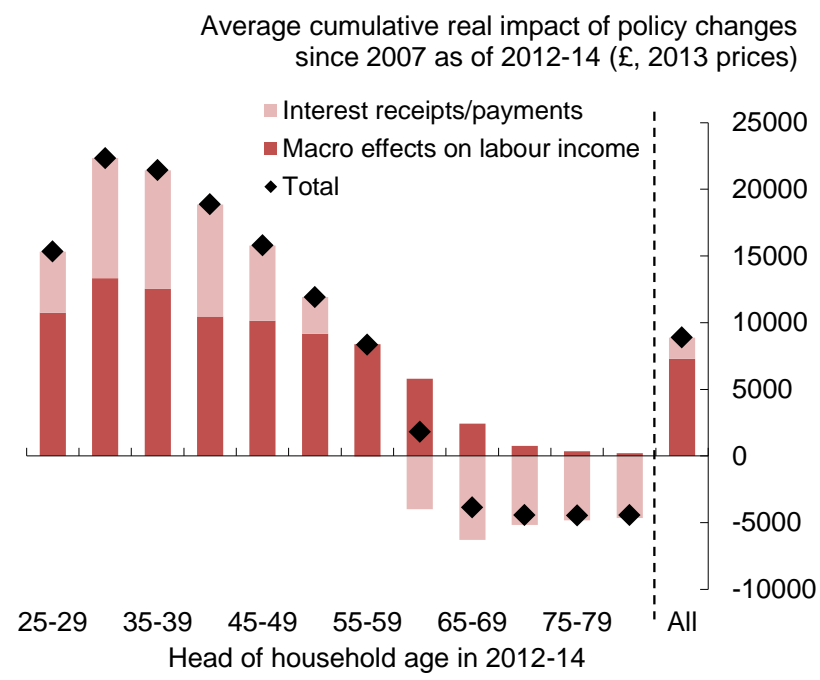

\section{Chart D17: Effects on wealth in cash terms}

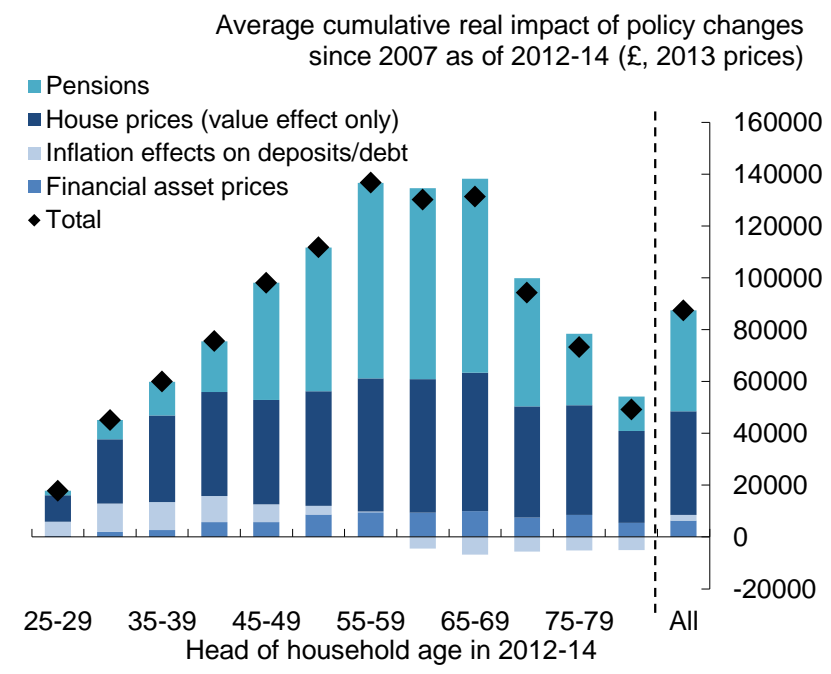

\section{Chart D16: Effects on income as a percentage of income}

Average cumulative real impact of policy changes since 2007 as of $2012-14$ (\% of annual income)

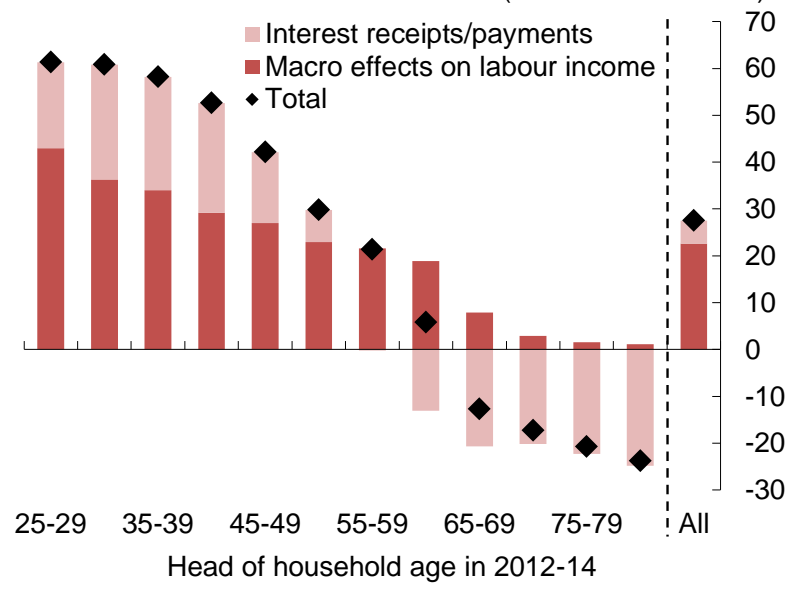

Chart D18: Effects on wealth as a percentage of wealth

Average cumulative real impact of policy changes since 2007 as of $2012-14$ (\% of net wealth)

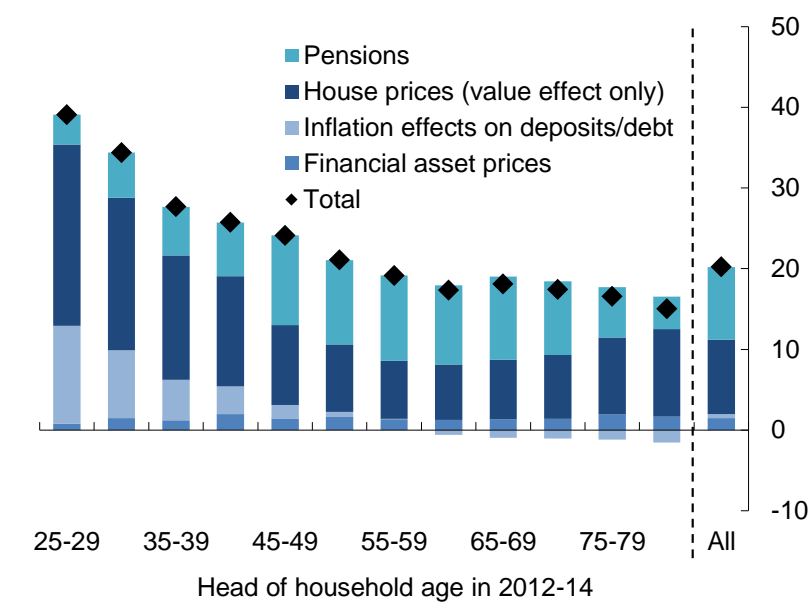


Chart D19: Effects on income and wealth as a percentage of income

Average cumulative real impact of policy changes

Pensions since 2007 as of $2012-14$ (\% of annual income)

- House prices (value effect only)

Inflation effects on deposits/deb

- Financial asset prices

Interest receipts/payments

- Macro effects on labour income

- Total

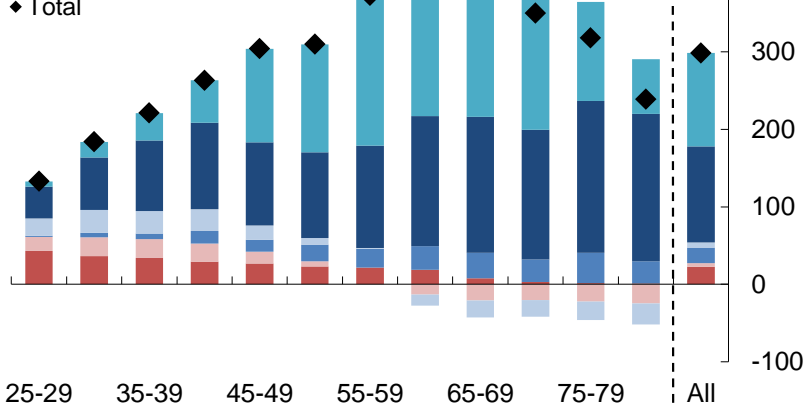

$25-29$

35-39 45-49 55-59 65-69 75-79

Head of household age in 2012-14

\section{Chart D21: Effects on pension wealth in cash terms by age}

Average cumulative real impact of policy changes since 2007 as of 2012-14 (£, 2013 prices)

\section{DB pensions} - DC pensions Pensions in payment

- Total pensions

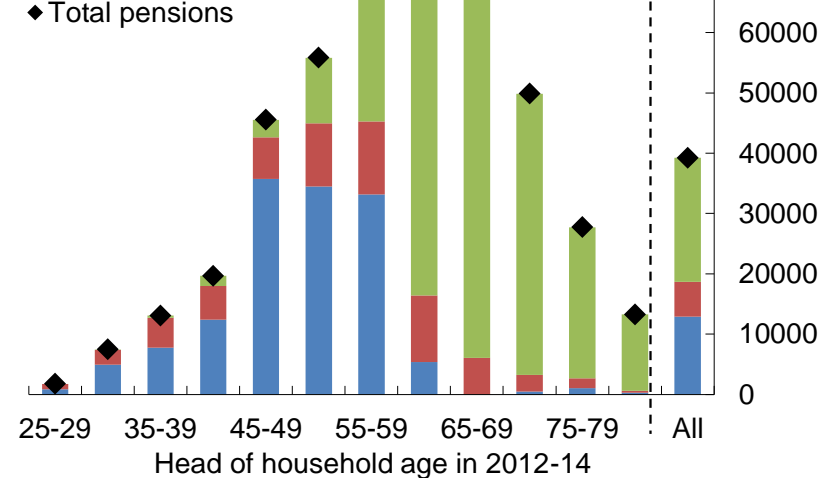

Chart D20: Effects on income and wealth as a percentage of net wealth

Average cumulative real impact of policy changes since 2007 as of $2012-14$ (\% of net wealth)

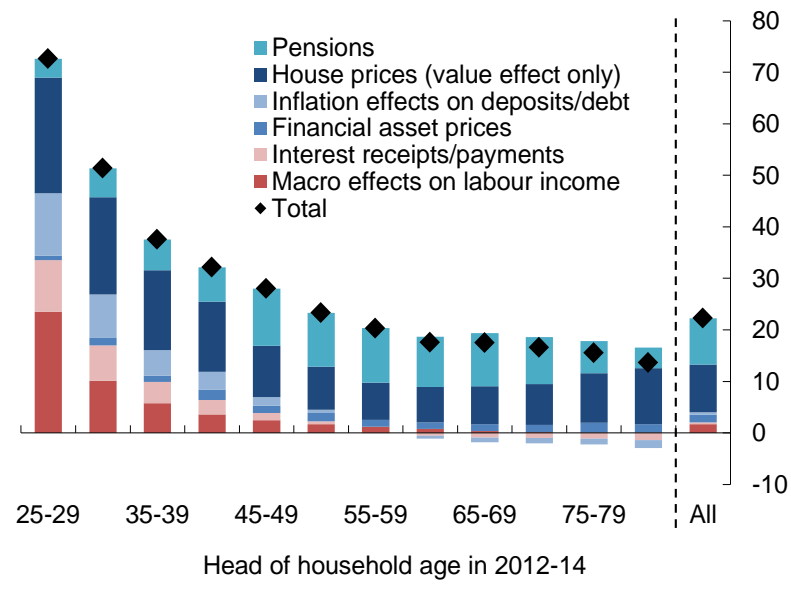




\section{Chart D22: Effects on income and financial wealth in cash terms}

Average cumulative real impact of policy changes since 2007 as of 2012-14 ( $£, 2013$ prices)

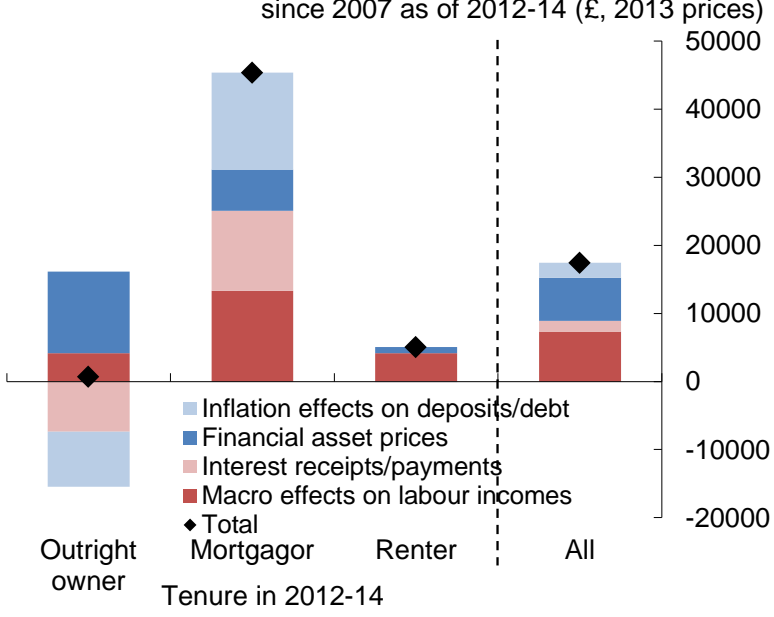

\section{Chart D24: Effects on income in percentage} terms

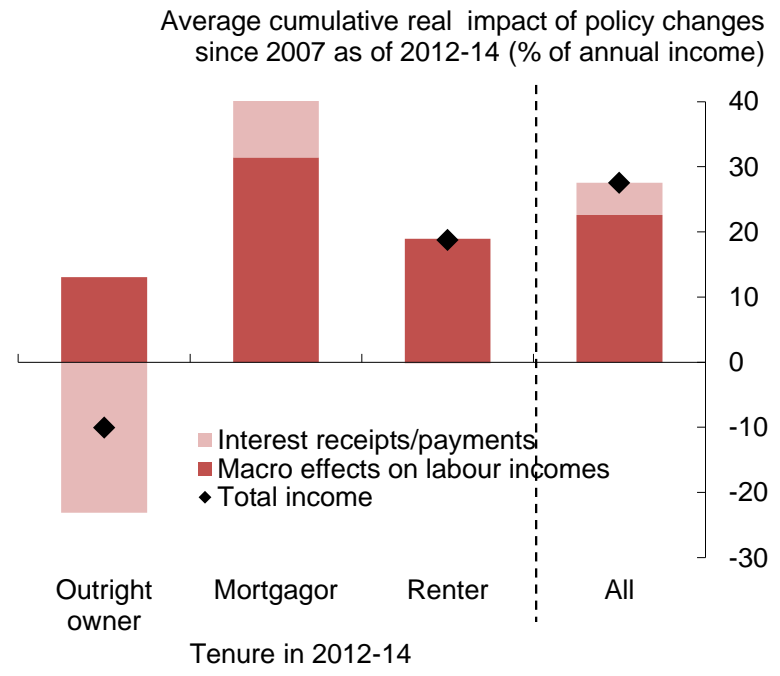

\section{Chart D23: All effects in cash terms}

Average cumulative real impact of policy changes - Pensions since 2007 as of 2012-14 ( 2,2013 prices) - House prices (value effect only) - Inflation effects on deposits/deb - Financial asset prices

Interest receipts/payments

- Total

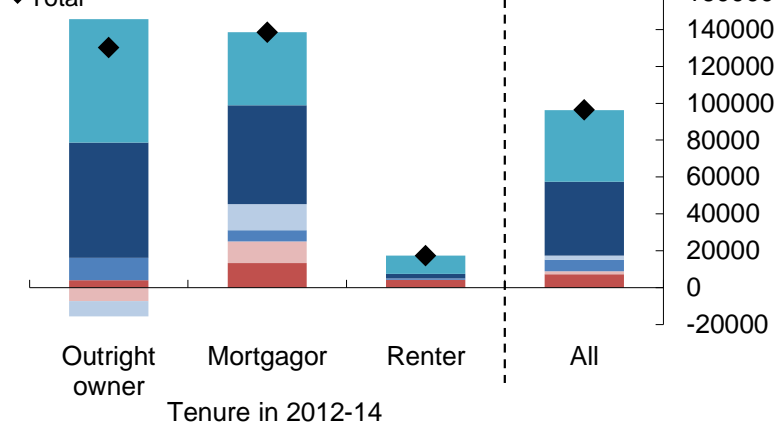

Chart D25: Effects on wealth in percentage terms

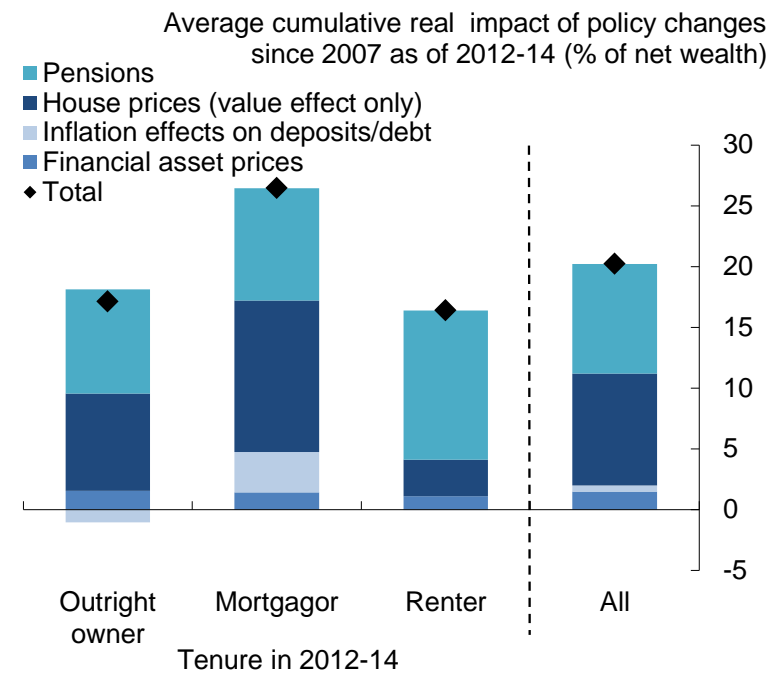




\section{Chart D26: Effects on income and financial wealth in cash terms}

Average cumulative real impact of policy changes since 2007 as of $2012-14$ ( $£, 2013$ prices)

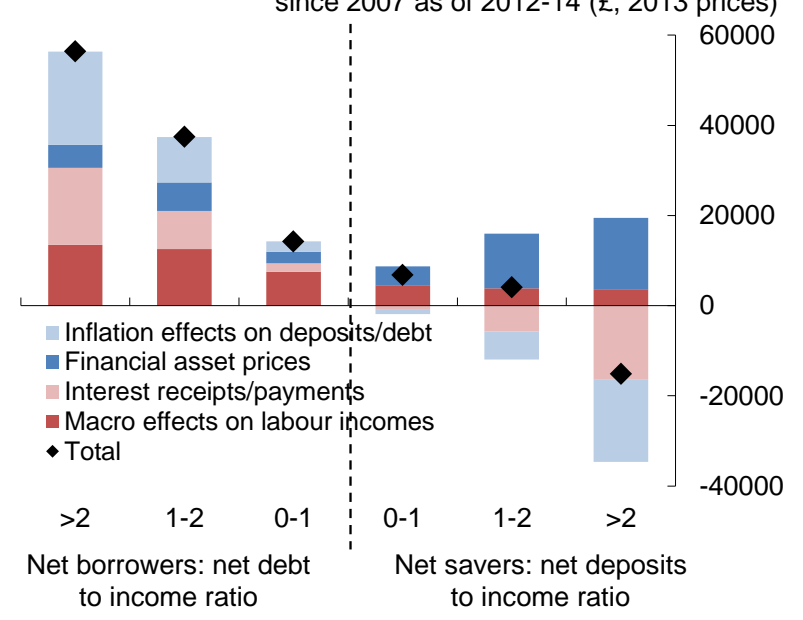

\section{Chart D28: Effects on income in percentage} terms

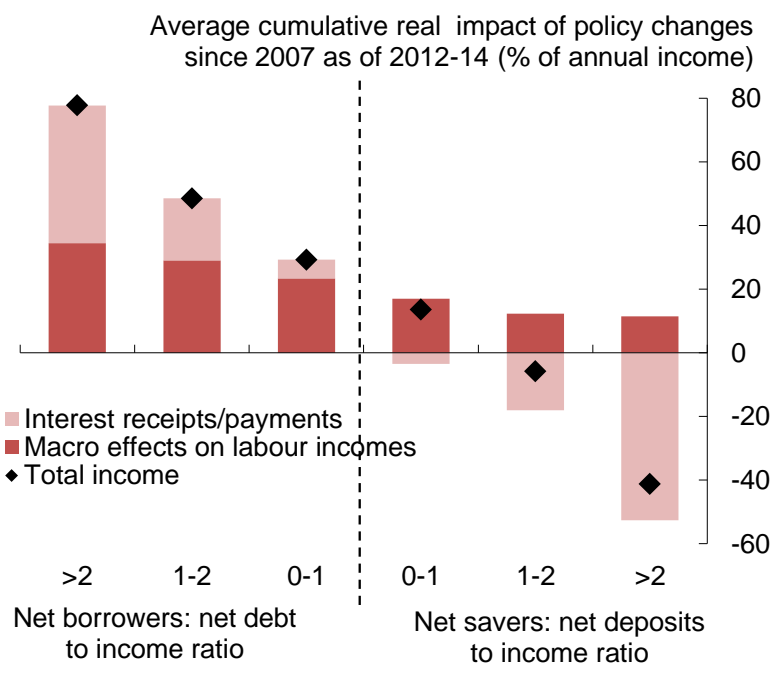

\section{Chart D27: All effects in cash terms}

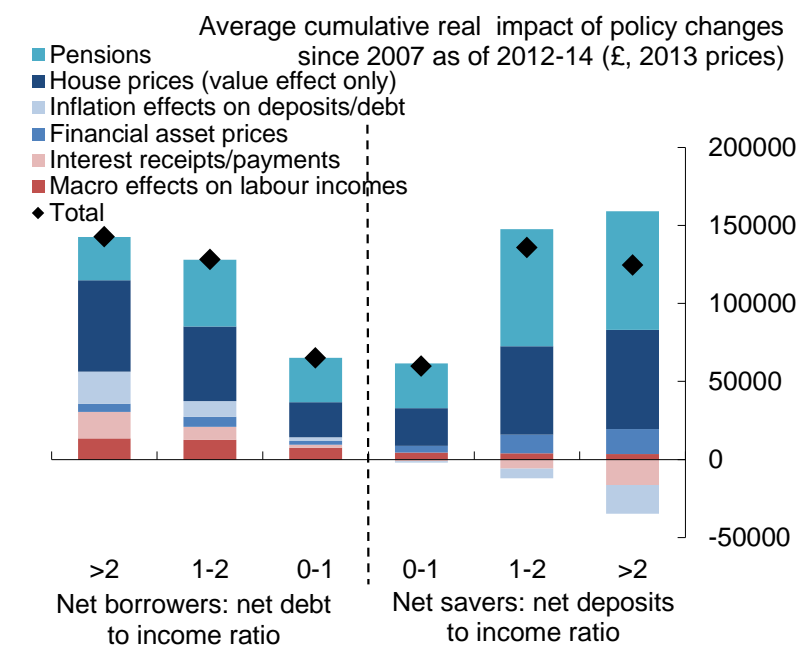

\section{Chart D29: Effects on wealth in percentage} terms

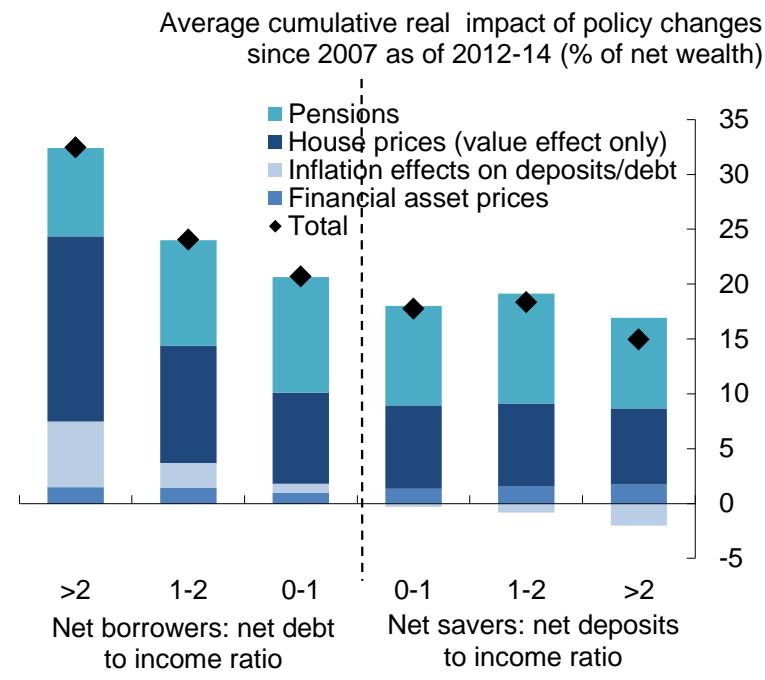




\section{Distributional effects of monetary policy changes since 2007 by economic activity of household head}

\section{Chart D30: Effects on income and financial wealth in cash terms}

Average cumulative real impact of policy changes since 2007 as of $2012-14$ ( $£, 2013$ prices)

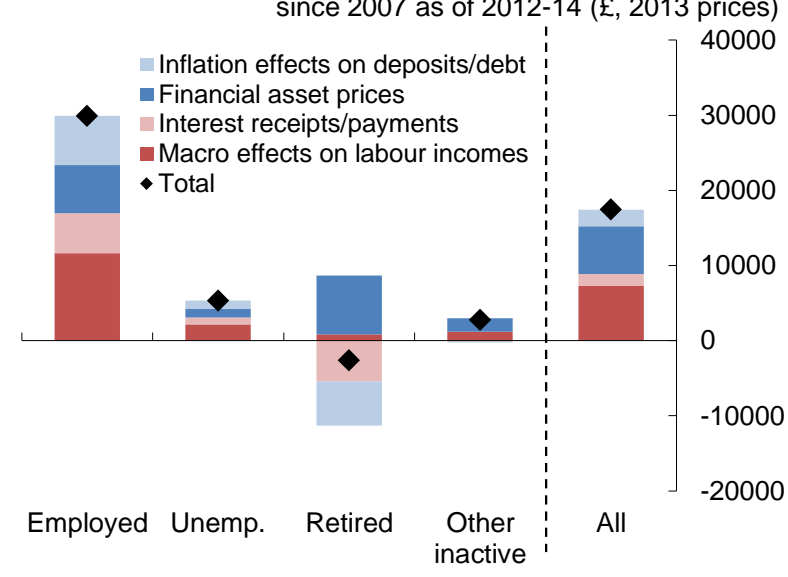

Economic activity of household head in 2012-14

\section{Chart D32: Effects on income in percentage terms}

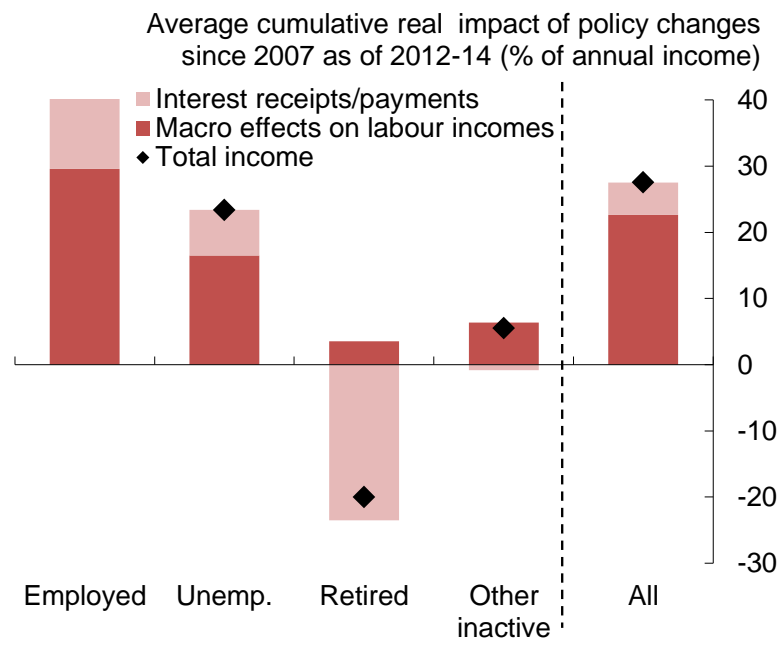

Economic activity of household head in 2012-14

\section{Chart D31: All effects in cash terms}

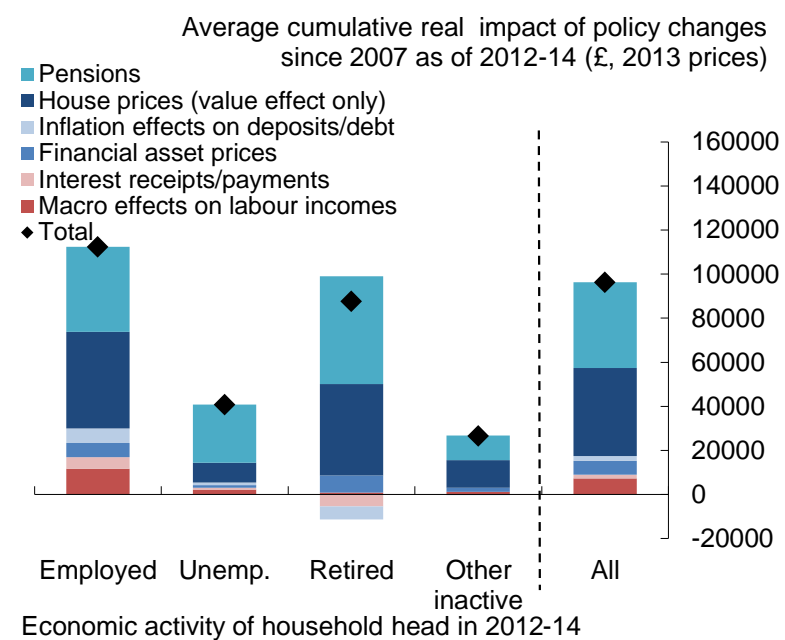

\section{Chart D33: Effects on wealth in percentage} terms

Average cumulative real impact of policy changes
$\square$ Pensions $\quad$ since 2007 as of $2012-14$ (\% of net wealth)

- House prices (value effect only)

Inflation effects on deposits/debt

- Financial asset prices

- Total

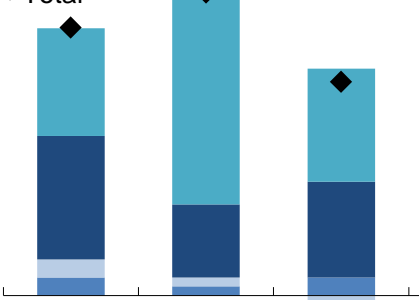

$\left.\begin{array}{ll}1 \\ 1\end{array}\right]$

30
25

25

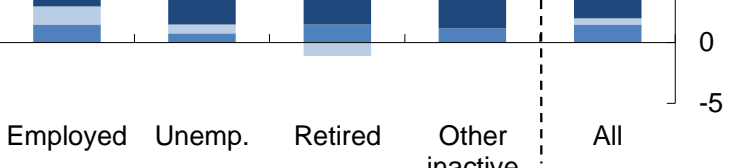

Economic activity of household head in 2012-14 


\section{Distributional effects of monetary policy changes since 2007 by education of household head}

\section{Chart D34: Effects on income and financial wealth in cash terms}

Average cumulative real impact of policy changes since 2007 as of $2012-14$ ( $£, 2013$ prices)

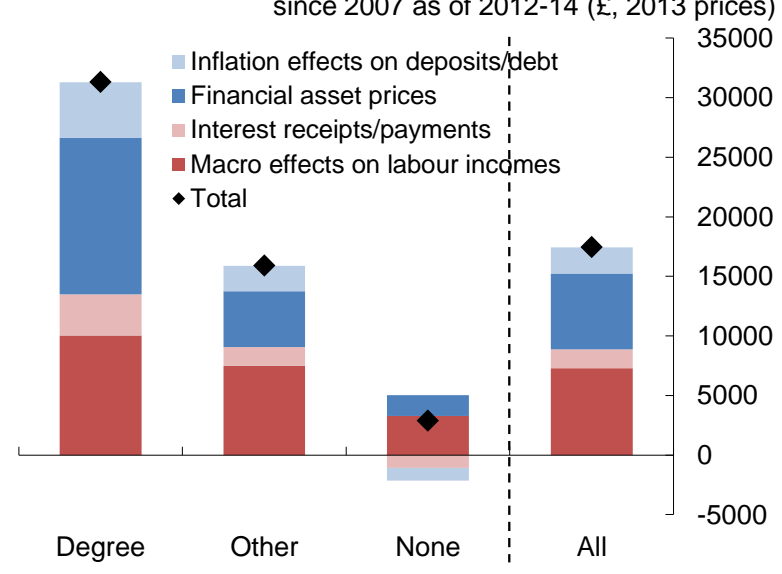

Highest qualification of household head in 2012-14

\section{Chart D36: Effects on income in percentage terms}

Average cumulative real impact of policy changes since 2007 as of $2012-14$ (\% of annual income)

Interest receipts/payments

- Macro effects on labour incomes

- Total income

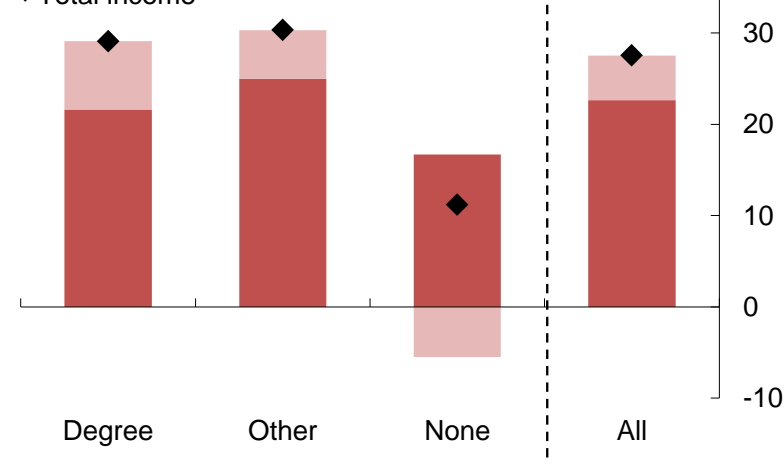

Highest qualification of household head in 2012-14

\section{Chart D35: All effects in cash terms}

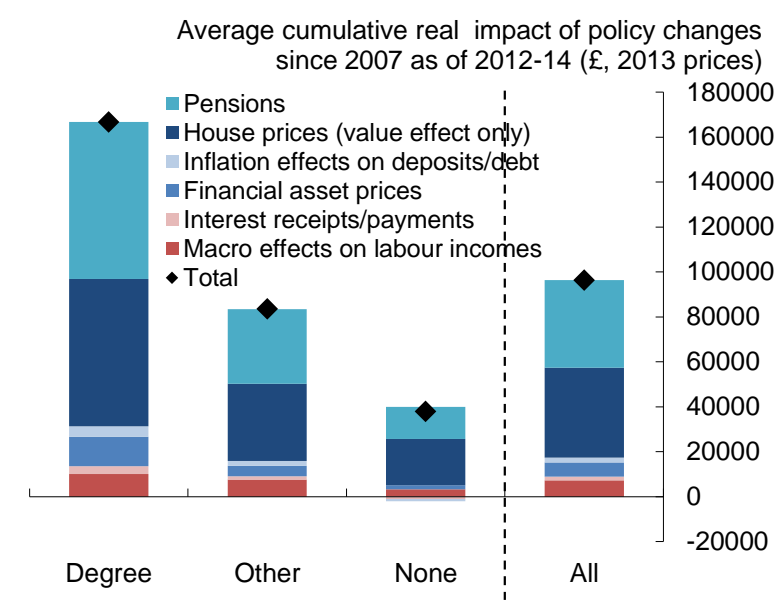

Highest qualification of household head in 2012-14

\section{Chart D37: Effects on wealth in percentage terms}

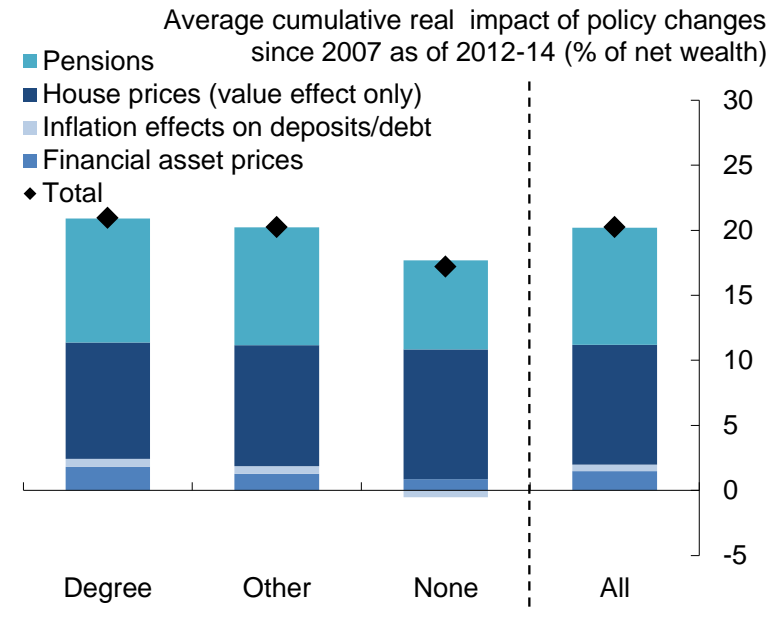

Highest qualification of household head in 2012-14 


\section{Distributional effects of monetary policy changes since 2007 by region ${ }^{46}$}

\section{Chart D38: Effects on income in cash terms}

Average cumulative real impact of policy changes since 2007 as of 2012-14 ( $£, 2013$ prices)

Macro effects on labour income

Net interest receipts/payments

- Total

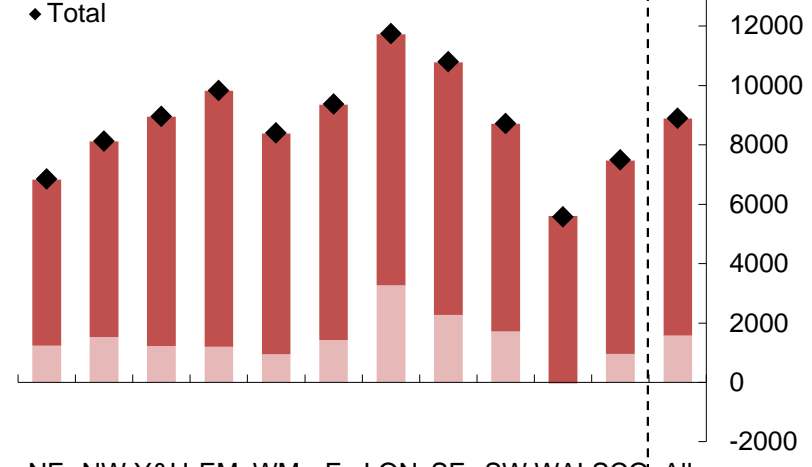

NE NW Y\&H EM WM E LON SE SW WALSCO' All

Region in 2012-14
Chart D39: Effects on income in percentage terms

Average cumulative real impact of policy changes since 2007 as of $2012-14$ (\% of annual income)

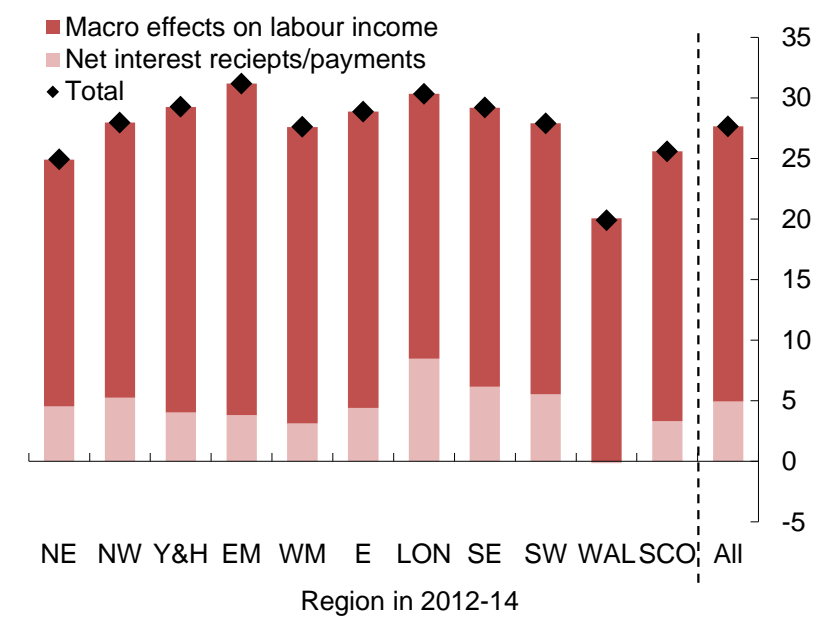

Chart D41: Effects on wealth in percentage terms

Average cumulative real impact of policy changes since 2007 as of 2012-14 (£, 2013 prices)

Pensions

- Housing value effect

Inflation effects on deposits/debt

- Financial asset prices

- Total

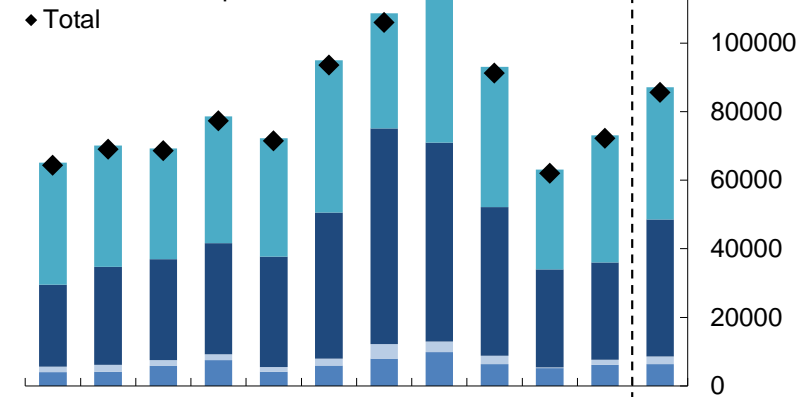

NE NW Y\&H EM WM E LON SE SW WALSCO' All

Region in 2012-14
140000

120000

100000

80000

60000

40000

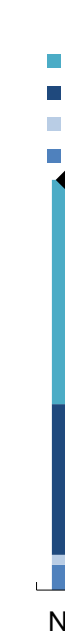

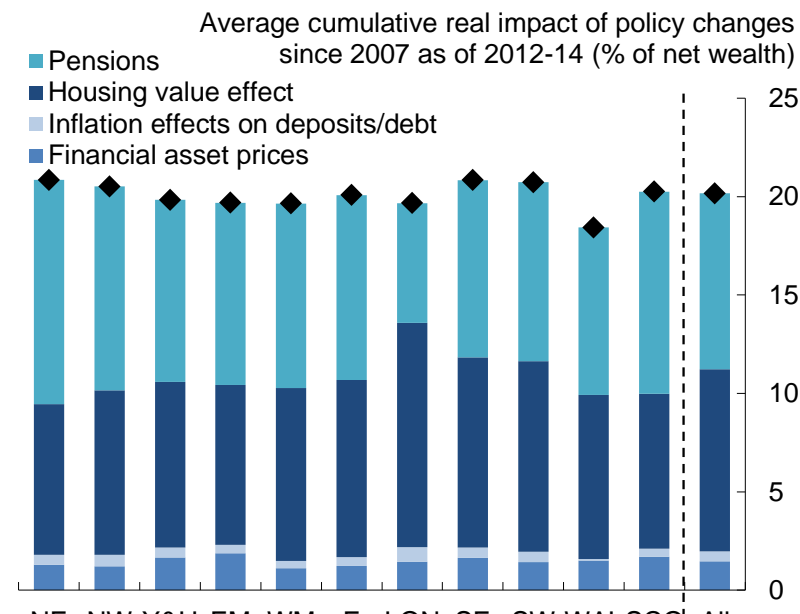

NE NW Y\&H EM WM E LON SE SW WALSCO, All

Region in 2012-14

\footnotetext{
${ }^{46}$ The Wealth and Assets Survey does not cover Northern Ireland is therefore excluded from our analysis.
} 
Chart D42: Effects of changes in Bank Rate by age in cash terms

Average cumulative real impact of policy changes since 2007 as of 2012-14 ( $£, 2013$ prices)

- House prices (value effect only)

- Inflation effects on deposits/debt

- Financial asset prices

Interest receipts/payments

- Macro effects on labour income

- Total

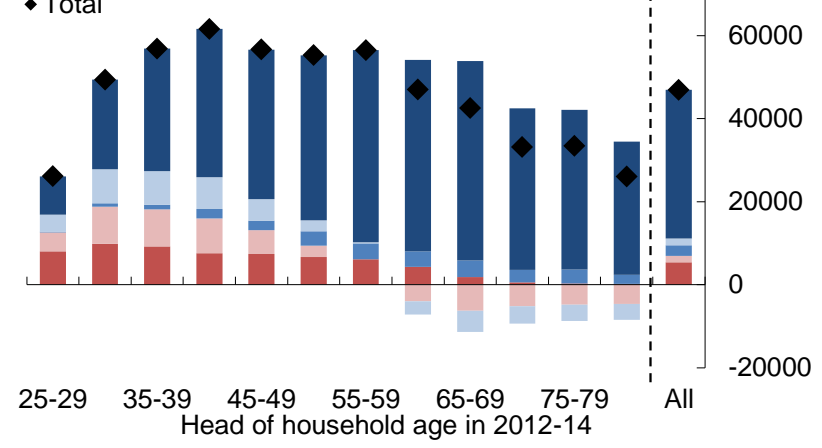

Chart D44: Effects of Bank Rate change to boost GDP by $1 \%$ a year (mid-2008 to mid2014) on income by income decile in percentage terms

Average cumulative real impact of policy changes since 2007 as of 2012-14 (\% of income)

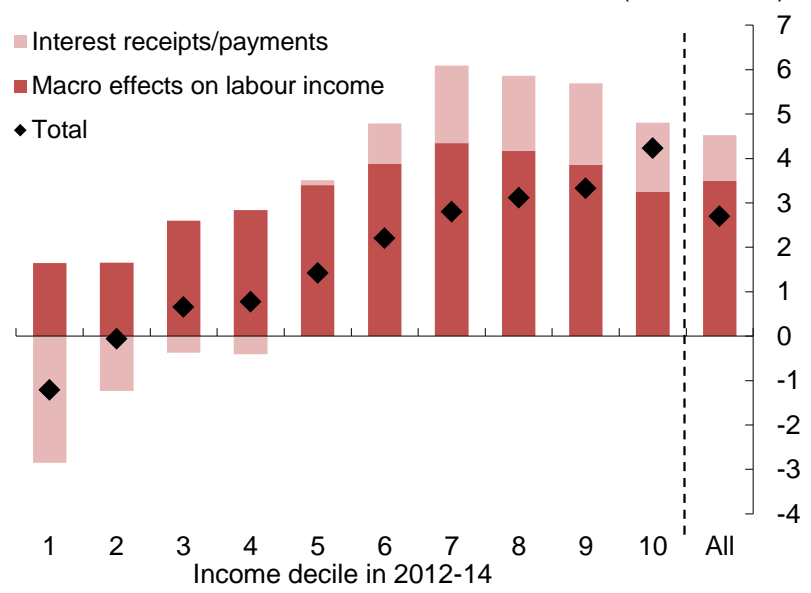

Chart D43: Effects of QE by age in cash terms

Average cumulative real impact of policy changes since 2007 as of 2012-14 ( $£, 2013$ prices)

- House prices (value effect only)

- Inflation effects on deposits/debt

- Financial asset prices

- Macro effects on labour income

- Total

60000

40000

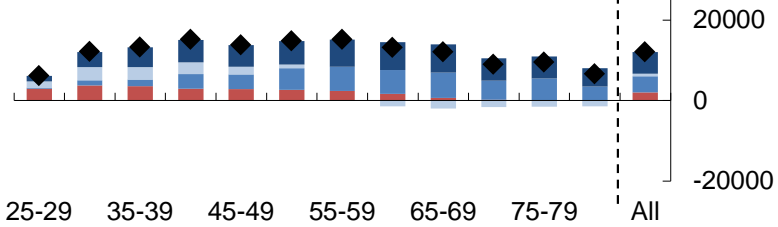

Head of household age in 2012-14

Chart D45: Effects of QE change to boost GDP by $1 \%$ a year (mid-2008 to mid-2014) on income by income decile in percentage terms

Average cumulative real impact of policy changes since 2007 as of $2012-14$ (\% of income)

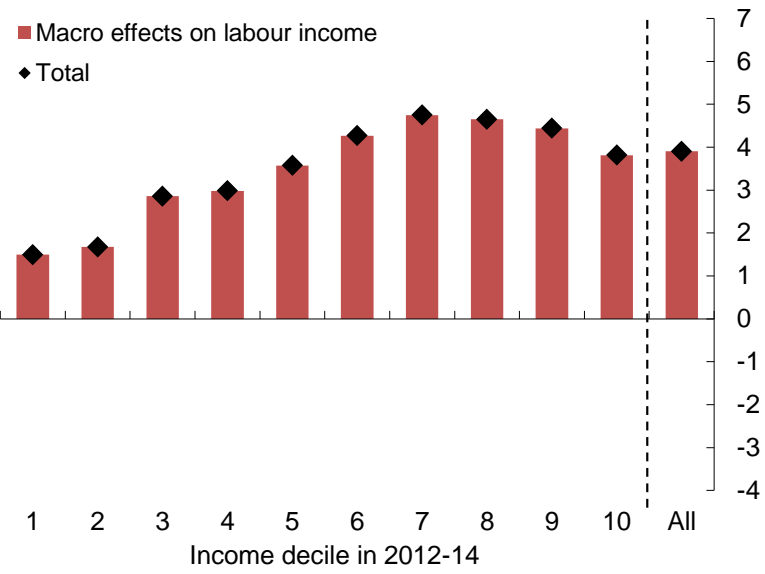


Chart D46: Effects of Bank Rate change to boost GDP by $1 \%$ a year (mid-2008 to mid2014) by income decile in cash terms

Average cumulative real impact of policy changes since 2007 as of $2012-14$ ( $£, 2013$ prices)

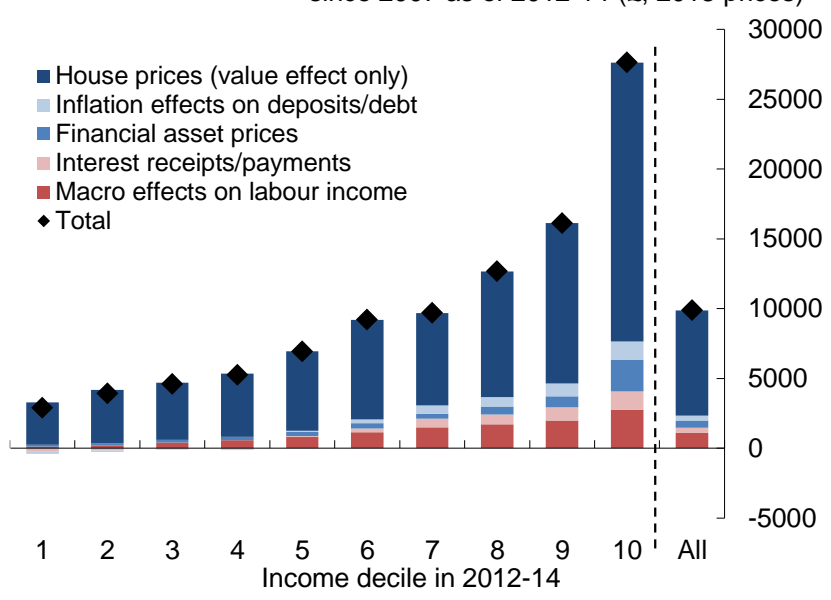

Chart D48: Effects of Bank Rate change to boost GDP by $1 \%$ a year (mid-2008 to mid2014) by income decile in percentage terms

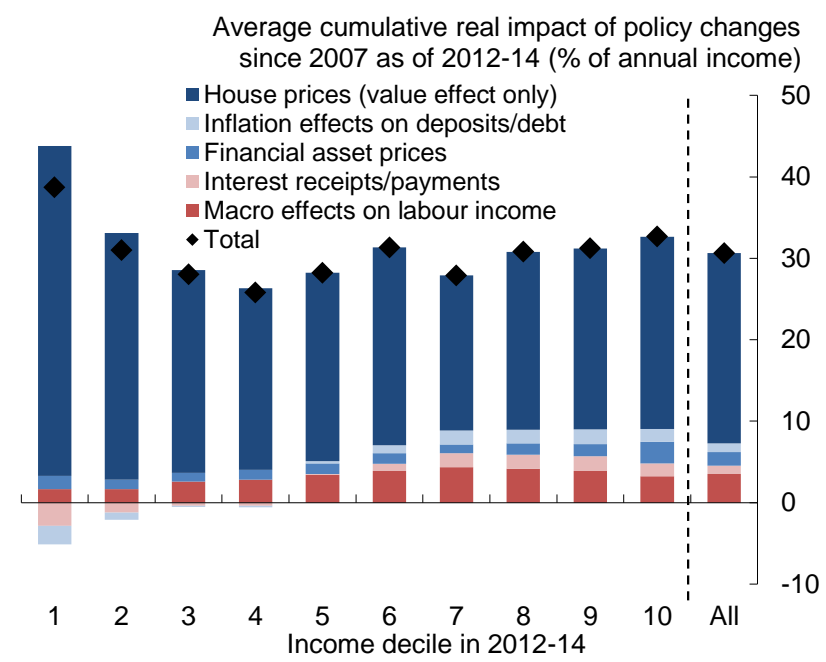

Chart D50: Effects of changes in Bank Rate by income decile in cash terms

Average cumulative real impact of policy changes since 2007 as of 2012-14 ( $£, 2013$ prices)

- House prices (value effect only)

Inflation effects on deposits/debt

- Financial asset prices

Interest receipts/payments

Macro effects on labour income

- Total

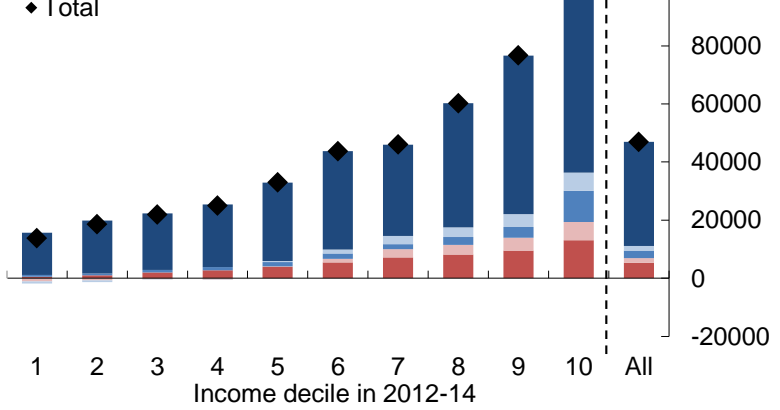

Chart D47: Effects of QE change to boost GDP by $1 \%$ a year (mid-2008 to mid-2014) by income decile in cash terms

Average cumulative real impact of policy changes since 2007 as of 2012-14 ( $£, 2013$ prices)

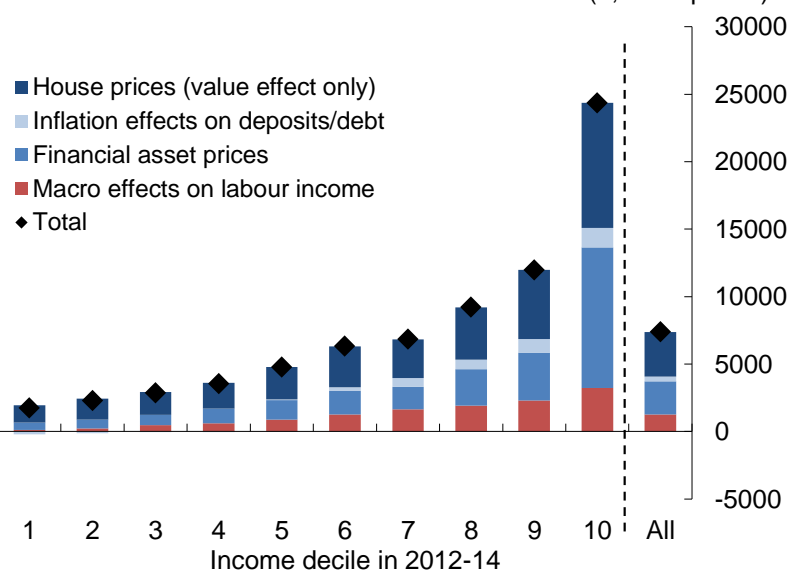

Chart D49: Effects of QE change to boost GDP by $1 \%$ a year (mid-2008 to mid-2014) by income decile in percentage terms

Average cumulative real impact of policy changes since 2007 as of 2012-14 (\% of annual income)

- House prices (value effect only)

- Inflation effects on deposits/debt

- Financial asset prices

Macro effects on labour income

- Total

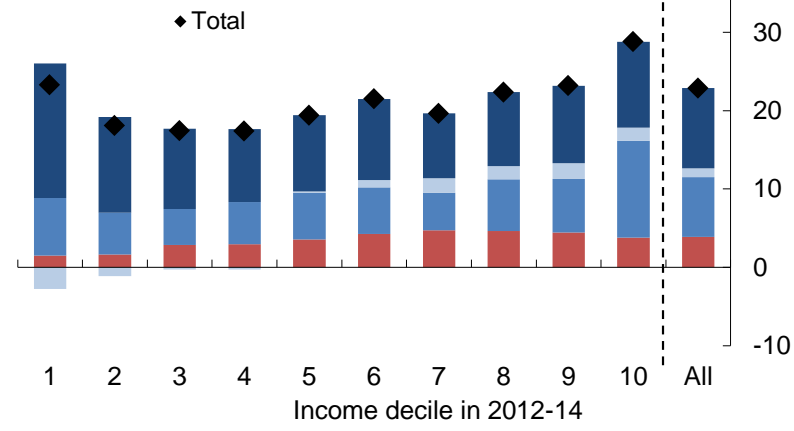

Chart D51: Effects of QE by income decile in cash terms

Average cumulative real impact of policy changes since 2007 as of 2012-14 ( $£, 2013$ prices)

- House prices (value effect only)

Inflation effects on deposits/debt

- Financial asset prices

Macro effects on labour income

- Total

140000

120000

100000

80000

60000

40000

20000

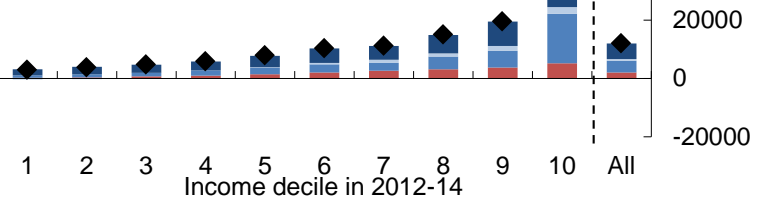


Chart D52: Effects of Bank Rate change to boost GDP by $1 \%$ a year (mid-2008 to mid2014) on wealth by wealth decile in percentage terms

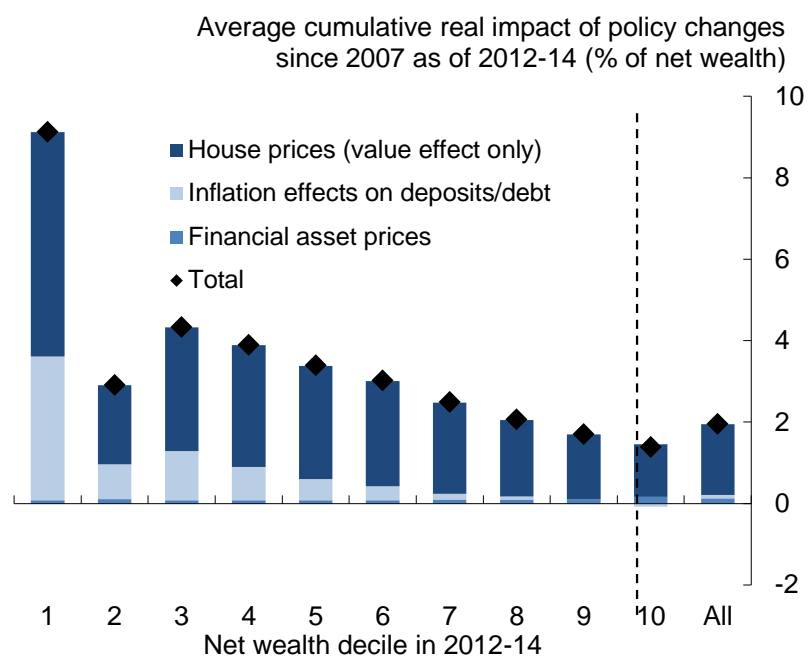

Chart D54: Effects of Bank Rate change to boost GDP by $1 \%$ a year (mid-2008 to mid2014) by wealth decile in percentage terms

Average cumulative real impact of policy changes since 2007 as of 2012-14 ( $£, 2013$ prices)

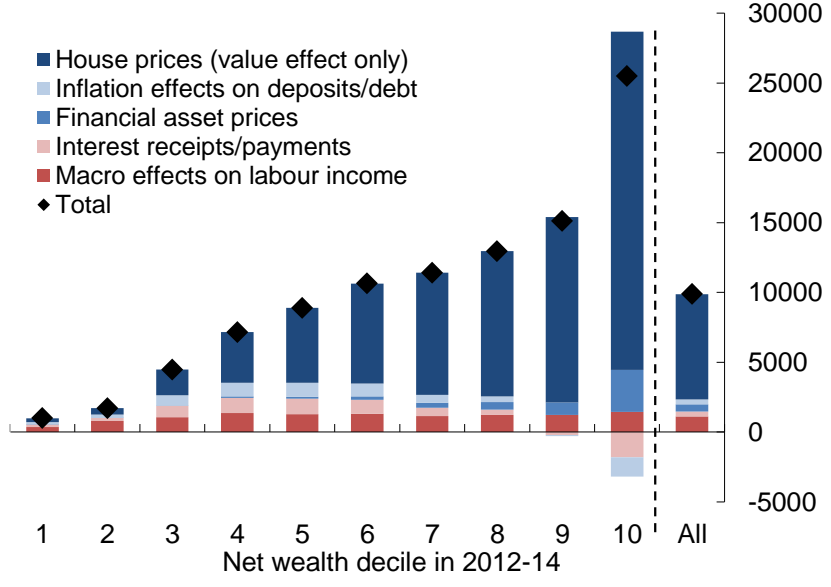

Chart D53: Effects of QE change to boost GDP by $1 \%$ a year (mid-2008 to mid-2014) on wealth by wealth decile in percentage terms

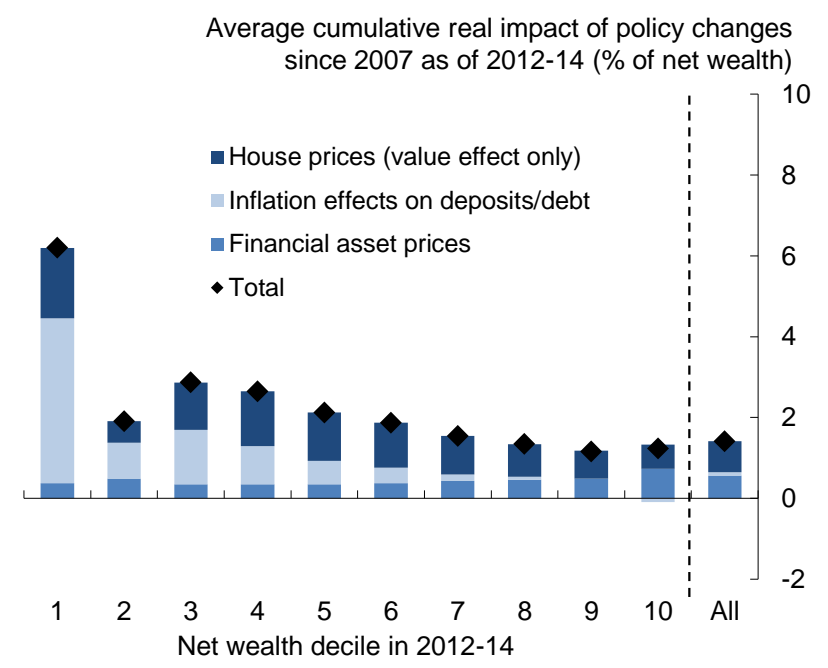

Chart D55: Effects of QE change to boost GDP by $1 \%$ a year (mid-2008 to mid-2014) by wealth decile in percentage terms

Average cumulative real impact of policy changes since 2007 as of 2012-14 ( $£, 2013$ prices)

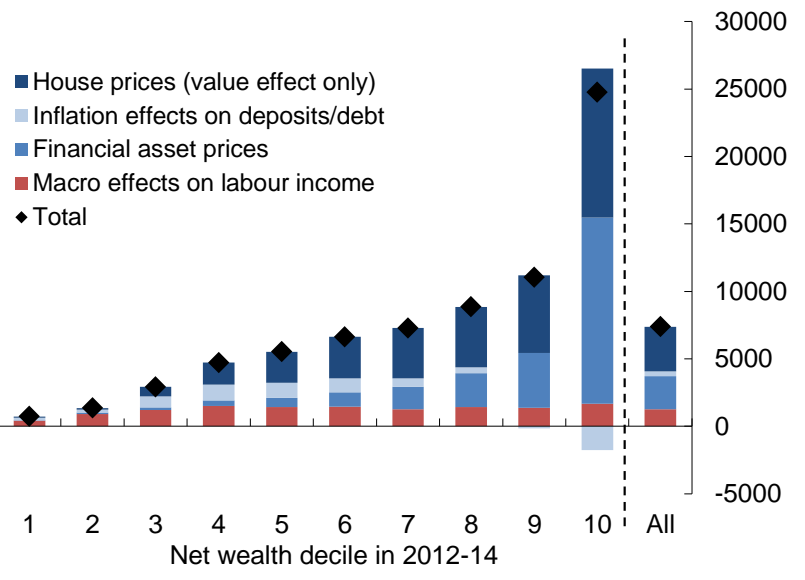


Chart D56: Effects of Bank Rate change to boost GDP by $1 \%$ a year (mid-2008 to mid2014) by wealth decile in percentage terms

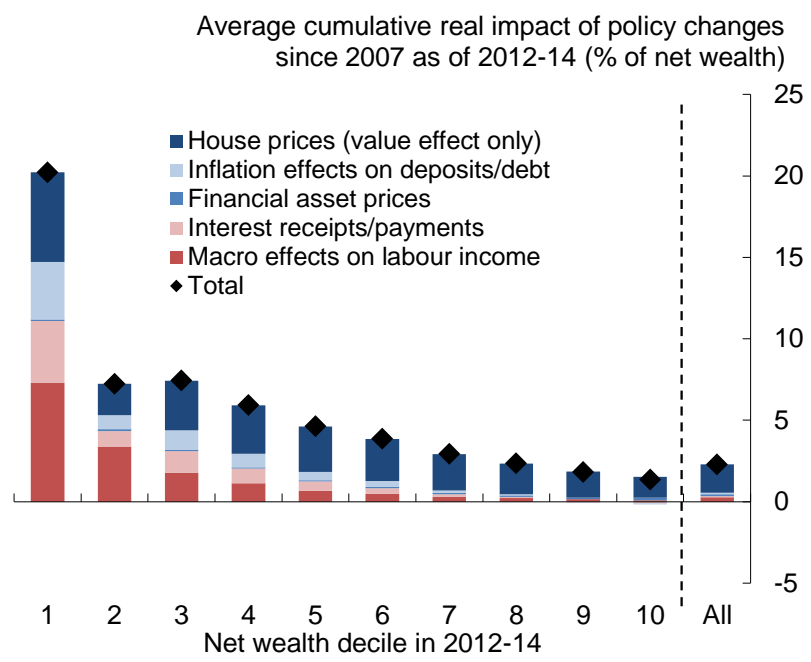

Chart D58: Effects of changes in Bank Rate by wealth decile in cash terms

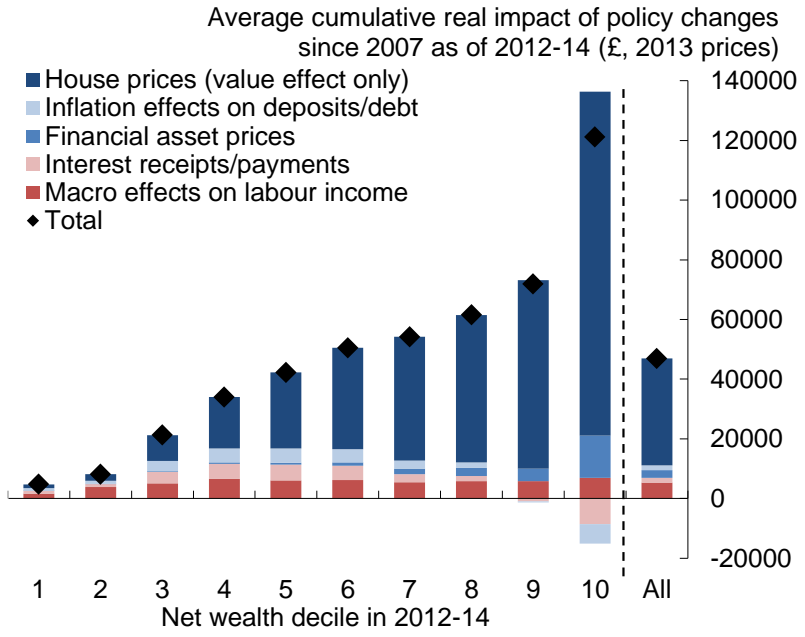

Chart D57: Effects of QE change to boost GDP by $1 \%$ a year (mid-2008 to mid-2014) by wealth decile in percentage terms

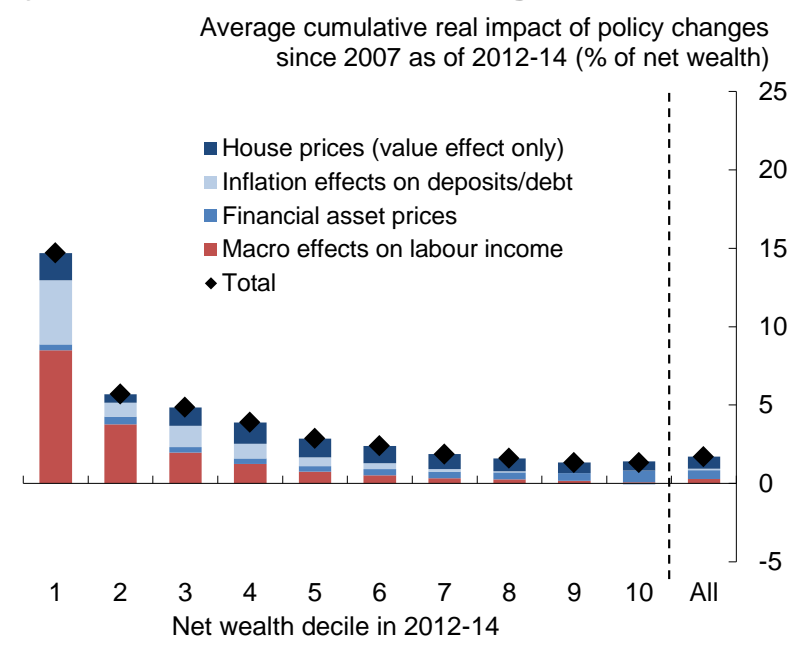

Chart D59: Effects of QE on income and wealth by income decile in cash terms

Average cumulative real impact of policy changes since 2007 as of 2012-14 ( , 2013 prices)

- House prices (value effect only)

Inflation effects on deposits/debt

- Financial asset prices

Macro effects on labour income

- Total

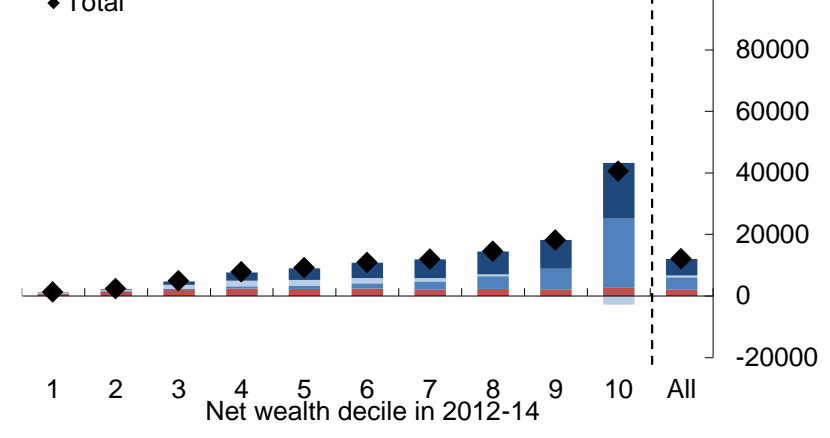

